\title{
Rare coagulation disorders
}

Citation for published version (APA):

Peyvandi, F. (2000). Rare coagulation disorders. [Doctoral Thesis, Maastricht University]. Universiteit Maastricht. https://doi.org/10.26481/dis.20001110fp

Document status and date:

Published: 01/01/2000

DOI:

10.26481/dis.20001110fp

Document Version:

Publisher's PDF, also known as Version of record

\section{Please check the document version of this publication:}

- A submitted manuscript is the version of the article upon submission and before peer-review. There can be important differences between the submitted version and the official published version of record.

People interested in the research are advised to contact the author for the final version of the publication, or visit the DOI to the publisher's website.

- The final author version and the galley proof are versions of the publication after peer review.

- The final published version features the final layout of the paper including the volume, issue and page numbers.

Link to publication

\footnotetext{
General rights rights.

- You may freely distribute the URL identifying the publication in the public portal. please follow below link for the End User Agreement:

www.umlib.nl/taverne-license

Take down policy

If you believe that this document breaches copyright please contact us at:

repository@maastrichtuniversity.nl

providing details and we will investigate your claim.
}

Copyright and moral rights for the publications made accessible in the public portal are retained by the authors and/or other copyright owners and it is a condition of accessing publications that users recognise and abide by the legal requirements associated with these

- Users may download and print one copy of any publication from the public portal for the purpose of private study or research.

- You may not further distribute the material or use it for any profit-making activity or commercial gain

If the publication is distributed under the terms of Article $25 \mathrm{fa}$ of the Dutch Copyright Act, indicated by the "Taverne" license above, 


\section{rare coagulation disorders flora peyvandi}


Rare Coagulation Disorders

\section{Flora Peyvandi \\ Rare Coagulation Disorders}

ISBN: 88-87052-08-5

\section{Wfetti}

Servizi di Comunicazione srl

P.le Arduino, 11 - 20149 Milano

lel. 02/4998041 - fax. 02/49980420

http://Ww.effetti.it

Cover: Persian Poems (Hafer) on a FVII protein gel by Oriol Rosellò 


\section{Rare Coagulation Disorders}

\section{PROEFSCHRIFT}

ter verkrijging van de graad van doctor ann de

Universiteit Maastrichtop gezag van de

Rector Magnificus, Prof. Dr. A.C. Nieuwenhuijzen Kruseman, volgens het besluit van het College van Decanen, in het openbaar te verdedigen op

vrijdag 10 November 2000

om 12.00 uur

door

Flora Peyvandi

Geboren op 29 november 1964 te Iran 


\section{Rare $\overline{\text { Coagulation Disorders }}$}

Promoters:

Prof. Dr. H.C. Hemker, Prof. of Biochemistry, UM

Prof. Dr. P.M. Mannucci, University of Milan- Prof. of Internal Medicine, Milan-IT

Beoordelingsscommissie:

Prof. Dr. J.P.M. Geraedts, Prof. of Genetics and Cell Biology,UM (chairman)

Prof. Dr. M.J.A.P. Daemen, Prof. of Pathology, UM

Prof. Dr. D.J. Perry, Prof. of Hemophilia and Hemostasis, University College of London, UK

Prof. Dr. U. Seligsohn, Prof. of Haematology, Chaim Sheba Medical Centre, Israel

Dr. G. Tans, Senior lecturer, Dep. of Biochemistry, UM

This thesis has been prepared at Angelo Bianchi Bonomi Hemophilia and Thrombosis Center, IRCCS Ospedale Maggiore of Milan, Italy, Hemophilia and Hemostasis Unit, Royal Free Hospital and Katharine Dormandy Trust - University College, London, UK and Hematology Section, VA Boston Healthcare System, Harvard Medical School, Boston, MA, USA.

Financial support by Istituto Sierovaccinogeno Italiano - ISI S.p.A., Castelvecchio Pascoli (Lu), Italy, for the publication of this thesis is gratefully acknowledged. 


\section{Contents}

\section{Chapter 1. Introduction}

1.1 General features of fibrinogen deficiency

1.2 Prothrombin deficiency

1.3 Factor $V$ deficiency

1.4 Factor VII deficiency

1.5 Combined deficiency of factor V and factor VIII

1.6 Factor $\mathrm{X}$ deficiency

\section{Chapter 2. Clinical studies}

Introduction

page 18

2.1 Bleeding and thrombosis in 55 patients with inherited afibrinogenemia. Lak M, Keihani M, Elahi F, Peyvandi F, Mannucci PM.

British Journal of Haematology 107: 204-206, 1999.

page 20

2.2 Symptoms of inherited factor $V$ deficiency in 35 Iranian patients.

Lak M, Sharifian R, Peyvandi F, Mannucci PM.

British Journal of Haematology 103: 1067-1069, 1998.

page 25

2.3 Clinical manifestations in 28 Iranian and Italian patients with severe factor VII deficiency.

Peyvandi F, Mannucci PM, Asti D, Abdoullahi M, Di Rocco N, Sharifian R.

Haemophilia 3: 242-246, 1997.

2.4 Bleeding symptoms in 27 Iranian patients with factor $\mathrm{V}$ and

VIII combined deficiency.

Peyvandi F, Tuddenham EGD, Akhtari AM, Lak M, Mannucci PM.

British Journal of Haematology 100: 773-776, 1998.

2.5 Congenital factor X deficiency: spectrum of bleeding symptoms in 32 Iranian patients.

Peyvandi F, Mannucci PM, Lak M, Abdoullahi M, Zeinali S, Sharifian R, Perry D.

British Journal of Haematology 102: 626-628, 1998. 


\section{Chapter 3. Molecular studies}

Introduction

page 52

3.1 Molecular characterization and three-dimensional structural analysis of mutations in 21 unrelated families with inherited factor VII deficiency.

Peyvandi F, Jenkins PV, Mannucci PM, Billio A, Zeinali S, Perkins J, Perry DJ.

Thromb Haemost 84: 250-7, 2000

page 53

3.2 Homozygous $2 \mathrm{bp}$ deletion in the human factor VII gene:

a non-lethal mutation that is associated with a complete absence of circulating factor VII.

Peyvandi F, Mannucci PM, Jenkins V, Lee A, Coppola R, Perry DJ.

Thromb Haemost, 84: 635-637; 2000

page 70

3.3 Characterization of two naturally occurring mutations in the second epidermal growth factor like domain of factor VII.

Hunault M, Arbini AA, Carew JA, Peyvandi F, Bauer KA.

Blood 93: 1237-1244, 1999.

page 78

3.4 Abnormal secretion and function of recombinant human factor VII as the result of modification to a calcium binding site caused by a 15 base pair insertion in the factor VII gene.

Peyvandi F, Carew J, Perry D, Hunault M, Khanduri U, Perkins SJ, Mannucci PM, Bauer KA.

Blood, accepted for publication.

page 96

3.5 Molecular analysis of the ERGIC 53 gene in 35 families with combined factor V-factor VIII deficiency.

Neerman-Arbez M, Johnson KM, Morris MA, McVey JH, Peyvandi F, Nichols WC, Ginsburg D, Rossier C, Antonarakis SW, Tuddenham EGD.

Blood 93: 2253.2260, 1999.

page 111

\section{Chapter 4. Therapeutic recommendations}

4.1 Treatment of fibrinogen deficiency

4.2 Treatment of prothrombin deficiency

4.3 Treatment of factor $\mathrm{V}$ deficiency 
4.4 Treatment of factor VII deficiency

4.5 Treatment of combined deficiency of factor $\mathrm{V}$ and factor VIII

4.6 Treatment of factor $\mathrm{X}$ deficiency

\section{Chapter 5. General conclusions}

5.1 Pattern of bleeding symptoms

5.2 Pattern of molecular defects

5.3 Recommendations

Chapter 6. Summary 
Rare Coagulation Disorders 


\section{chapter 1}

\section{Introduction}




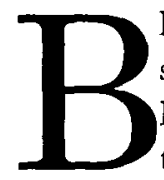
lood coagulation consists of a series of reactions that ultimately lead to the formation of the proteolytic enzyme thrombin that transforms soluble fibrinogen into threedimensional fibrin (Figure 1). Inherited deficiencies or defects of plasma proteins involved in blood coagulation generally lead to lifelong bleeding disorders, whose severity is inversely proportional to the degree of factor deficiency (less factor/more bleeding). The most frequent are hemophilia $A$ and $B$, due to the deficiency or defect of factor VIII and IX respectively. Inherited as X-linked recessive traits, hemophilia $A$ and $B$ have prevalence in the general population of approximately 1 in 10,000 and 1 in 50,000 with no significant racial difference (1). Hemophilia $A$ and $B$ are clinically indistinguishable from each other and occur in mild, moderate and severe forms (corresponding to plasma factor levels of $6-30 \%, 2-5 \%$ and $1 \%$ or less, respectively). Other inherited defects of coagulation factors that cause a bleeding disorder (afibrinogenemia, hypoprothrombinemia, deficiencies of factors V, VII, X, XI and XIII) are generally much rarer. They have prevalences varying between 1 in 500,000 and 1 in 2,000,000 (Table 1), with the exception of factor XI deficiency which reaches polymorphic frequency among Ashkenazi Jews and von Willebrand disease which may affect 1 in 100 (2). All these defects are transmitted as autosomal recessive traits expressed clinically only in homozygotes. As a consequence of the rarity of these disorders, the type and severity of symptoms, the
Fig. 1 - A simplified scheme of blood coagulation

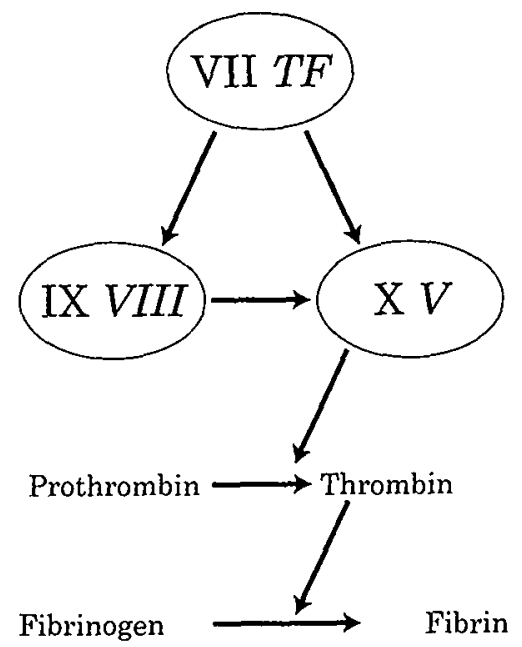

The oval represent a surface of procongulant phospholipid, clotting factors are indicated by roman numerals, the (pro-) enzymes are underlined, the cofactors are in italics.

$T F=$ tissue factor

The feed back activation of factor V and VII by thrombin is not indicated.

spectrum of gene defects and the management of bleeding episodes are not so known and established as for hemophilia A and B and von Willebrand disease.

In populations where consanguineous marriages are frequent, such as those from Muslim countries and Southern India, recessive coagulation disorders are more frequent and reach together prevalences higher than those of hemophilia $B$, representing a significant clinical and social problem. This situation typically occurs in the Islamic Republic of Iran, a country with a population of 64 
Table 1 - General features of rare coagulation disorders

\begin{tabular}{llrrr} 
Deficiency & $\begin{array}{l}\text { Estimated } \\
\text { prevalence }\end{array}$ & $\begin{array}{l}\text { Approximate number } \\
\text { of reported cases }\end{array}$ & $\begin{array}{l}\text { Gene on } \\
\text { chromosome }\end{array}$ & $\begin{array}{c}\text { Approximate number of } \\
\text { reported mutations }\end{array}$ \\
\hline Fibrinogen & $1: 1$ million & 300 & 4 & $<90^{*}$ \\
Prothrombin & $1: 2$ millions & 40 & 11 & $<20$ \\
Factor V & $1: 1$ million & 150 & 1 & $<10$ \\
Combined factor V+VIII & $1: 1$ million & 40 & 18 & $<6$ \\
Factor VII & $1: 500,000$ & 150 & 13 & $<80$ \\
Factor X & $1: 1$ million & 40 & 13 & $<25$ \\
Factor XIII & $1: 1$ million & 60 & A subunit:6 & $<20$ \\
& & & B subunit:1 & \\
\hline
\end{tabular}

* mainly in dysfibrinogencmia

millions, where a registry of congenital coagulation disorders has been kept since the 1970s (3). Table 2 compares the absolute number and prevalences of registered Iranian patients with clinically significant inherited coagulation disorders (factor levels of 10 per cent or less) with those registered in the United Kingdom by the Hemophilia Center Director Organiza-tion (UKHCDO) and in Italy by the Istituto Superiore di Sanità on behalf of the Associazione Italiana Centri Emofilia (AICE). The three countries are comparable not only because they have similar general populations of approximately 60 million, but also because they have kept hemophilia registries for a long time. Table 2 shows that while in the three countries the total numbers of registered patients are similar, the number and prevalences of inherited deficiencies of fibrinogen, prothrombin, factor $\mathrm{V}$, factor $\mathrm{V}$ and VIII, factor VII, factor X and factor XIII are three to seven times higher in Iran. Only factor XI deficiency is more prevalent in the United
Kingdom than in Iran and Italy, probably because Jewish communities are relatively small in the latter countries. With this as background, a joint project was initiated in 1996 between the Tehran Hemophilia Center and those in London and Milan. Our plans were to unravel the molecular basis of rare coagulation disorders and, taking advantage of a large and regularly followed patient population, to establish the pattern of bleeding symptoms and identify the most efficacious and safe forms of treatment. The purpose of this thesis is to summarize the general features of recessive coagulation disorder as known hitherto, to review the experience gained in a large series of patients in terms of clinical manifestations and treatment and to characterize the molecular defects underlying those disorders.

Factor XIII deficiency and type 3 von Willebrand disease will not be dealt with because data collection and genotypic analysis on patients with these defects is still incomplete. 
Table 2 - Number of patients and (between parenthesis) relative frequency of inherited coagulation disorders in Iran, Italy and United Kingdom (excluding von Willebrand disease).

\begin{tabular}{lccc} 
Defect & Iran & Italy & $\begin{array}{c}\text { United } \\
\text { Kingdom }\end{array}$ \\
\hline Fibrinogen & 70 & 10 & 11 \\
Prothrombin & $(1.5 \%)$ & $(0.2 \%)$ & $(0.2 \%)$ \\
& $(0.3 \%)$ & 7 & 1 \\
Factor V & $70.2 \%)$ & $(0.02 \%)$ \\
& $(1.5 \%)$ & 21 & 28 \\
Factor VII & 300 & 58 & $(0.6 \%)$ \\
& $(6.6 \%)$ & $(1.3 \%)$ & $(1.3 \%)$ \\
Factor V+VIII & 80 & 29 & 18 \\
& $(1.7 \%)$ & $(0.7 \%)$ & $(0.3 \%)$ \\
Factor VIII & 3000 & 3428 & 3554 \\
(hemophilia A) & $(65.4 \%)$ & $(80.0 \%)$ & $(76.8 \%)$ \\
Factor IX & 900 & 626 & 762 \\
(hemophilia B) & $(19.6 \%)$ & $(15.0 \%)$ & $(16.1 \%)$ \\
Factor X & 60 & 16 & 25 \\
& $(1.3 \%)$ & $(0.4 \%)$ & $(0.5 \%)$ \\
Factor XI & 20 & 60 & 150 \\
& $(0.4 \%)$ & $(1.3 \%)$ & $(3.3 \%)$ \\
Factor XIII & 80 & 31 & 26 \\
& $(1.7 \%)$ & $(0.7 \%)$ & $(0.5 \%)$ \\
\hline All defects & 4595 & 4286 & 4637 \\
\hline
\end{tabular}

Data are obtained from the most recent adjournments (1996) of the Registries of Inherited Bleeding Disorders kept in Iran (courtesy of Mr. Afshar and Dr. Lak, Iman Khomeini Hospital and Iranian Hemophilia Society), Italy (Dr. A. Ghirardini, Istituto Superiore di Sanità) antd United Kingdom (Dr. P. Giangrande, UK Hemophilia Center Director Organization). Only patients with factor levels of 10 per cent or less were evaluated (for fibrinogen deficiency, $10 \mathrm{mg} / \mathrm{dL}$ or less).

\subsection{Fibrinogen deficiency}

Fibrinogen deficiency is heterogeneous and two main phenotypes can be distinguished. In afibrinogenemia, plasma levels of the protein are unmeasurable or very low using assays measuring clottable and immunoreactive protein whereas in dysfibrinogenemia low clottable fibrinogen contrasts with normal fibrinogen antigen. Three separate genes located on chromosome 4 code for the $\alpha$-, $\beta$ and $\gamma$-chains of fibrinogen (1). There is at the moment very little information on the gene lesions that cause afibrinogenemia $(4,5)$, whereas more than 80 abnormalities associated with dysfibrinogenemia have been identified (6). Experimental disruption of the $\alpha$-chain gene made mice completely deficient in all the fibrinogen chains (7). There was no evidence of defective embryonal development but overt bleeding developed at birth in about one third of the animals, most frequently in the peritoneal cavity, skin and joints. Ultimately blood loss was controlled, so that most mice survived the neonatal period and reached adulthood despite recurrent bleeding episodes (7).

\subsection{Prothrombin deficiency}

Prothrombin deficiency is probably the rarest coagulation defect, with a prevalence of 1 in $2,000,000$. Measuring plasma levels of prothrombin as functional activity or immunoreactive protein, two main phenotypes can be distinguished: hypoprothrombinemia, characterized by concomitantly low levels of activity and antigen, and dysprothrombinemia, characterized by the normal synthesis of a dysfunctional protein (low coagulant activity but normal antigen levels) $(8,9)$. To our knowledge no living patient with unmeasurable plasma prothrombin has been reported so far, consistent with experimental data indicating 
that in mice complete prothrombin deficiency is incompatible with life (10). Prothrombin is encoded by a gene located in chromosome 11 (1). There is at the moment relatively little published information on the molecular basis of hypoprothrombinemia and dysprothrombinemia. It is remarkable that only gene mutations causing single amino acid substitutions have been identified so far in patients with hypoprothrombinemia (11).

\subsection{Factor V deficiency}

The majority of cases are characterized by the concomitant deficiency of factor $\mathrm{V}$ activity and antigen, but approximately one fourth have normal antigen levels, indicating the presence of a dysfunctional protein (12). Factor $\mathrm{V}$ is contained in platelets, probably synthesized by mega-karyocytes (13). About one third of patients with inherited factor $\mathrm{V}$ deficiency have a prolonged bleeding time (11). The relationship between this abnormality of primary hemostasis and the content and function of factor $V$ in patient platelets remains unclear. The factor $V$ gene is on chromosome 1 , and a relatively small number of the molecular lesions which underlie the deficiency has been identified (14-17). The experimental deficiency of factor $\mathrm{V}$ in mice leads to a dramatic bleeding tendency with defective embryonic development and early hemorrhagic death (18). However, a more recent study has been shown that mice that express minimal factor $\mathrm{V}$ activity below the levels of assay detection $(<0.1 \%)$ differ from the original knock out mice because they survive (19).

\subsection{Factor VII deficiency} Factor VII deficiency is the most common of the rare coagulation disorders (1 per 500,000 population) (1). The majority of patients have concomitantly low levels of factor VII functional activity and antigen, but some cases are characterized by normal or low borderline levels of factor VII antigen contrasting with lower levels of functional activity (20). In some patients factor VII coagulant activity is highly dependent upon the source of tissue factor used in the assay (20). The factor VII gene is on chromosome 13 adjacent to the factor $X$ gene (1), and at least 80 mutations have been identified in deficient kindreds (21). A list of these mutations can be obtained in the Internet http://europium.mrc.rpms.ac.uk/usr/WWW/ WebPages/FVII/database.dir/titlespage.htm . Most mice made experimentally deficient in factor VII develop normally but some suffer fatal perinatal bleeding (22).

\subsection{Combined deficiency of factor V and factor VIII}

For many years the mechanism of the combined deficiency of these clotting factors coded by different genes and transmitted with different patterns of inheritance (autosomal recessive for factor $\mathrm{V}, \mathrm{X}$-linked for factor VIII) has not been understood. Recently, a substantial proportion of patients were found to have mutations in the gene ERGIC-53 on chromosome 18 (23). This gene encodes a $53 \mathrm{kD}$ homo-hexameric transmembrane lectin which resides in the endoplasmic reticulum/Golgi intermediate 
compartment (ERGIC) and probably acts as a chaperone in the intracellular transport and secretion of both factor $\mathrm{V}$ and factor VIII (24). Efficient trafficking of factor $\mathrm{V}$ and VIII requires a functional ERGIC and is dependent on post-translation modifications of a specific cluster of aspargic acid linked oligosaccharides to a fully glucose trimmed mamose structure. Patients with the combined defect of factor $\mathrm{V}$ and factor VIII have concomitantly low levels of the two factors (usually, between 5 and $20 \%$ ), both as coagulant activity and antigen (25). Combined defects of clotting factors other than factor $\mathrm{V}$ and VIII have been described in very rare cases (26).

\section{References}

1. Tuddenham EGD, Cooper DN: The molecular genetics of hemostasis and its inherited disorders. Oxford University Press, 1994.

2. Girolami A, De Marco L, Dal Bo Zanon R, Patrassi G, Cappellato MG: Rare quantitative and qualitative abnormalities of coagulation. Clin Haematol 1985,14: 385-411.

3. Shoa'i I, Ala F, Forouzanfar N: Hemophilia in Iran. In: Haemophilia (F. Ala, KWE Denson, editors). Excerpta Medica, 1973, p. XII.XV.

4. Neerman-Arbez $M$, Honsberg $A$, Antonorakis $\mathrm{SE}$, Morris MA: Deletion of the fibrinogen alpha chain gene (FGA) causes congenital afibrinogenemia. J Clin Invest 1999, 103: 215-218.

5. Duga S, Asselta R, Simonic T, Santagostino E, Mannucci PM, Malcovati M. Tenchini ML: First identification of a missense mutation in the

\subsection{Factor $\mathrm{X}$ deficiency}

Like factor VII, factor $\mathrm{X}$ is encoded by a gene on chromosome 13 (1). No more than 25 mutations associated with factor $\mathrm{X}$ deficiency have been described so far (for reviews, see 27,28 ). Phenotypes are characterized by concomitantly low levels of coagulant activity and antigen or by low coagulant activity contrasting with normal or low borderline antigen values. Mice rendered experimentally deficient in factor $\mathrm{X}$ by targeted inactivation of the factor $\mathrm{X}$ gene showed frequent embryonic lethality (29). Those who survived bled to death intra-abdominally at birth and in the central nervous system within the first 3-4 weeks of life (29).

D-domain of the fibrinogen beta chain in a case of congenital afibrinogenemia. Thromb Haemostas 1999, 92 (suppl.).

6. Martinez J: Congenital dysfibrinogenemia. Curr Opin Hematol 1997, 4: 357-365.

7. Suh TT, Holmback K, Jensen NJ, Daugherty CC, Small K, Simon DI, Potter S, Degen JL: Resolution of spontaneous bleeding events but failure of pregnancy in fibrinogen deficient mice. Genes Dev 1995;15: 2020-33.

8. Roberts HR, Hoffman M: Other clotting factor deficiencies. In: Hemostasis and Thrombosis: Basic Principles and Clinical Practice. 4th edition (RW Colman, J Hirsh, VJ Marder, EW Salzman, editors). J.B. Lippincol Company, Philadelphia, 1999: in press.

9. Roberts HR, Bingham MD: Other coagula- 


\section{Chapter 1 -Introduction}

tion factor deficiencies. In: Thrombosis and Hemorrhage. 2nd Edition (J Loscalzo, AL Schafer. editors). Williams and Wilkins, Baltimore, 1998, pp 773.802 .

10. Sun WY, Witte DP, Degen JL, Colbert MC, Holmback K, Xiao Q, Bugge TH, Degen SJ:

Prothrombin deficiency results in embryonic and neonatal lethality in mice. Proc. Nall Acad Sci USA 1998, 95: 7597-8002.

11. Akhavan S, Lak M, Mancuso G, Baudo F, Mazzucconi MG, Perkins SJ, Mannucci PM:

Molecular characterization of 11 kindreds with prothrombin deficiency. Thromb Haemost 1999, 82 (suppl.).

12. Chiu HC, Whitaker E, Colman RW: Heterogeneity of human factor $V$ deficiency. Evidence for the existence of an antigen-positive variant. $J$ Clin Invest 1983, 72: 493-503.

13. Tracy PB, Eide LL, Bowie EJ, Mann KG: Radioimmunoassay of factor $\mathrm{V}$ in human plasma and platelets. Blood 1982, 60: 59-63.

14. Murray JM, Rand MD, Egan JO, Murphy S, Kim HC, Mann KG: Factor $V_{\text {NewBrunswick: }}$ $\mathrm{Ala}_{221}$-to Val substitution results in reduced cofactor activity. Blood 1995, 86: 1820-1827.

15. Lunghi B, Castoldi E, Mingozzi F, Bernardi $F$ : A novel factor $V$ null mutation detected in a thrombophilic patient with pseudo-homozygous $A P C$ resistance and in an asymptomatic unrelated subject. Blood 1998,92:1463-1464.

16. Zehender JL, Hiraki D, Jones C, Gross N, Gruber FC: Familial coagulation factor $V$ deficiency caused by a novel 4 base pair insertion in the factor $V$ gene. Thromb Haemostas 1999,82:1097-99.

17. Guasch JF, Cannegieter S, Reitsma PH, Van't Veer-Korthof ET, Bertina RM: Severe coa- gulation factor $V$ deficiency caused by a $4 \mathrm{bp}$ deletion in the factor $\mathrm{V}$ gene. $\mathrm{Br} J$ Haematol 1998,101:32-39.

18. Cui J, O'Shea KS, Purkayastha A, Saunders TL, Ginsburg D: Fatal hemorrhage and incomplete block of embryogenesis in mice lacking coagulation factor V. Nature 1996, 384: 66-68.

19. Yang TL, Cui J, Taylor JM, Yang A, Gimber SB, Ginsburg D: Rescue of fatal neonatal hemorrhage in factor $\mathrm{V}$ deficient mice by low transgene expression. Thromb Haemostas 2000;83:70-77.

20. Triplett DA, Brandt JT, Batard MA, Dixon JL, Fair DS: Hereditary factor VII deficiency heterogeneity defined by combined functional and immunochemical analysis. Blood 1985,66:1284-1287.

21. Cooper DN, Millar DS, Wacey A, Banner DW, Tuddenham EGD: Inherited factor VII deficiency: molecular genetics and pathophysiology. Thromb Haemostas 1997,78:151-160.

22. Rosen ED, Chan JC, Idusogie E, Clotman F, Vlasuk G, Luther T, Jalbert LR, Albrecht S, Zhong L, Lissens A, Schoonjans L, Moons L, Collen D, Castellino FJ, Carmeliet P: Mice lacking factor VII develop normally but suffer fatal perinatal bleeding. Nature 1997,390:290-294.

23. Nichols WC, Seligsohn U, Zivelin A, Terry VH, Hertel CE, Wheatley MA, Moussali MJ, Hauri HP, Ciavarella N, Kaufman RJ, Ginsburg D: Mutations in the gene for ERGIC-53, a protein of the endoplasmic reticulum/Golgi intermediate compartment cause combined deficiency of coagulation factors $\mathrm{V}$ and VIII. Cell 1998;93:61-64.

24. Moussali M, Pipe SW, Hauri HP, Nichols WC, Ginsburg D, Kaufman RJ: Mannose-depen- 
dent endoplasmic reticulum (ER)-Golgi

intermdiate compartment-53 mediated ER to Golgi trafficking of coagulation factor $V$ and VIII.

J Biol Chem 1999; 274: 32539-42

25. Giddings JC, Seligsohn U, Bloom AL: Immunological studies in combined factor $\mathrm{V}$ and factor VIII deficiency. Br J Haematol 1977, 37:257.

26. Soff GA, Levin J: Familial multiple coagulation factor deficiency. Sem Thromb Haemostas 1981;7:112-48.
27. Perry DJ: Factor $X$ and its deficiency states. Haemophilia 1997,3:159-72.

28. Cooper DN, Millar DS, Wacey A, Pemberton $\mathrm{S}$, Tuddenham EGD: Inherited factor $\mathrm{X}$ deficiency: molecular genetics and pathophysiology. Thromb Haemostas 1997, 78: 161-172.

29. Dewerchin M, Liang Z, Moons L, Carmeliet P, Castellino FJ, Collen D, Rosen ED: Blood coagulation factor $\mathrm{X}$ deficiency causes partial embryonic lethality and fatal neonatal bleeding in mice. Thromb Hemostas $2000 \mathrm{Feb}$, 83:2:185-190 


\section{chapter 2}

\section{Clinical studies}

Bleeding and thrombosis in 55 patients with inherited afibrinogenemia

British Journal of Haematology 107: 204-206, 1999

Symptoms of inherited factor $\mathrm{V}$ deficiency in 35 Iranian patients

British Journal of Haematology 103: 1067-1069, 1998

Clinical manifestations in 28 Iranian and Italian patients with severe factor VII deficency

Haemophilia 3: 242-246, 1997

Bleeding symptoms in 27 Iranian patients with factor V and VIII combined deficiency

British Journal of Haematology 100: 773-776, 1998

Congenital factor $\mathrm{X}$ deficiency: spectrum of bleeding symptoms in 32 Iranian patients

British Journal of Haematology 102: 626-628, 1998 


\section{Rare Coagulation Disorders}

\section{Introduction}

Textbooks contain chapters on rare coagulation disorders and describe their clinical manifestations $(1,2)$. A review article was published in 1985 (3). In these sources, information on the spectrum of bleeding symptoms stems from reports of single cases or small series of patients. There have been attempts to analyze a larger number of cases by pooling those reported in the literature (3) or distributing questionnaires to the largest hemophilia centers (4). Because these approaches have obvious limits of inaccuracy, incomplete ascertainment and bias towards publishing the most striking cases, in this thesis we chose to minimize these drawbacks by directly investigating a relatively large number of patients from the Iranian registry. For factor V, factor VII and factor X deficiencies approximately three-fourth of the patients had a severe deficiency (plasma levels of $1 \%$ of normal or less). The remaining patients with these defects had moderately severe $(2-5 \%)$ or mild deficiencies (6-10\%). No patient with factor levels higher than $10 \%$ was considered, except for combined factor V and VIII deficiency (factor ranges $4-14 \%$ ). None of the patients with prothrombin deficiency had factor levels below $4 \%$. All patients with fibrinogen deficiency had levels below $10 \mathrm{mg} / \mathrm{dL}$, which is the lower limits of sensitivity of the functional assay used in this study. Therefore, it appears that the different groups of patients with factor deficiencies were comparable, with a prevalence of severe defects except for prothrombin and combined factor $\mathrm{V}$ and VIII deficiency.

To evaluate critically the reliability of bleeding symptoms as reported by patients, a few criteria were established before the study in order to evaluate whether or not symptoms had to be accepted as valid. Epistaxis qualified only when it occurred spontaneously more than five times lifelong, from both nostrils, lasted more than $10 \mathrm{~min}$ or required hospital admission. Menorrhagia was defined as menstrual periods lasting at least 6 days and requiring the therapeutic use of combined estrogen-progestogen preparations or causing iron deficiency. Bleeding in the gastrointestinal and urinary tracts and in the central nervous system had to be documented by hospital records. Muscle hematomas and hemarthroses qualified when they occurred spontaneously or following minor traumas and caused at least transient signs of functional joint or muscle impairment. Oral bleeding qualified if it lasted more than $10 \mathrm{~min}$ or required the intervention of an oral surgeon, whether caused by dental extractions or by bites to lips, cheecks and tongue. Surgical or postpartum bleeding had to cause a delay in discharge from hospital or require blood transfusion. Bleeding symptoms occurring after dental extractions or surgery (inclu- 
ding circumcision) qualified only when they occurred before the coagulation defect was diagnosed, in patients who had not received replacement therapy before the procedures. Easy bruising was not considered because the evaluation of this symptom by patients was considered too subjective. Clinical histories were collec-

\section{References}

1. Colman RW, Hirsh J, Marder VJ, Salzman EW: Basic Principles and Clinical Practice. 4th edition (editors). J.B. Lippincot Company

2. Roberts HR, Bingham MD: Other coagulation factor deficiencies. In: Thrombosis and

Hemorrhage. 2nd Edition (J. Loscalzo, A.L. Schafer; editors). Williams and Wilkins, Baltimore, 1998, pp 773-802. ted by the same physician for all patients. The next articles included in this thesis report the data obtained in patients with afibrinogenemia (2.1), factor $V$ deficiency (2.2), factor VII deficiency (2.3), combined factor $\mathrm{V}$ and factor VIII deficiency (2.4) and factor $\mathrm{X}$ deficiency (2.5).

3. Girolami A, De Marco L, Dal Bo Zanon R, Patrassi G, Cappellato MG: Rare quantitative and qualitative abnormalities of coagulation. Clin Haematol 1985, 14: 385-411.

4. Mariani G, Mazzucconi MG: Factor VII congenital deficiency: clinical picture and classification of the variants. Haemostasis 1983, 13: 169 . 174 


\section{Bleeding and thrombosis in 55 patients with inherited afibrinogenemia}

M. Lak ${ }^{1}$, M. Keihani ${ }^{1}$, F. Elahi' ${ }^{1}$, F. Peyvandi ${ }^{2}$ and P.M. Mannucci ${ }^{2}$

'Hemophilia Center, Iman Khomeini Hospital, Teheran, Iran and 'Angelo Bianchi Bonomi Hemophilia and Thrombosis Center and Fondazione Luigi Villa, IRCCS Maggiore Hospital, Milan, Italy

British Journal of Hematology 107: 204-206, 1999 


\section{Summary}

Knowledge on the spectrum of symptoms in patients with inherited afibrinogenemia is limited by the rarity of this coagulation defect. We compared a large series of 55 afibrinogenemic patients from Iran with 100 patients with severe factor VIII deficiency, the most frequent inherited defect of coagulation. In afibrinogenemia there was a higher frequency of mucosal-type bleeding symptoms but joint and muscle bleeding was less frequent and severe than in hemophilia. Umbilical cord bleeding was relatively frequent only in afibrinogenemic patients. Two young patients developed spontaneous thrombotic episodes and three women had recurrent abortions. Overall, in afibrinogenemia bleeding symptoms are qualitatively different and somewhat less severe than in hemophilia. Afibrinogenemia can also be accompanied by thrombotic manifestations.

Keywords: afibrinogenemia, thrombosis, hemophilia

\section{Introduction}

Afibrinogenemia, a rare coagulation disorder transmitted as an autosomal recessive trait (Roberts \& Bingham, 1998), is relatively more frequent in communities where consanguineous marriages are common (Fried $\&$ Kaufman, 1980). In Iran a national registry of inherited coagulation disorders lists 70 patients with afibrinogenemia. In contrast, similar registries kept in Italy and in the United Kingdom, countries that like Iran have general populations of approximately 60 millions but relatively few consangui- neous marriages, list 10 and 11 patients, respectively. Knowledge on the overall spectrum of bleeding manifestations in afibrinogenemia are scanty and probably inaccurate, being based upon reports of single cases or small series that tend to emphasize the most severe and striking symptoms (Fried \& Kaufman, 1980; Al-Mondhiry \& Ehmann, 1994). Thrombotic complications have been described in afibrinogenemic patients (Roberts \& Bingham, 1998). In this study, we tried to provide more accurate information by examining a large sample of 55 Iranian patients. Their symptoms were compared with those observed in patients with severe hemophilia A, the most typical and frequent inherited disorder of blood coagulation.

\section{Patients and methods}

Afibrinogenemia was diagnosed when plasma fibrinogen levels were unmeasurable both as functional activity (the Clauss method based upon the fibrin polymerization time using bovine thrombin; Laboratoire Stago, Asnieres, France) and immunoreactive protein (electroimmunoassay using rabbit anti-human fibrinogen antiserum supplied by Laboratoire Stago). Standards were supplied by the manufacturer. The lower limit of sensitivity of both assays is $10 \mathrm{mg} / \mathrm{dL}$. Factor VIII deficiency was diagnosed by an APTTbased assay using substrate plasma from a severely deficient patient.

Fifty-five patients from 48 kindreds (2-73 years, 27 males and 28 women, $78 \%$ of all registered patients) were examined in 


\section{Rare Coagulation Disorders}

Tehran by the same physician (M.L.). Most of them were from consanguineous marriages and the asymptomatic parents had in average half-normal levels of plasma fibrinogen. To evaluate critically the reliability of bleeding symptoms as reported by patients qualification criteria were established (Lak et al, 1998). In any give patients, muscle hematomas and hemarthroses were considered as symptoms when they occurred spontaneously or disproportionately to minor traumas and caused at least transient clinical signs of functional impairment of the involved joints or muscles. Thrombotic episodes and lifeendangering hemorrhagic symptoms such as umbilical cord, gastrointestinal, urinary tract and central nervous system bleeding had to be documented by hospital records. A mild mucosal tract hemorrhage such as epistaxis qualified only when it occurred more than five times lifelong, from both nostrils, lasted more than 10 min or required hospital admission. Menorrhagia, evaluated in 20 women of childbearing age, was defined by menstrual periods that lasted at least 6 days and required treatment (replacement therapy, antifibrinolytic amino acids, estrogenprogestogen medication or iron supplementations). Oral bleeding qualified if it did require local hemostasis measures, whether caused by dental extractions or fall of deciduous teeth or by bites to lips, cheeks and tongue. Excessive bleeding after surgery (including circumcision) and in the post-partum period qualified only when it occurred before the diagnosis of afibrinogenemia was established, so that no prophylactic replacement therapy had been administered.

\section{Results and discussion}

Symptoms in patients with afibrinogenemia are shown in Table 1, which also shows the corresponding data in 100 patients with hemophilia A matched for age (range 4-71 years) and severity (factor VIII $1 \%$ or less). The most frequent and life-endangering hemorrhagic symptom was umbilical cord bleeding ( $85 \%$ of patients). Bleeding in the central nervous system was relatively rare (in 3 of 55 patients) at variance with other 


\section{Chapter 2 - Clinical studies}

reports (Fried \& Kaufman, 1980).

Hemarthroses and hematomas were frequent ( $54 \%$ and $72 \%$, respectively), but only 15 patients had clinical signs of musculoskeletal damage. While hematuria and gastrointestinal bleeding never occurred in this series, bleeding in other mucosal tracts such as epistaxis and menorrhagia were frequent ( $72 \%$ of all patients the former, $70 \%$ of women the latter). Circumcision and other surgical maneuvers were sometime accompanied by excessive oozing and impaired wound healing ( $40 \%)$.

Overall, it appears that in afibrinogenemia bleeding symptoms are qualitatively different and somewhat less severe than in hemophilia. For instance, a smaller proportion of patients had spontaneous joint and muscle bleeding, the most common and typical symptom in hemophilia (Table 1). Permanent damage to the musculoskeletal system and the resulting handicaps were definitely rarer. Hematuria, not unusual in hemophiliacs, was absent in this series. On the other hand, umbilical cord bleeding, never seen in hemophiliacs, was highly prevalent among afibrinogenemic patients. The relatively high frequency of mucosal-type symptoms such as nose bleeding and menorrhagia might be explained by the fact that in afibrinogenemia platelet fibrinogen is usually deficient (Roberts \& Bingham, 1998). There have been reports of decreased fertility and recurrent abortions in afibrinogenemic women (Goodwin, 1989). Recurrent abortions (more than two and consecutive) were seen in three of 18 married Iranian women. One had two miscarriages and never completed a pregnancy, another had four consecutive miscarriages and the third after two miscarriages eventually delivered a normal child after prophylactic treatment with cryoprecipitate twice weekly during the first six months of pregnancy. Therefore, afibrinogenemic women tend to have recurrent abortions.

Perhaps, as shown in mice made fibrinogen deficient by abrogating the a-chain gene (Suh et al, 1995), afibrinogenemia affects the implantation of the embryo.

Arterial or venous thromboses have been reported to occur spontaneously or after infusion of fibrinogen-containing preparations in afibrinogenemic patients (see Roberts \& Bingham, 1998). In our series, a 5-year-old boy developed paraplegia as a consequence of thrombosis of the cerebral sagittal sinus. A 14-year-old girl developed ischemic gangrene of the right foot due to the thrombotic occlusion of the popliteal artery and the amputation of the toe was eventually necessary. Both thrombotic complications occurred at a young age and in the absence of fibrinogen infusion or circumstantial risk factors. The puzzling association of a severe coagulation defect such as afibrinogenemia and thrombosis found previously and in this series has as yet no definite explanation. It has been suggested that thrombotic events are related to thrombininduced platelet aggregation in vivo due to poor neutralization of this enzyme, in turn due to lack of its adsorption on fibrin (Chafa et al, 1995). 


\section{References}

1. Al-Mondhiry H, Ehmann WC (1994):

Congenital afibrinogenemia. American Journal of Hematology 46: 343-347.

2. Chafa O, Chellali T, Sternberg C, Reghis A, Hamladji PM, Fischer AM (1995): Severe hypofibrinogenemia associated with bilateral ischemic necrosis of toes and fingers. Blood Coagulation and Fibrinolysis 1995; 6: 549-552.

3. Fried K, Kaufman S (1980): Congenital afibrinogenemia in 10 offspring of uncle-niece marriages. Clinical Genetics 18: 223-227.

4. Goodwin TM (1989): Congenital hypofibrinogenemia in pregnancy. Obstetrics Gynecology Survey 44: 157.161.
5. Lak M, Sharifian R, Peyvandi F, Mannucci PM (1998): Symptoms of inherited factor $V$ deficiency in 35 Iranian patients. British Journal of Haematology 103: 1067-1069

6. Roberts HR, Bingham MD (1998): Other coagulation factor deficiencies. In: Thrombosis and Hemorrhage. 2nd Edition ( $\mathrm{J}$ Loscalzo, AL Shafer, editors). Williams \& Wilkins, Baltimore pp. 773-802.

7. Suh TT, Holmback K, Jensen NJ, Daugherty CC, Small K, Simon DI, Potter S, Dogen JL (1995): Resolution of spontaneous bleeding events but failure of pregnancy in fibrinogen deficient mice. Genes Development 15: 2020-2033. 


\title{
Symptoms of inherited factor V deficiency in 35 Iranian patients
}

\author{
M. Lak', F. Peyvandi', R. Sharifian ${ }^{1}$ and P.M. Mannucci ${ }^{2}$ \\ ' National Hemophilia Center, Iman Khomeini Hospital, Tehran, Iran \\ ${ }^{2}$ Angelo Bianchi Bonomi Hemophilia and Thrombosis Center, IRCCS \\ Maggiore Hospital, University of Milan, Italy
}

British Journal of Hematology 103: 1067-1069, 1998 


\section{Summary}

The type of bleeding symptoms have been evaluated in 35 Iranian patients with the inherited deficiency of factor $\mathrm{V}$, with plasma levels between $1 \%$ and $10 \%$. The most frequent symptoms included epistaxis and excessive bleeding after surgery.

Hemarthroses and muscle hematomas were less common, even in severely deficient patients. More severe symptoms such as gastrointestinal and central nervous system bleeding were rare. The severity of bleeding symptoms was only partially related to the degree of factor $\mathrm{V}$ deficiency in plasma. On the whole, human factor $\mathrm{V}$ deficiency is characterized by a moderately severe bleeding phenotype.

Key words: factor $V$ deficiency, inherited coagulation disorders, bleeding symptoms

\section{Introduction}

In the most frequent congenital coagulation disorders such as hemophilia $A$ and $B$, von Willebrand disease and factor XI deficiency, the pattern of the clinical manifestations of the bleeding tendency is well established. Other congenital coagulation defects are very rare (frequencies of less than 1 in one million in the general population; Girolami et al, 1985). Accordingly, information on the spectrum of bleeding symptoms is limited and scattered, being based upon reports of single cases or small series of patients. In countries where consanguineous marriages are frequent, genetic diseases transmitted with an autosomal recessive pattern of inheritance are relatively more prevalent. In
Iran recessive coagulation disorders occur approximately ten times more frequently than in Western countries. We analyzed the clinical manifestations of 35 Iranian patients diagnosed with a congenital deficiency of factor V (Owren, 1947).

\section{Patients and methods}

The subjects comprised 25 males and 10 females, ages 3 to 65 years, belonging to 30 unrelated families. In 24 families patients were born from marriages between first-or second-degree cousins. To minimize bias and to evaluate critically the reliability of the clinical history as reported by patients, a specially tailored questionnaire (available on request) was delivered to the patients by one of us (M.L.). A descriptive threshold was used below which a reported bleeding symptom was not taken into consideration. Epistaxis was accepted when it was recurrent, from both nostrils and lasted longer than 10 minutes or required hospital admission. Menorrhagia was defined as menstrual periods of at least 6 days needing hormonal treatment or causing iron deficiency. Gastrointestinal bleeding, haematuria and intracranial bleeding had to be documented by hospital records. Hematomas and hemarthroses were classified when they caused the transient or permanent presence of clinical or radiological signs of joint or muscle impairment. Oral bleeding was classified as any episode lasting longer than 10 minutes, caused by tooth extractions or eruptions or by bites to lips, cheek and tongue. Surgical and post-partum bleeding was 
considered any bleeding causing a delay in discharge from hospital or requiring blood transfusion. Bleeding symptoms occurring after surgery (including circumcision) were considered only when they occurred before diagnosis and patients were not treated prophylactically.

Plasma levels of factor $\mathrm{V}$ coagulant activity were measured with a prothrombin time-based manual assay using rabbit thromboplastin (Ortho

Diagnostic System) and factor $V$ deficient plasma obtained from a congenitally deficient patient with unmeasurable plasma levels (normal laboratory range: 71-125\%). Factor VIII coagulant activity was also measured in all patients to exclude the combined deficiency of factor V and VIII, which is frequent in Iran (Peyvandi et al, 1998a). Patients were classified in three groups: severe (16 patients with factor V $1 \%$ or less), moderate (13 patients with $2-5 \%$ factor $\mathrm{V}$ ) and mild (6 patients with factor V $6-10 \%$ ).

\section{Results}

Table I summarizes the number and prevalence of each bleeding symptom in patients divided into the three groups of plasma factor $\mathrm{V}$ levels.

Soft tissue bleeding. The most frequent symptom was bleeding in the oral cavity (57\% of all cases), which occurred after bites to the tongue or lips or following the extraction of permanent teeth. This symptom occurred with similar frequency in the three categories of factor deficiency, even though in severely deficient patients bleeding tended to be more severe. Excessive bleeding was also found after surgery (43\%), most often after circumcision, whatever the degree of factor deficiency. Hemarthroses and hematomas occurred in about onefourth of the patients, including those with milder deficiency. In no patient was there any musculo-skeletal damage of clinical significance, but early signs of arthropathy were seen on radiological or ultrasound examination in all patients who had hemarthroses. Subdural and intracerebral bleeding 
occurred in two patients with severe deficiency and one child had prolonged bleeding when the umbilical stump fell.

Mucosal bleeding. Epistaxis was relatively frequent $(57 \%)$ and occurred even in patients with mild deficiency (5 of 6 cases). Menorrhagia occurred in 5 of the 10 women of child-bearing age, all had severe or moderate factor deficiency. Other symptoms such as gastrointestinal and urinary tract bleeding were rare, with no triggering lesion identified in the 4 patients who had these symptoms.

\section{Discussion}

Since only 150 factor $V$ deficient patients are known so far (Girolami et al, 1985), this large series contributes substantially to our knowledge of the spectrum of the clinical manifestations of this disorder. In most patients bleeding symptoms first developed during the first six years of life, but only one bled from the umbilical stump. There was no instance of cephalohematoma. Epistaxis was frequent, even in patients with moderate and mild deficiency. In contrast, other symptoms of mucosal bleeding such as melena and hematuria were relative rare. We have previously found a surprisingly high frequency of epistaxis in the inherited deficiencies of factor VII and X (Peyvandi et al, 1997 and 1998b). It remains to be explained why epistaxis is more frequent in recessive coagulation disorders than in hemophilia A and B. Postoperative and oral cavity bleeding was relatively common, but not predictable, as these symptoms also occurred in patients with 5 to $10 \%$ plasma levels. Variations in the platelet levels of factor $V$ and in the skin bleeding time, not measured in our patients, may explain this discrepancy (Bredeerveld et al, 1975). Hemarthroses and hematomas occurred in 26 and $29 \%$ of the patients, but were not the most frequent and severe symptoms as in classic hemophilia. On the whole, in factor V deficient patients hemorrhagic manifestations are not as severe or frequent as in hemophiliacs with corresponding degrees of coagulation factor deficiency. This moderately severe phenotype sharply contrasts with the dramatic early-lethal bleeding phenotype found in knock-out mice lacking factor $\mathrm{V}$ (Cui et al, 1996). Perhaps the genetic lesions of the Iranian patients are such that traces of factor $V$ can be produced, rendering the phenotype less severe.

Factor $\mathrm{V}$ is the only inherited bleeding disorder for which no concentrate is available.

Fresh-frozen plasma is the mainstay of treatment in Iran. In our experience, single daily dosages of $15.20 \mathrm{ml} / \mathrm{kg}$ are usually adequate to control most spontaneous hemorrhages in soft tissues and mucosal tracts. A frequent symptom such as epistaxis can be usually controlled by local measures and antifibrinolytic drugs, so that replacement therapy is rarely necessary. In a few surgical cases, prolonged treatments with large amounts of fresh-frozen plasma caused volume overload. Therefore, a factor $\mathrm{V}$ concentrate is warranted. 


\section{References}

1. Breederveld K, Giddings JC, ten Cate JW Bloom A: (1975) The localization of factor $V$ within normal platelets and the demonstrations of a platelet factor V deficiency. British Journal of Haematology 29, 405-412.

2. Cui J, O'Shea KS, Puskayastha A, Saunders TL, Ginsburg D: (1996) Fatal haemorrhage and incomplete block of embryogenesis in mice lacking coagulation factor $\mathrm{V}$. Nature 384: 66-68.

3. Girolami A, De Marco L, Dal Bo Zanon R, Patrassi G, Cappellato MG: (1985) Rare quantitative and qualitative abnormalities of coagulation. Clinics in Hematology 14, 385.411.

4. Owren PA: (1947) The coagulation of blood. Investigation on a new clotting factor. Acta Medica Scandinavia 194: 11-41.
5. Peyvandi F, Mannucci PM, Asti D, Abdoullahi M, Di Rocco N, Sharifian R: (1997) Clinical manifestations in 28 Italian and Iranian patients with severe factor VII deficiency. Hemophilia 3, 242-246.

6. Peyvandi F, Tuddenham EGD, Akhtari AM, Lak M, Mannucci PM: (1998a) Bleeding symptoms in 27 Iranian patients with the combined deficiency of factor V and factor VIII. British Journal of Haematology 100, 773.776.

7. Peyvandi F, Mannucci PM, Lak M, Abdoullahi M, Zeinali S, Sharifian R, Perry D: (1998b) Congenital factor $X$ deficiency: spectrum of bleeding symptoms in 32 Iranian patients. British Journal of Haematology 102, 626.628. 


\section{Clinical manifestations in 28 Italian and Iranian patients with severe factor VII deficiency}

F. Peyvandi', P. M. Mannucci', D. Asti', M. Abdoullahi',

N. Di Rocco' and R. Sharifian ${ }^{2}$

'Angelo Bianchi Bonomi Hemophilia and Thrombosis Center and the Institute of Internal Medicine, IRCCS Maggiore Hospital and University of Milan, Italy,

${ }^{2}$ Haemophilia Center, University of Tehran, Islamic Republic of Iran

Haemophilia 3: 242-246, 1997 


\section{Chapter 2 - Clinical studies}

\section{Summary}

There has been wide variation in the reported haemorrhagic manifestations of factor VII deficiency. We examined type and frequency of clinical manifestations in 28 Iranian and Italian patients with severe deficiency (factor VII coagulant activity $2 \%$ or less). The most frequent symptoms were epistaxis and menorrhagia, whereas soft tissue bleeding such as haemarthrosis and muscle haematoma was less frequent. Only 5 of 9 patients who underwent surgery without factor VII replacement therapy had postoperative bleeding severe enough to require blood transfusion. No thrombotic manifestation occurred. A factor VII functional assay based on the use of human thromboplastin was a better predictor of the bleeding tendency of these patients than a rabbit thromboplastin-based functional assay or immunoassay. On the whole, this study shows that in severe factor VII deficiency bleeding in mucosal tracts is not uncommon. Surgery can sometimes be performed without replacement therapy and without haemorrhagic complications.

Keywords: factor VII, factor VII deficiency, congenital bleeding disorders.

\section{Introduction}

Congenital deficiency of factor VII, first described in 1951 by Alexander et al. (1), is an autosomal recessive disorder of blood coagulation.

According to textbooks, prevalence in the general population is $1: 500000$, accounting for approximately $0.5 \%$ of all congenital coagulation disorders (2). The Italian Registry of
Congenital Coagulation Disorders lists 57 patients with severe or moderate deficiency of factor VII (less than 5\%), so that the prevalence of the defect in Italy is 1:950 000, close to that quoted in textbooks. From reports in the literature, in general single cases or small series, it appears that the type and frequency of clinical manifestations of this rare disorder are quite varied (3-6). In the framework of a collaboration between the haemophilia centres of Milan in Italy and of Tehran in the Islamic Republic of Iran (where factor VII deficiency is relatively frequent because consanguineous marriages are customary among Muslims), we chose to reassess the issue of variation in clinical manifestations of factor VII deficiency. Twenty-eight patients with severe deficiency, the largest series ever reported in a single study, have been examined by the same physician. Plasma levels of factor VII coagulant activity (VII:C) and factor VII antigen (VII:Ag) were also measured in the attempt to correlate phenotypes with the type and frequencv of clinical manifestations.

\section{Patients and methods}

Iranian patients. This group consisted of 18 patients (six women, 12 men, age range 8-5 years) belonging to 14 families selected solely on factor VII levels (see below) and availability to attend the Tehran He-mophilia Centre for interview, clinical examination and blood sampling. On the basis of the historical values of plasma VIII:C levels as obtained using a rabbit thromboplastinbased functional assay, patients with less 
than $2 \%$ VII:C were selected for this study. In 12 of the 14 families factor-VII-deficient patients were born from marriages berween flrst-degree $(n=10)$ or second-degree $(n=2)$ cousins.

Italian patients. This group consisted of 10 patients (seven women and three men, age range 6-53 years), belonging to seven different families. They were selected with the same criteria of the Iranian patients, including cut-off VII:C levels. In none of the families was there consanguineity.

Collection of clinical and laboratory data Patients from both groups attended the haemoplilia centres of Milan and Tehran, where the same physician (F.P.) examined them, constructed family pedigrees and collected the medical history, with specific questions on the occurrence of bleeding and thrombotic symptoms. A structrured questionnaire was used for this purpose. For symptoms such as bruising, haematoma and haemarthrosis, questions were focused on the presence or no of a traumatic cause, on severity, frequency and localization; for epixtaxis, on frequency, occurrence from both nostrils and need for local and systemic therapy; for menorrhagia, on duration of the menstrual period and on the number of absorbents used; for melena, haematuria and CNS bleeding, on clinical manifestations and severity; for postsurgical and postextraction bleeding, on duration, recurrence, wound haematoma formation and need for transfusional or haemostatic therapy.

Plasma preparation and storage. Blood samples were collected in siliconized vacuum tubes containing $0.129 \mathrm{M}$ buffered trisodium citrate and plasma was separated by centrifugation at $20^{\circ} \mathrm{C}, 2000 \mathrm{~g}$ for $10 \mathrm{~min}$. Platelet-poor plasma was subdivided in aliquots, put in plastic tubes, snap-frozen in a dry ice - methanol-acetone mixture and stored in the deep-freezer at $-70^{\circ} \mathrm{C}$. The Iranian samples were transported frozen from Tehran to Milan in containers with dry ice.

VII:C assays. VII:C was measured using a previously described functional assay (7). Factor-VII-deficient plasma was purchased from Dade International (Miami, FL, USA). Three types of thromboplastins were used to obtain three sets of VII:C values: rabbit thromboplastin (OBT, Ortho Diagnostic System, Raritan, NJ, USA), human recombinant thromboplastin (Recombiplastin, Ortho Diagnostic System) and bovine thromboplastin (Instrumentation Laboratory, Milan, Italy). VII:C assay were carried out manually and VII:C levels were calculated using as standard frozen plasma pooled from 40 normal individuals ( 20 men and 20 women not pregnant and not taking oral contraceptives). Standard plasma was given an arbitrary value of $100 \%$ VII:C and patient values were calculated accordingly.

VII:Ag assay. VII:Ag was measured using a previously described enzyme immunoassay (8). This method is based on the use of murine monoclonal antibodies against human factor VII. VII:Ag levels were calculated using as standard the same pooled plasma used for VII:C assays and the same method of result expression. 


\section{Results}

Since there was no substantial difference between the Iranian and Italian patients for demographic features and factor VII levels, the results obtained in the two groups are presented together (Table 1).

Table 1 shows the VII:C and VII:Ag levels obtained for each thromboplastin. In the majority of patients $(n=23)$ there was an excellent correspondence between the very low levels of VII:C ( $2 \%$ or less) obtained with each thromboplastin. On the other hand, in four Iranian patients belonging to the same sibship and in an additional unrelated Iranian patient, unmeasurable VII:C levels with the rabbit thromboplastin-based assay contrasted with low levels obtained with human thromboplastin (17-37\%) and normal levels with bovine thromboplastin (70-130\%). Table 1 also shows that these patients had normal to very high levels of VII:Ag (106$240 \%$ ). In the remaining 23 patients, VII:Ag levels ranged from unmeasurable (less than $1 \%$, three cases) to low (1-50\%, nine cases) or normal (51-150, 11 cases).

Table 1 also gives the bleeding symptoms observed lifelong in each patient and Table 2 summarizes the overall prevalence for each symptom. For some symptoms the number of patients considered is smaller than the total number of 28 , because for menorrhagia only women in the fertile age were considered and for dental extractions and surgery only those who underwent procedures without replacement therapy. The most frequent bleeding symptoms were epistaxis and menorrhagia. Other haemorrhages in mucosal tracts, such as haematuria and melena, occurred only in three and four patients. Soft-tissue bleeding was relatively uncommon, as haemarthrosis was reported in six patients, muscle haematomas in three and easy bruising in nine. CNS bleeding had occurred in five patients (four cases of intracerebral bleeding and one case of subarachnoidal bleeding). In patietits who had undergone dental extractions, bleeding was reported to be excessive and prolonged in 10/15 cases. Major surgery or circumcision had been performed in nine patients: five of them had excessive bleeding, which required blood transfusion in four (Table 3). No thrombotic episode had occurred.

There was no relationship between the patient phenotype, expressed by VII:C and VII:Ag levels, and the frequency of bleeding. Exceptions were the Iranian patients with a clear discrepancy between unmeasurable VII:C levels with rabbit thromboplastin and higher levels with human or bovine thromboplastins (Table 1). Two of them had no bleeding symptom, in spite of the fact that during their life span (ages 30 and 55 years) they had undergone multiple dental extractions or surgical procedures. The remaining three patients had relatively mild symptoms (menorrhagia and postextraction bleeding).

\section{Discussion}

The epitome of congenital coagulation defects is haemophilia. In patients with severe factor VIII or IX deficiency symptoms are quite typical, with a prevalence of soft-tissue haemorthages (haemarthrosis, muscle haematomas) and a relative paucity of mucosal tract 
Tab. 1 - Demographic features, haemorrhagic symptoms and plasma levels of factor VII coagulant activity (VII:C) with different thromboplastin and of factor VII (VIIAg) in Italian and Iranian patients

\begin{tabular}{|c|c|c|c|c|c|c|c|c|c|c|}
\hline Family & Patient & $\begin{array}{l}\text { Sex/ } \\
\text { age }\end{array}$ & Country & $\begin{array}{l}\text { Easy } \\
\text { bruising }\end{array}$ & Haemarthrosis & Haematoma & Epistaxis & Melena & Haematuria & Menorrhagia \\
\hline 1 & I & $M / 28$ & Italy & & & & $\cdot$ & & & \\
\hline \multirow[t]{2}{*}{2} & 1 & $\mathrm{~F} / 53$ & Italy & - & - & & - & & - & - \\
\hline & ПI & $\mathrm{M} / 53$ & Italy & & - & - & & & & \\
\hline 3 & I & $F / 38$ & Italy & - & • & & & & & - \\
\hline \multirow[t]{3}{*}{4} & I & $F / 39$ & Italy & - & & & - & & & - \\
\hline & II & $F / 34$ & Italy & & & & - & & & \\
\hline & III & $F / 33$ & Italy & & & & • & & & \\
\hline 5 & I & $M / 6$ & Italy & - & & & - & & & \\
\hline 6 & I & $F / 13$ & Italy & & & & - & & & \\
\hline 7 & 1 & $\mathrm{~F} / 7$ & Italy & & & & & - & & \\
\hline \multirow[t]{4}{*}{8} & 1 & $\mathrm{~F} / 51$ & Iran & - & & & & & & \\
\hline & II & $\mathrm{F} / 45$ & Iran & & & & & & & - \\
\hline & III & $M / 55$ & Iran & & & & & & & \\
\hline & IV & $\mathrm{F} / 30$ & & & & & & & & \\
\hline 9 & $\mathrm{I}$ & $F / 21$ & Iran & & & & & & & $\bullet$ \\
\hline 10 & I & $\mathrm{F} / 14$ & Iran & & & - & & & & \\
\hline 11 & I & $\mathrm{M} / 9$ & Iran & - & & & - & & & \\
\hline 12 & I & $\mathrm{M} / 27$ & Iran & & & & - & & & \\
\hline 13 & I & $M / 15$ & Iran & & & & - & - & & \\
\hline 14 & I & $\mathrm{M} / 17$ & Iran & & - & - & & & & \\
\hline 15 & I & $\mathrm{M} / 8$ & Iran & & & & - & & & \\
\hline \multirow[t]{2}{*}{16} & I & $\mathrm{F} / 30$ & Iran & - & & & • & & & • \\
\hline & I & $\mathrm{M} / 12$ & Iran & & & & • & & & \\
\hline 17 & I & $\mathrm{M} / 8$ & Iran & & • & & • & & • & \\
\hline 18 & I & $\mathrm{M} / 24$ & Iran & & & & • & & & \\
\hline 19 & I & $M / 15$ & Iran & & & & • & • & & \\
\hline 20 & I & $\mathrm{M} / 15$ & Iran & • & • & & • & • & & \\
\hline 21 & I & $M / 18$ & Iran & - & & & • & & • & \\
\hline
\end{tabular}

haemorrhages such as epistaxis and melena (2). The only exception to this pattern is haematuria, not unusual in haemophilia. When dental extractions and surgical procedures are carried out without replacement therapy, prolonged and life-threa-tening bleeding occurs almost invariably. Since Factor VII deficiency is a congenital defect of blood coagulation like factor VIII and IX deficiencies, one would expect similar clinical symptoms. 

$\begin{array}{lll}\text { CNS } & \text { Post Post } & \text { VII:C } \\ \text { bleeding } & \begin{array}{l}\text { surgical extraction rabbit human bovine } \\ \text { bleeding bleeding }\end{array}\end{array}$

\begin{tabular}{|c|c|c|c|c|c|c|}
\hline & & $\cdot$ & $<1$ & $<1$ & $<1$ & 3 \\
\hline \multirow[t]{3}{*}{ • } & $\cdot$ & • & $<1$ & $<1$ & $<1$ & 33 \\
\hline & & & $<1$ & $<1$ & $<1$ & 42 \\
\hline & & & $<1$ & $<1$ & $<1$ & $<1$ \\
\hline \multirow[t]{3}{*}{ • } & • & $\bullet$ & 1 & $<1$ & $<1$ & 54 \\
\hline & & & 2 & 1 & $<1$ & 43 \\
\hline & & & 2 & 1 & $<1$ & 55 \\
\hline \multirow[t]{2}{*}{ • } & & & $<1$ & $<1$ & $<1$ & $<1$ \\
\hline & & & $<1$ & $<1$ & $<1$ & 5 \\
\hline \multirow[t]{9}{*}{ • } & & & $<1$ & $<1$ & $<1$ & 2 \\
\hline & & $\bullet$ & $<1$ & 37 & 130 & 240 \\
\hline & & & $<1$ & 27 & 90 & 224 \\
\hline & & & $<1$ & 24 & 100 & 156 \\
\hline & & & $<1$ & 17 & 70 & 106 \\
\hline & & $\bullet$ & $<1$ & 22 & 80 & 130 \\
\hline & & & $<1$ & $<1$ & $<1$ & 77 \\
\hline & & & $<1$ & $<1$ & $<1$ & 78 \\
\hline & & $\bullet$ & $<1$ & $<1$ & $<1$ & 104 \\
\hline \multirow[t]{10}{*}{ • } & & & $<1$ & $<1$ & $<1$ & 132 \\
\hline & & & $<1$ & $<1$ & $<1$ & 135 \\
\hline & & & $<1$ & $<1$ & $<1$ & $<1$ \\
\hline & & $\bullet$ & $<1$ & $<1$ & $<1$ & 133 \\
\hline & $\bullet$ & & $<1$ & $<1$ & $<1$ & 80 \\
\hline & • & $\bullet$ & $<1$ & $<1$ & $<1$ & 6 \\
\hline & & $\bullet$ & $<1$ & $<1$ & $<1$ & 129 \\
\hline & & & $<1$ & $<1$ & $<1$ & 101 \\
\hline & & & $<1$ & $<1$ & $<1$ & 4 \\
\hline & & & $<1$ & $<1$ & $<1$ & 1 \\
\hline
\end{tabular}

Our patients and those of Mariani \& Mazzucconi (6), which make the two largest series of patients with severe or moderate factor VII deficiency reported ( 28 and 24 cases, respectively), are not totally consistent with
Tab. 2 - Prevalence of each bleeding symptom in patie with factor VII deficiency.

\begin{tabular}{lccl} 
Symptoms & $\begin{array}{l}\text { No. with } \\
\text { symptoms/ } \\
\text { no. considered }\end{array}$ & Prevalence & $\begin{array}{l}\text { Prevalence ir } \\
\text { Mariani's } \\
\text { series (ref.6) }\end{array}$ \\
\hline Easy bruising & $9 / 28$ & $32 \%$ & $29 \%$ \\
Haemarthrosis & $6 / 28$ & $21 \%$ & $66 \%$ \\
Haematoma & $3 / 25$ & $12 \%$ & $45 \%$ \\
Epistaxis & $18 / 28$ & $64 \%$ & $62 \%$ \\
Melena & $4 / 28$ & $14 \%$ & $16 \%$ \\
Haematuria & $3 / 28$ & $10 \%$ & $29 \%$ \\
Menorrhagia & $6 / 10$ & $60 \%$ & $90 \%$ \\
CNS bleeding & $5 / 28$ & $17 \%$ & n.r \\
Postsurgical & & & \\
bleeding & $5 / 9$ & $55 \%$ & n.r. \\
Postextraction & & & \\
bleeding & $10 / 15$ & $66 \%$ & $25 \%$ \\
\hline
\end{tabular}

n.r. =data not reported.

this prediction. In both studies a most prevalent symptom was epistaxis (Table 2). The reasons for the frequency of this symptom, more typical of platelet than of coagulation defects, is not clear at the moment. Even though the skin bleeding time was not measured because this test is not part of our screening of coagula-tion defects, others have found prolongations of the bleeding time in patients with factor VII deficiency (9). These observations, and the relative frequency of mucosal bleeding in the presence of normal platelet count, warrant a study of platelet function in factor-VII-deficient patients.

Our patients, while consistent with those reported by Mariani \& Mazzucconi (6) for the high frequency of mucosal bleeding, do not confirm their findings of a high frequency of haemarthrosis (16 of 24 patients) (Table 2 ). 


\begin{tabular}{|c|c|c|}
\hline Patient code & Type of operation & $\begin{array}{l}\text { Bleeding } \\
\text { complications }\end{array}$ \\
\hline \multirow[t]{2}{*}{$2 / I$} & Tonsillectomy & yes* \\
\hline & Appendectomy & yes* \\
\hline $4 / I$ & Tonsillectomy & yes $^{*}$ \\
\hline $4 / 11$ & Rhinoplasty & no \\
\hline $4 / \mathrm{III}$ & Appendectomy & no \\
\hline 8/III & Circumcision & no \\
\hline $12 / I$ & Circumcision & no \\
\hline $\mathrm{I} 6 / \mathrm{I}$ & Circumcision & yes \\
\hline $17 / \mathrm{II}$ & Thoracotomy & yes* \\
\hline $19 / 1$ & Circumcision & yes* \\
\hline
\end{tabular}

*Required blood transfusion.

Even though a few of our patients (6/28) had arthropathy as a consequence of recurring joint bleeding, the majority of them never had haemarthrosis in spite of the fact that, unlike those in the study by Mariani \& Mazzuconi, all had severe factor VII deficiency ( $2 \%$ or less). It would appear therefore that haemarthrosis is not the most typical clinical manifestations of factor VII deficiency. In their review of 75 cases reported in the literature, Ragni et al. (4) pointed out a relatively high prevalence of CNS bleeding (16\%). Our data are consistent with their observation, with five of 28 cases (17\%). Goodriough et al. (10) were the first to describe factor-VlI-deficient patients with a positive personal history for thrombosis, with clinical manifestations such as myocardial infarction, pulmonary embolism, superficial thrombophlebitis, angi-na pectoris and caval vein thrombosis. In our patients, some of whom had reached a relatively advanced age and hence have been exposed to a relatively high risk, no thrombotic episode was reported. In this and in Mariani's series, the existence of an association between factor VII deficiency and thrombosis is not apparent. This is not surprising because it is not biologically plausible that a se-vere coagulation defect determines a prothrombotic state.

The large heterogeneity of laboratory findings observed in our patients with factor VII deficiency has been observed previously. Goodnight et al. (11) were the first to document such heterogeneity in patients who had a discrepancy between low levels of VII:C and higher levels of VII:Ag. Subsequently, the existence of immunological variants of factor VII deficiency has been confirmed by several investigators. Triplert et al. (5), studying 26 patients with low VII:C levels and varied VII:Ag levels, observed that VII:C values obtained with human thromboplastin-based assays correlated better with clinical symptoms than those obtained with rabbit thromboplastin. This is confirmed in five members of two Iranian kindreds characterized by higher VII:C levels with human and bovine thromboplastin than with rabbit thromboplastin. This functional factor VII variant (called Padua 1) was first described by Girolami et al. (12) in an Italian patient and subsequently found in additional Italian, French and Japanese patients (1315). Both in the four previously reported cases and in the five cases identified by us bleeding symptoms were mild or totally 
absent. The quasi normal reactivity of factor VII Padua with homologous (human) tissue factor is likely to explain this situation.

On the whole, this study demonstrates that the symptoms of patients with factor VII deficiency are more similar to those of a combined vascular coagulation defect such as von Willebrand disease than to those of a typical coagulation defect such as haemophilia A. The reasons for this behaviour are unknown at the moment and warrant the study of platelet function in these patients. This study confirms the occurrence of a very high phenotypic heterogeneity in factor VII deficiency, consistent with the heterogeneity of the molecular defects found in these patients at the DNA level (16). In the screening of coagu-

\section{References}

1. Alexander C, Goldstein R, Landwehr C, Cook CD: Congenital SPCA deficiency: a new hitherto unrecognized coagulation defect with hemorrhage rectified by serum and serum fractions. $J$ Clin Invest 1951; 30: 596 608.

2. Hougie $\mathrm{C}$ : Hemophilia and related conditions: congenital deficiency of prothrominin (factor II), factor V, factor VII and X. In: Williams WJ, Beuder E, Erslev AJ, Litchman MA, eds. Hematology 3rd edn. New York: McGraw. Hill, 1983.

3. Mardet VJ, Schulman NR: Clinical aspects of congenital factor VII deficiency. Am J Med lation defects, VII:C assays with human thromboplastin should be preferred, because rabbit thromboplastin-based assays may give very abnormal results in individuals with a small bleeding risk.

\section{Acknowledgments}

Our thanks to the staff of the Iranian Hemophilia Society, and to the VicePresident, Y. Afshar, for their invaluable help and assistance in the whole study. Franca Franchi and Raffaella Coppola helped with the factor VII assays. We also acknowledge the collaboration and help provided by the Isfahan Blood Transfusion Center, the staff of the Iman Khomeini Hospital of Teheran (especially Mrs Bidar) and by Dr Sirous Zeinali of the Pasteur Institute of Tehran.

1964; 37:182-94..

4. Ragni MV, Lewis JH, Spero JA, Hasiba U: Factor VII deficiency. Am J Hematol 1981; 10: 79-88.

5. Triplett DA, Brandt JT, McGann Batard MA, Schaeffer Dixon JL, Fair DS: Hereditary factor VII deficiency: heterogeneity defined by combined functional and immunochemical analysis. Blood 1985; 66: 1284-87.

6. Mariani G, Mazzucconi MG: Factor VII congenital deficiency. Haemostasis 1983; 13: 169.77.

7. Poggio M, Tripodi A, Mariani G, Mannucci PM: Factor VII clotting assay: influence of different thromboplastins and factor VII defi- 
cient plasmas. Thromb Haemostas 1991; 65:160-4.

8. Coppola R, Tomhesi S, Valentini F, Alborali S, Albertini A, Mannucei PM: Enzyme-linked immunosorbent assay of human factor VII based upon a monoclonal antibody that recognizes the native conformation of the protein. Thromb Res 1992; 68: 282-93.

9. Bernardi F, Liney DL, Patracchini $P$, et al: Molecular defects in CRM + factor VII deficiencies: modelling of missense mutations in the catalytic domain of FVIr. Br.J Haematol 1994; 86: 610-8.

10. Goodnough LT, Saito H, Rarnoff OD:

Thrombosis or myocardial infarction in congenital clotting factor abnormalities and chronic thrombocytopenias: a report of 21 patients and a review of 50 previously reported cases. Medicine 1983; 62: 248-55.

11. Goodnight SH, Feinstein DJ, Osterud B, Rapaport SI: Factor VII antibody-neutralizing material in hereditary and acquired factor
VII deficiency. Blood 1971; 38: 1-8.

12. Girolami A, Fabris F, Dal Bo Zanon R, Ghiotto G, Burul A: Factor VII Padua: a congenital coagulation disorder due to an abnormal factor VII with a peculiar activation pattern. J Lab Clin Med 1978; 91: 387.95.

13. Girolami A, Patrassi G, Cappellato G, Casonato A: Another family with factor VII Padua clotting defect. Acta Haematol 1979;52: 4.11.

14. Croze M, Brizard CP: Factor VII Padua: another case? Haemostasis 1982; 11: 185-8.

15. Takamiya O, Funahashi S, Kinoshita S, Yoshioka A, Yoshioka K, Ikawa H: Factor VII activity and antigen in a patient with abnormal factor VII. Clin Lab Haematol 1988; 10 : 159-65

16. Cooper DN, Millar DS, Wacey A, Banner DW, Tuddenham EGD: Inherited factor VII deficiency: molecular genetics and pathophysiology. Thromb Haemostas 1997; 78:151-60. 


\section{Bleeding symptoms in 27 Iranian patients with the combined deficiency of factor V and factor VIII}

F. Peyvandi'1,3, E.G.D. Tuddenham², A.M. Akhtari', M. Lak ${ }^{1}$ and P.M. Mannucci ${ }^{3}$

'Hemophilia Center, Iman Khomeini Hospital, Tehran, Iran; ${ }^{2}$ MRC Hemostasis Research Group, Royal Postgraduate Medical School, London, United Kingdom

${ }^{3}$ Angelo Bianchi Bonomi Hemophilia and Thrombosis Center, IRCCS Maggiore Hospital, University of Milan, Italy.

British Journal of Hematology 100:773-776, 1998 


\section{Summary}

Inherited deficiency of factors V and VIII is the most frequent combined coagulation defect. The cases reported so far are mostly single cases or small series from different centers, making it difficult to evaluate the overall pattern of clinical manifestations of the combined defect. We examined at a single institution 27 Iranian patients.

Mucocutaneous and post-surgical bleeding were the most frequent clinical manifestations. The presence of two defects did not make the severity of bleeding greater than that expected in patients with single coagulation defects of similar degrees.

Key words: factor V, factor VIII, combined factor $\mathrm{V}$ and factor VIII deficiency

\section{Introduction}

The inherited combined deficiency of factor $\mathrm{V}$ and factor VIII, first described by Oeri et al (1954), has been subsequently reported in at least 62 families (106 cases) according to our current review of the literature. A single genetic defect, transmitted with an autosomal recessive pattern of inheritance, is thought to be responsible for the combined deficiency. Recently the gene has been localized to chromosome 18q (Nichols et al, 1997a; Neerman Arbez et al, 1997) and the protein product of the gene is a component of the endoplasmic reticulum-Golgi intermediate compartment, previously termed ERGIC 53 (Nichols et al, 1997b).

The homozygous phenotype of the combined deficiency is usually characterized by plasma levels of factor V and VIII coagulant activities ranging between 4 and $30 \%$, with correspondingly low levels of immunoreactive proteins (Soff \& Levin, 1981; Giddings et al, 1982). Whereas in congenital defects of single coagulation factors the pattern of bleeding symptoms and their relationship to plasma factors levels are quite well established, relatively little information is available for combined defects, of which factor V and VIII deficiency is the archetype. From published reports, in general single cases or small series, it would appear that in homozygotes the type and severity of clinical manifestations are variable, whereas heterozygotes, who have borderline or normal levels of factors V and VIII, are usually asymptomatic (Soff \& Levin, 1981; Seligsohn et al, 1982). In Iran the combined deficiency of factor V and VIII is relatively frequent (like other autosomal recessive coagulation disorders; see Shoa'i et al, 1977; Peyvandi et al, 1997), because consanguineous marriages are frequent among Muslims. We chose to reassess the pattern of the clinical manifestations in a large series of Iranian patients.

\section{Patients and methods}

The combined deficiency was diagnosed when factor $V$ coagulant activity was below 40 per cent and factor VIII coagulant activity below 45 per cent.

These cut-off values are the lower limits of the normal factor distribution at the Tehran Hemophilia Centre. The patients studied were 27 (12 women, 15 men, age range 6-48 years). In 14 of the 16 families patients were born from marriages between first-degree 
$(n=12)$ or second-degree $(n=2)$ cousins. Patients were selected solely on factor $V$ and VIII levels (see above) and availability to attend the Hemophilia Centre for interview, clinical examination and blood sampling. Three physicians (E.G.D.T., F.P and M.A.) examined them, constructed family pedigrees and collected the medical history, with questions tailored to evaluate the significance of the bleeding symptoms reported. For hematoma and hemarthrosis, questions were focused on the presence or not of a traumatic cause, on localization and frequency and on the presence or not of functional and radiological joint and muscle damage; for epistaxis, on frequency (at least two episodes without a history of trauma), and on the need for compression or medical treatment; for menorrhagia, on duration of the menstrual period (6 days or more), number of absorbent pads used daily (10 or more) and occurrence of iron-deficiency anemia; for melena, hematuria and intracranial bleeding, on the need for hospital treatment; for circumcision, dental extractions and other surgical procedures, on duration of bleeding, recurrence, wound hematoma formation and the need for hospital admission or transfusion therapy. Bruising was not considered, because it was difficult to evaluate the reliability of this symptom as reported by patients.

Factor assays. Factor $\mathrm{V}$ coagulant activity was measured with a prothrombin-timebased assay, using factor $\mathrm{V}$ deficient plasma (less than $1 \%$ ) produced by ageing at $37^{\circ} \mathrm{C}$ human plasma collected in EDTA and a rabbit thromboplastin (OBT, Ortho Diagnostic
System, Raritan, NJ). Factor V levels were calculated using as standard frozen plasma pooled from 40 healthy men and 2 women. Standard plasma was given an arbitrary value of $100 \%$ and patient values were calculated accordingly. Factor VIII coagulant activity was measured with an APTT-based assay, using as substrate citrated plasma from a patient with severe hemophilia A (factor VIII levels less than $1 \%$ ). Factor VIII levels were calculated as for factor $\mathrm{V}$.

\section{Results}

Table 1 shows that the factor $V$ level ranged from 2 to $21 \%$ (median: 11\%), factor VIII from 2 to $22 \%$ (median: $13 \%$ ). Eleven patients had levels of both factors of $10 \%$ or lower, 8 had both factors above $10 \%$, whereas the remaining $8 \mathrm{had}$ one factor above and the other below the $10 \%$ limit.

Table 1 also gives the bleeding symptoms that had occurred lifelong in each patient. For some symptoms the number of patients is less than 27 , because for menorrhagia only the 12 women in the fertile age were considered and for circumcision only the 11 boys who underwent the procedure without replacement therapy were taken into account. The most frequent spontaneous bleeding symptoms were of the mucosal type, epistaxis (21/27) and menorrhagia (7/12).

Gastrointestinal bleeding occurred in 2 patients, hematuria in none. Soft tissue bleeding was less frequent, as spontaneous hemarthrosis was reported in 7 patients and muscle hematoma in two (Table 1). In two patients (IV-2, factor V $5 \%$ and factor VIII 
Tab. 1 - Bleeding symptoms in 27 patients with combined factor $V$ and factor VIII deficiency

\begin{tabular}{|c|c|c|c|c|c|c|c|c|}
\hline Family & Patient & Sex & $\begin{array}{l}\text { Age } \\
(y r)\end{array}$ & $\begin{array}{l}\text { Factor V } \\
\text { activity } \\
(\%)\end{array}$ & $\begin{array}{l}\text { Factor VIII } \\
\text { activity } \\
(\%)\end{array}$ & Epistaxis & Menorrhagia & $\begin{array}{l}\text { Gastrointestinal } \\
\text { bleeding }\end{array}$ \\
\hline \multirow[t]{3}{*}{ I } & 1 & $\mathbf{M}$ & 25 & 8 & 6 & - & & \\
\hline & 2 & $\mathbf{F}$ & 10 & 11 & 9 & - & & \\
\hline & 3 & $\mathbf{F}$ & 17 & 7 & 14 & - & - & \\
\hline II & 1 & F & 26 & 8 & 7 & - & - & \\
\hline III & 1 & $\mathbf{F}$ & 21 & 20 & 15 & & & \\
\hline \multirow[t]{2}{*}{ IV } & 1 & $\mathbf{F}$ & 33 & 21 & 18 & - & & \\
\hline & 2 & $\mathbf{M}$ & 37 & 5 & 22 & - & & \\
\hline V & 1 & $\mathbf{F}$ & 17 & 7 & 9 & - & - & \\
\hline \multirow[t]{2}{*}{ VI } & 1 & $\mathbf{F}$ & 15 & 15 & 14 & & - & \\
\hline & 2 & $\mathbf{M}$ & 14 & 14 & 13 & • & & \\
\hline VII & 1 & $\mathbf{M}$ & 43 & 13 & 8 & - & & - \\
\hline \multirow[t]{3}{*}{ VIII } & 1 & $\mathbf{M}$ & 24 & 18 & 21 & - & & \\
\hline & 2 & $\mathbf{M}$ & 34 & 9 & 8 & - & & \\
\hline & 3 & $\mathbf{M}$ & 12 & 5 & 6 & & & \\
\hline IX & 1 & $\mathbf{M}$ & 29 & 18 & 8 & - & & \\
\hline \multirow[t]{2}{*}{$x$} & 1 & $\mathbf{M}$ & 12 & 19 & 16 & - & & \\
\hline & 2 & $\mathbf{F}$ & 20 & 12 & 15 & - & - & \\
\hline XI & 1 & $\mathbf{M}$ & 43 & 18 & 17 & - & & \\
\hline XII & 1 & $\mathbf{M}$ & 22 & 2 & 2 & - & & \\
\hline XIII & 1 & $\mathrm{~F}$ & 14 & 5 & 6 & • & - & \\
\hline \multirow[t]{4}{*}{ XIV } & 1 & $\mathbf{F}$ & 35 & 10 & 13 & - & & \\
\hline & 2 & $\mathbf{M}$ & 45 & 10 & 6 & & & - \\
\hline & 3 & $\mathbf{F}$ & 30 & 10 & 6 & & & \\
\hline & 4 & $F$ & 34 & 10 & 21 & • & - & \\
\hline$X V$ & 1 & $\mathbf{M}$ & 48 & 9 & 14 & & & \\
\hline \multirow[t]{2}{*}{ XVI } & 1 & $\mathbf{M}$ & 6 & 10 & 8 & - & & \\
\hline & 2 & $\mathbf{M}$ & 32 & 7 & 5 & - & & \\
\hline
\end{tabular}

-= presence of the symptom $\quad N=$ no excessive bleeding after the procedure or event

$22 \%$; and XII- 1 , factor V $2 \%$ and factor VIII $2 \%$ ) spontaneous joint and muscle bleeding had led to actual severe functional impairment and radiological damage in the hip and knee joints, with a large femural pseudotumor in patient XII-1. Intracranial bleeding had occurred in one patient, with no obvious traumatic cause. Among the 17 patients who had dental extractions without replacement therapy, bleeding was reported to be excessive and prolonged in 14 cases (one case required blood transfusion). Eight of the 12 boys 

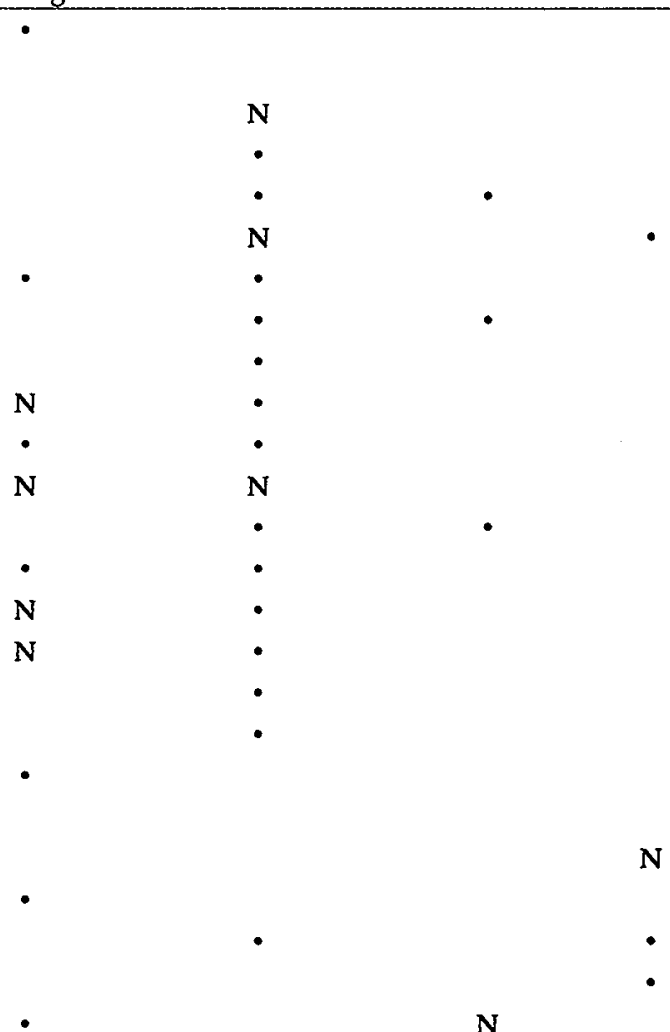

who underwent circumcision without replacement therapy had excessive bleeding that required blood transfusion in one. In four patients who had major surgery without replacement therapy, three had excessive bleeding but no transfusion. After parturi- tion, 3 of 4 women had excessive bleeding, but no transfusion. There was no strong relationship between the phenotypic severity, expressed by the combinations of low factor $\mathrm{V}$ and VIII levels, and the frequency of bleeding: the 11 patients with levels of both fac- 
tors below $11 \%$ had 30 different bleeding symptoms lifelong, the 8 patients with levels above $11 \%, 19$ symptoms.

\section{Discussion}

Until now, the largest series of patients with combined factor V and VIII deficiency examined at a single institution were 14 homozygotes from 8 unrelated Oriental Jewish families reported by Seligsohn et al (1982), who estimated a frequency of homozygous disease of $1: 100.000$ in Oriental Jews. Our series of 27 patients, none of whom originated from the community of Iranian Jews, are the largest series ever reported. In Iran, a total of 64 patients are currently known to have the combined deficiency of factor V and VIII, with symptoms severe enough to postulate that they are homozygotes. Since the population of the country is 60 millions, a rough estimate of the frequency of the combined deficiency is $1: 100.000$, similar to that found in Oriental Jews. Consanguineous marriages and the low fatality rate of the disease, even with little available treatment, are likely to explain the relatively high frequency of this recessive bleeding disorder.

The main goal of this retrospective study was to establish the bleeding manifestations typical of the homozygous state. Patients were examined at a single institution, trying as far as possible to use homogeneous and objective criteria to ascertain the significance of the bleeding symptoms reported. Patients were phenotypicall quite homogeneous, with median levels of factor $\mathrm{V}$ and VIII around $10 \%$, typical of the homozygous state for the combined deficiency (Soff \& Levin, 1981; Giddings et al, 1982; Seligsohn et al, 1982). Preliminary data indicate mutational heterogeneity at the ERGIC-53 locus in the Iranian families described here in (unpublished observation). The most commonly noted clinical manifestations were epistaxis, menorrhagia and excessive bleeding after surgical trauma and delivery, in agreement with Seligsohn et al (1982). Surprisingly, Seligsohn et al (1982) found no case of excessive bleeding after circumcision, whereas two thirds (8/12) of our male patients bled excessively when the procedure was carried out without replacement therapy. Whereas circumcision is performed at birth in Jews, it is usually performed at 5-7 years of age in Muslims. Perhaps the trauma of the operation is less at birth than during childhood. Spontaneous soft tissue bleeding was relatively infrequent, but two patients had signs of severe arthropathy.

On the whole, the type and severity of symptoms were similar to those that occur in patients with single deficiencies of factor $\mathrm{V}$ and factor VIII, with a predominance of mucocutaneous bleeding and post-operative bleeding. There is no clear evidence that the severity of bleeding is heightened by the concomitant presence of two coagulation defects.

\section{Acknowledgments}

The study was performed with the assistance of the Iranian Haemophilia Society. E.G.D.T. wishes to thank Dr. Sharifian for facilitating his stay in Teheran, and the work reported here. 


\section{Chapter 2 - Clinical studies}

\section{References}

1. Giddings JC, Sugrue A, Bloom AL: (1982) Quantitation of coagulant antigens and inhibition of activated protein $\mathrm{C}$ in combined factor V/VIII deficiency. British Journal of

Haematology 52: 495-502.

2. Neerman Arbez M, Antonorakis SE, Blouin JL, Zeinali S, Akhtari M, Afshar Y, Tuddenham EDG: (1997) The locus for combined factor V/factor VIII deficiency maps to 18q21, between D18S849 and D18S1103. American Journal of Human Genetics 61: 143-150.

3. Nichols WC, Seligsohn U, Zivelin A, Terry VH, Arnold ND, Siemienak DR, Kaufman RJ, Ginsburg D: (1997a) Linkage of combined factor $V$ and VIII deficiency to chromosome $18 q$ by homozygosity mapping. Journal of Clinical Investigation 99: 596.601.

4. Nichols WC, Seligsohn U, Zivelin A, Terry $\mathrm{VH}$, Hertel $\mathrm{CH}$, Wheatley MA, Yang A, Siemienak DR, Hauri H.P, Kaufman RJ, Ginsburg D: (1997b) Combined factor $\mathrm{V}$ and VIII deficiency is caused by mutations in a resident protein of the endoplasmic reticulum-Golgi intermediate compartment. Blood 90 (suppl. 1): $123 a$.

5. Oeri J, Mattler M, Isenschmid H, Hauser F, Koller F: (1954) Angeborener Mangel an Faktor V (parahaemophilie) Verbunden mit Echter Haemophilie A bei zwei Brudern. Modern Problems in Paediatrics 1: 575-588.

6. Peyvandi F, Mannucci PM, Asti D, Abdoullahi M, Di Rocco N, Sharifian R: (1997) Clinical manifestations in 28 Italian and Iranian patients with severe factor VII deficiency. Hemophilia 3: in press.

7. Seligsohn U, Zivelin A, Zwang E: (1982) Combined factor $\mathrm{V}$ and factor VIII deficiency among non-Ashkenazi Jews. New England Journal of Medicine 307: 1191-1195.

8. Shoa'i I, Lavergne JM, Ardaillou N, Obert B, Ala F, Meyer D: (1977) Heterogeneity of von Willebrand's disease: study of $\mathbf{4 0}$ Iranian patients. British Journal of Haematology 37: 67 83.

9. Soff GA, Levin J: (1981) Familial multiple coagulation factor deficiencies. Seminars on Thrombosis and Haemostasis 7: 112-148. 


\section{Congenital factor $X$ deficiency: spectrum of bleeding symptoms in 32 Iranian patients}

F. Peyvandi', ${ }^{12}$, P.M. Mannucci'2, M. Lak', M. Abdoullahi' ${ }^{1}$, S. Zeinali ${ }^{3}$, R. Sharifian ${ }^{1}$ and D. Perry ${ }^{4}$

'Hemophilia Center, Imam Khomeini Hospital, Tehran, Iran

'Angelo Binnchi Bonomi Hemophilia and Thrombosis Center, IRCCS

Maggiore Hospital, University of Milan, Italy

${ }^{3}$ Pasteur Institute, Tehran, Iran

${ }^{+}$Hemophilia Center and Hemostasis Unit, Royal Free Hospital, London, United Kingdom.

British Journal of Hematology 102:626-628,1998 


\section{Summary}

The spectrum of the clinical manifestations of congenital factor $\mathrm{X}$ deficiency was studied in 32 patients from Iran. The most frequent symptom was epistaxis, which occurred in $72 \%$ of patients, with all degrees of deficiency. Other mucosal hemorrhages such as hematuria and gastrointestinal bleeding were less frequent and occurred mainly in patients with unmeasurable factor X. Menorrhagia occurred in half of the women in the reproductive age. Soft tissue bleeding occurred in two-thirds of the patients, and was characterized by spontaneous hematomas and hemarthroses that in 5 patients led to severe arthropathies. Bleeding from the umbilical stump was an unexpected finding in 9 patients. This study demonstrated that bleeding tendency of factor $\mathrm{X}$ deficiency is severe and correlates with factor levels.

Key words: Factor X, Factor X deficiency

\section{Introduction}

Congenital deficiency of coagulation factor $\mathrm{X}$, first described over 30 years ago (Telfer et al, 1956; Hougie et al, 1957), is usually diagnosed by a concomitant prolongation of the prothrombin time and activated partial thromboplastin time in patients who bleed. The disease is rare (only approximately 50 families have been reported) and genetic transmission is autosomal recessive (usually, only homozygotes are symptomatic) (Perry, 1997). Until now only single cases or small series of patients have been reported, so that the spectrum of the clinical manifestations of the disease is not well established. We report a large series of patients with factor $\mathrm{X}$ deficiency diagnosed and followed-up at the National Hemophilia Centre in Tehran. The study was undertaken because of the high frequency of factor $X$ deficiency in Iran, a country where consanguineous marriages are frequent.

\section{Patients and methods}

Thirty-two patients with factor $\mathrm{X}$ deficiency (23 males, 9 females, age 5 to 72 years) from 25 unrelated Iranian families were studied. In 23 of the families, patients were born from marriages between first-or second- degree cousins. All patients were diagnosed and regularly followed up at the National Hemophilia Centre in Tehran, where detailed records of clinical events occurring in hospital or at home were kept. For the purpose of this study, patients were selected solely on factor X activity levels (see below) and their ability to attend the Hemophilia Centre for interview, physical examination and blood collection. The registry of congenital coagulation disorders kept at the National Hemophilia Centre lists 50 patients with factor $\mathrm{X}$ deficiency in the whole country, with a prevalence of the disease of 1 in 1.200 .000 in the general population. Hence, the present cohort of 32 patients appears to be representative of the whole population. On the basis of the plasma levels of factor $\mathrm{X}$ coagulant activity (FX:c), measured with a prothrombin-time-based assay using rabbit thromboplastin and factor $\mathrm{X}$ deficient plasma (normal range: 65-120\%), patients were classified in three groups: severe (18 patients 
Table 1 - Prevalence of bleeding symptoms in congenital factor $\mathrm{X}$ deficiency

\begin{tabular}{lllll} 
Symptom & $\begin{array}{l}\text { All patients } \\
(\mathrm{n}=32)\end{array}$ & $\begin{array}{l}\text { FX:c<1\% } \\
(\mathrm{n}=18)\end{array}$ & $\begin{array}{l}\text { FX:c 1-5\% } \\
(\mathrm{n}=9)\end{array}$ & $\begin{array}{l}\text { FX:c 6-10\% } \\
(\mathrm{n}=5)\end{array}$ \\
\hline Epistaxis & $23 / 32(72 \%)$ & $11 / 18(61 \%)$ & $8 / 9(88 \%)$ & $4 / 5(80 \%)$ \\
Menorrhagia* & $4 / 8(50 \%)$ & $3 / 5$ & $1 / 1$ & $0 / 2$ \\
Gl bleeding & $12 / 32(38 \%)$ & $12 / 18(66 \%)$ & $0 / 9$ & 0.5 \\
Haematura & $8 / 32(25 \%)$ & $7 / 18(39 \%)$ & $1 / 9$ & $0 / 5$ \\
Haemarthrosis & $22 / 32(69 \%)$ & $14 / 18(77 \%)$ & $7 / 9(77 \%)$ & $1 / 5$ \\
Haematoma & $21 / 32(66 \%)$ & $14 / 18(77 \%)$ & $6 / 9(66 \%)$ & $1 / 5$ \\
CNS bleeding & $3 / 32(9 \%)$ & $2 / 18(11 \%)$ & $1 / 9(11 \%)$ & $0 / 5$ \\
Umbilical cord bleeding & $9 / 32(28 \%)$ & $7 / 18(39 \%)$ & $1 / 9(11 \%)$ & $1 / 5$ \\
\hline
\end{tabular}

* Eight women of reproductive age

with less than 1\% FX:c), moderate (9 patients with FX:c from 1 to $5 \%$ ) and mild (5 patients with FX:c from 6 to $10 \%$ ).

Collection of clinical data. All consultations were performed by the same physician (M.L.), who examined the patients, constructed family pedigrees and collected medical histories, with questions tailored to evaluate the significance of the bleeding symptoms reported. For hematoma and hemarthroses, questions and physical examination were focused on the presence or not of a traumatic cause, on localization and frequency and on the presence or not of functional and radiological joint and muscle damage; for epistaxes, on the frequency (at least three episodes from both nostrils without a history of trau$\mathrm{ma})$, and on the need for local compression or medical treatment; for menorrhagia, on the duration of the menstrual period (6 days or more), number of absorbent pads used daily (10 or more) or the occurrence of iron deficiency with no other source of bleeding; for gastrointestinal bleeding, hematuria and intracranial bleeding, on the need for hospital treatment.

Bleeding symptoms after dental extraction and minor/major surgery (including circumcision) were not included in the evaluation because we realized that most patients had been diagnosed early in life because of bleeding episodes. Therefore, they had usually received prophylactic treatment with freshfrozen plasma or prothrombin complex concentrates before any surgical procedure. Bruising was not included, because it was difficult to evaluate the significance and reliability of this symptom as reported by patients.

\section{Results}

Table 1 summarizes the prevalence of each symptom in patients divided according to FX:c in plasma. Only one patient (FX:c 6\%) had none of the bleeding symptoms evaluated in this study. Diagnosis was made because he bled excessively after a war wound.

Mucosal tract bleeding. The most frequent 


\section{Chapter 2 - Clinical studies}

spontaneous bleeding symptom was epistaxis, which occurred in $72 \%(23 / 32)$ of patients, in all severity groups. Eight of 9 women were in the reproductive age; menorrhagia occurred in four of them (50\%). Gastrointestinal bleeding that led to anemia and hospital admittance occurred in $38 \%$ of all patients. None of these patients had lesions in the gastrointestinal tract that could explain the bleeding. Similarly there was no obvious cause for macroscopic hematuria, which occurred in $25 \%$ of patients. All except one of these patients have severe FX:c deficiency.

Soft tissue bleeding. Spontaneous hematomas and recurrent hemarthroses occurred in $66 \%$ and $69 \%$ of patients, mainly but not exclusively in those with severe and moderate deficiency. In 5 patients recurrent hemarthroses led to the development of a significant impairment of joint function. Intracerebral bleeding occurred in two patients with FX:c levels of $<1 \%$ and in one with $3 \%$. In them, bleeding occurred spontaneously and all patients eventually recovered with no residual neurological lesion. An unexpected finding in $9 / 23$ patients (28\%) was bleeding from the umbilical stump, which occurred in seven case with a severe deficiency and two moderate or mild deficiency.

\section{Discussion}

Factor X plays a pivotal role in blood coagulation, being at the intersection between the tissue factor and contact phase pathways of thrombin formation. Hence, patients with factor $\mathrm{X}$ deficiency might be expected to have particularly severe bleeding symptoms. The present study has attempted to address this by examining a large series of patients regularly followed-up at a single institution. Aware of the limits of a retrospective analysis of self-reported bleeding symptoms, we have attempted to minimize bias by using as much as possible hospital records and stringent criteria, such as the occurrence of anemia and the need for hospital treatment, before assigning bleeding symptoms to each patient.

The occurrence and frequency of bleeding symptoms correlated with the degree of factor $\mathrm{X}$ deficiency. An exception was epistaxis, that occurred in patients with all degrees of deficiency. On the other hand, other bleeding manifestations in mucosal tracts, such as hematuria and gastrointestinal bleeding, occurred almost exclusively in patients with unmeasurable factor $\mathrm{X}$ levels and no obvious anatomical lesion. The types of bleeding manifestations were similar to those seen in patients with factor VIII and IX deficiency (hemophilia A and B), with the exception of epistaxes and umbilical cord bleeding. Epistaxes were the most frequently reported symptom, an observation previously made in a series of 28 patients with severe factor VII deficiency studied with the same criteria (Peyvandi et al, 1997). Why this mucosal bleeding symptom, relatively unusual in patients with coagulation defects such as factor VIII and IX deficiencies, is so prevalent in factor VII and X deficiency is unclear. Bleeding from the umbilical stump is consi- 
dered peculiar of factor XIII deficiency. In factor XIII deficiency, this symptom is usually delayed, because clot formation occurs normally at birth but stabilization of fibrin is impaired. In our series of factor $\mathrm{X}$ deficient patients, bleeding occurred between 7 and 10 days after birth, at the time of detachment of the stump, and 6 of 9 patients with this symptom had anemia severe enough to require blood transfusion.

In conclusion, this study of a large series of patients from a single institution indicates

\section{References}

1. Telfer TP, Denson KW, Wright DR: (1956) A new coagulation defect. $\mathrm{Br}$ J Haematol 2: 308 316.

2. Hougie C, Barrow HM, Graham JB: (1957) Stuart clotting defect. Segregation of a hereditary hemorrhagic state from the heterozygous heretofore called stable factor (SPCA, proconvertin factor VII deficiency). $J$ Clin that the bleeding tendency of factor $\mathrm{X}$ deficiency may be severe and occurs early in life in patients with unmeasurable factor $X$ levels. Mucosal and soft-tissue bleeding symptoms are frequent and umbilical cord bleeding, often considered indicative of factor XIII deficiency, may be one of the earlier manifestations.

\section{Acknowledgments.}

This study was performed with the help of the Iranian Hemophilia Society.

Invest 36: 485-493.

3. Peyvandi F, Mannucci PM, Asti D, Abdoullahi M, Di Rocco N, Sharifian R: (1997) Clinical manifestations in 28 Italian and Iranian patients with severe factor VII deficiency. Hemophilia 3: $242-246$.

4. Perry DJ: (1997) Factor $X$ and its deficiency states. Hemophilia 3: 159-172. 


\section{chapter 3}

\section{Molecular studies}

Molecular characterization and three-dimensional structural analysis of mutation in 21 unrelated families with inherited factor VII deficiency

Thromb Haemost 84: 205-7,2 000

Homozygous 2bp deletion in the human factor VII gene: a non-lethal mutation that is associated with a complete absence of circulating factor VII

Thromb Haemost, 84: 635-637, 2000

Characterization of two naturally occurring mutations in the second epidermal growth factor like domain of factor VII

Blood 93: 1237-1244, 1999

Abnormal secretion and function of recombinant human factor VII as the result of modification to a calcium binding site caused by a 15 base pair insertion in the factor VII gene Blood, accepted for publication

Molecular analysis of the ERGIC 53 gene in 35 families with combined factor Vfactor VIII deficiency

Blood 93: 2253-2260, 1999 


\section{Introduction}

As outlined before information on the molecular lesions underlying recessive coagulation disorders is relatively scarce due to the rarity of these disorders. We thought that the study of Iranian patients had two main advantages: they are more frequent than in other countries and, being usually the result of consanguineous marriages, the gene defects in the two alleles are likely to be the same, facilitating screening and characterization. In the frame of the Iranian project, two defects were chosen to start the genotype analysis. The first is factor VII deficiency, because factor VII is a key factor placed at the intersection between the so called extrinsic and intrinsic coagulation systems. Therefore, it was thought that the natural mutations of the factor VII gene underlying factor VII deficiency might help to clarify the structure function relationship of the factor in blood coagulation. Moreover, factor VII deficiency it is the most frequent of the rare coagulation disorders, so that identification of the actual mutations is likely to be clinically useful in the Iranian population, should prenatal diagnoses become necessary in some of the women. We include in Section 3 of the thesis four papers, one that describes as a whole the factor VII gene mutations found in the Iranian patients (3.1) and three additional ones $(3.2-4)$ that characterize in more details mutations of specific significance and novelty. The second defect chosen for this first part of the study was the combined deficiency of factors V and VIII, because at the time of starting this project no mutation underlying this disorder had yet been identified. In paper 3.5 we report in a collaborative study several new mutations in the ERGIC gene that associated with the combined factor $\mathrm{V}$ and VIII deficiency. 


\title{
Molecular characterisation and three-dimensional structural analysis of mutations in 21 unrelated families with inherited factor VII deficiency
}

\author{
F. Peyvandi ${ }^{1,2}$, P.V. Jenkins' ${ }^{1}$ P.M. Mannucci', A. Billio ${ }^{3}$, \\ S. Zeinali ${ }^{4}$, S.J. Perkins ${ }^{5}$ and D.J. Perry ${ }^{1}$
}

'Haemophilia Centre and Haemostasis Unit, Department of Haematology,

Royal Free and University College Medical School, Royal Free Campus, Pond Street, London

${ }^{2}$ Angelo Bianchi Bonomi Haemophilia and Thrombosis Center and Fondazione Luigi Villa, IRCCS Maggiore Hospital and University of Milan, Italy

${ }^{3}$ Department of Hematology, City Hospital, Bolzano, Italy ${ }^{4}$ Pasteur Institute, Biotechnology Department, Tehran, Iran ${ }^{5}$ Department of Biochemistry and Molecular Biology, Royal Free and University College Medical School, Royal Free Campus, Rowland Hill Street, London.

Thromb Haemost 84:250-7, 2000 


\section{Rare $\overline{\text { Congulation Disorders }}$}

\section{Summary}

Factor VII (FVII) is a four-domain glycoprotein that plays a critical role in the initiation of blood coagulation. Hereditary deficiencies of this plasma protein results in a bleeding diathesis that varies in severity amongst affected patients. We have analysed the FVII gene in 27 patients with FVII deficiency from 21 unrelated families predominantly of Middle-Eastern extraction.

A total of 19 different mutations were identified, of which 12 were novel and 7 had been previously reported. Nine of the 12 novel mutations were missense mutations located in the Gla domain (Ser23Pro), the second epidermal growth factor domain (Cys135Arg) and the catalytic serine protease domain (Arg247Cys, Arg277Cys, Ser282Arg, Pro-303Thr, Ser363Ile, Trp364Cys, Trp364Phe), of which five are homozygous. Three novel splice mutations were identified in intron 1a (IVS1a+5), intron 2 (IVS2+1) and intron 6 (IVS6+1).

Of the seven previously reported mutations, five were missense mutations of which three are homozygous (Gln100Arg, Arg152Gln, Arg304Gln, Cys310Phe and Thr359Met), one was a $17 \mathrm{bp}$ deletion (10585del17bp) and one was a splice site mutation within intron 7 (IVS7+7).

This study has significantly extended the current database of FVII mutations, including the number of known homozygous mutations. Conformational analyses of crystal structures for FVIIa and the FVIIa-tissue factor complex provided likely explanations for the effect of the missense mutations on FVIIa secretion or function. In particular, since 23 missense mutations were located to the serine protease domain, mostly to the region between the catalytic triad and the contact surface with tissue factor, this showed that the orientation of the serine protease domain relative to bound tissue factor in the complex is crucial for functional activity.

\section{Introduction}

Factor VII (FVII) is a vitamin K-dependent glycoprotein that plays a vital role in the initiation of coagulation. FVII is synthesised in the liver and circulates in the plasma as a single-chain zymogen at a concentration of $0.5 \mu \mathrm{g} / \mathrm{ml}$ (1). Following damage to the vascular endothelium, the cell surface receptor for FVII, tissue factor (TF), is exposed and forms a complex with FVII $(2,3)$. Subsequent activation of FVII occurs through a proteolytic cleavage at Arg152-Ile153 to give a two-chain active serine protease, factor VIIa (FVIIa) (4). FVIIa is composed of a light chain (152 residues) and a heavy chain (254 residues) linked by a disulphide bond, and this directly activates factors IX and X to lead to the generation of thrombin (4-6).

FVII contains four independently-folded protein domains (4). The gene for FVII is 12.8 $\mathrm{kb}$ in length and located $2.8 \mathrm{~kb} 5$ of the factor $\mathrm{X}$ gene on the long arm of chromosome 13. It contains 9 exons (1a, $1 \mathrm{~b}, 2-8)$ and 8 introns, and its gene structure is broadly similar to those of factors IX and X, protein C and protein $S(6)$. The alternative splicing of FVII mRNA leads to transcripts that encode 
pre-pro leader sequences of either 38 or 60 amino acids, as this is encoded by exons 1 a and $1 \mathrm{~b}$, and about $90 \%$ of the FVII transcripts in the liver lack exon 1b (7). Exons 2 and 3 encode parts of the propeptide and the Gla domain, whilst exons 4 and 5 encode the EGF-1 and EGF-2 domains (EGF: epidermal growth factor). Exons 6, 7 and 8 encode the catalytic serine protease (SP) domain. In the complex with FVIIa, the N-terminal fibronectin type III domain of TF makes contact with the EGF-1, EGF-2 and SP domains, and the C-terminal one makes contacts with the EGF-1 and Gla domains.

FVII deficiency is a rare, autosomally-inherited, recessive disorder that affects approximately 1 in 500,000 of the population. In contrast to many of the inherited bleeding disorders, there is a relatively poor correlation between the levels of FVII and the bleeding manifestations $(8,9)$. Type 1 mutations correspond to when both the activity and antigen levels are proportionally reduced (i.e. when low levels of FVII occur in plasma), while Type 2 mutations correspond to when the antigen level of FVII is normal but the activity is reduced (dysfunctional). The most recent review of human FVII mutations lists 35 of these (10). The majority of these are missense ones, but in addition include a small number of deletions, splice site abnormalities and nonsense mutations. An updated list of FVII mutations is available on the Internet at http://europium.csc.mrc.ac.uk. In this study, the genetic and structural characterisation of 19 known and novel mutations in a group of patients of predominantly
Middle-Eastern extraction with FVII deficiency is reported. Consanguineous marriage in such countries is common, and therefore the frequency of homozygous mutations is increased. The correlation of mutation sites with their location in a three-dimensional structure has potential to provide valuable molecular insights into function (11), especially if the mutations are homozygous and therefore are well defined in their clinical effect. Here, we show how analyses of the large number of mutations in terms of structures for FVIIa and its complex with TF (1215) offer explanations for the decreased secretion or function of FVII. In particular, we show that the high concentration of mutation sites within the SP domain corresponds to a protein interface between the SP domain and $\mathrm{TF}$ which is likely to be crucial for the initiation of the thrombin formation pathway and is unable to tolerate evolutionary modification.

\section{Patients and methods}

Patients: 27 patients from 21 unrelated families and comprising 13 males and 14 females (age 5-58 yrs) with FVII deficiency were studied. Families were predominantly Iranian in origin $(n=13)$, but included a smaller number from other countries, namely Italy $(n=4)$, Malta $(n=1)$, Pakistan $(n=1)$ and the UK $(n=1)$. Eleven out of 14 patients from Iran were the offspring of consanguineous marriages. Informed consent for investigation was obtained from all individuals. To establish the type and severity of bleeding symptoms, we used a questionnaire which 
was specially tailored to collect focused and objective information from patients (16). Severe bleeders were classified as those who had spontaneous and/or life-threatening bleeding episodes, such as hemarthroses, muscle hematomas, umbilical cord, gastrointestinal and central nervous system hemorrhages. Mild bleeders were patients who bled only after trauma or surgery or who had minor bleeding problems such as epistaxes or menorrhagia. Non-bleeders were those without any history of bleeding.

Factor VII assays: FVII coagulant activity (FVII:C) was measured in plasma using a one-stage prothrombin time-based assay and FVII deficient plasma (Dade International, Miami, Florida). Three types of thromboplastins were used to obtain FVII:C values, namely rabbit thromboplastin (OBT, Ortho Diagnostic Systems, Raritan, NJ), human recombinant thromboplastin (Recombiplastin, Ortho Diagnostic Systems) and bovine thromboplastin (Instrumentation Laboratory, Milan, Italy). FVII:C values were calculated using as standard pooled plasma from 40 normal individuals ( 20 men and 20 women not pregnant and not taking oral contraceptives). Standard plasma was assigned an arbitrary FVII:C value of $100 \%$. Levels of FVII antigen (FVII:Ag) were measured using an enzyme immunoassay based on two murine monoclonal antibodies against FVII with epitopes on its light chain (17). The enzyme immunoassay based on these antibodies have been compared with a commercial enzyme immunoassay based on polyclonal antibodies and found to give comparable
FVII:Ag values in parallel with known FVII expression levels (17). FVII:Ag levels were calculated using the same normal pooled plasma as the FVII:C standard.

DNA analysis: Genomic DNA was purified from peripheral blood leukocytes according to standard protocols. Following DNA extraction, the coding region, intron/exon boundaries and the untranslated regions of the FVII gene were amplified by polymerase chain reaction (PCR) and screened for mutations by single strand conformation polymorphism analysis (SSCP) (18) and conformation sensitive gel electrophoresis (CSGE) (19). Direct sequencing of amplified DNA was used to confirm and identify the presence of any mutations.

PCR: Amplification reactions were carried out in $100 \mu \mathrm{l}$ volumes and comprised: 100 $500 \mathrm{ng}$ of DNA, 100 pmoles of each oligonucleotide primer, $200 \mu \mathrm{M}$ of each dNTP, 1.5 $\mathrm{mM} \mathrm{MgCl} 2,50 \mathrm{mM} \mathrm{KCl}, 10 \mathrm{mM}$ Tris- $\mathrm{HCl} \mathrm{pH}$ 8.3 and 2 units of Taq polymerase. Reactions were denatured at $94^{\circ} \mathrm{C}$ for $5 \mathrm{~min}$, then 40 cycles of amplification were performed. On the last cycle, the extension time was increased to $10 \mathrm{~min}$. Oligonucleotide sequence data and amplification parameters are available on request.

Single stranded conformation polymorphism (SSCP) analysis: $1 \mu$ of the final PCR product was mixed with $5 \mu$ of denaturation buffer ( $95 \%$ formamide, $0.05 \%$ xylene cyanol, $0.05 \%$ bromophenol blue), denatured for $10 \mathrm{~min}$ at $94^{\circ} \mathrm{C}$, then placed on ice for $2 \mathrm{~min}$. 3-4 $\mu$ l of each denatured sample was loaded onto a $10 \%$ polyacrylamide 
gel (99:1 acrylamide: bisacrylamide) in TrisBorate-EDTA buffer (0.09 M Tris-Borate, 2 $\mathrm{mM}$ EDTA) supplemented with $7.5 \%$ urea. Gels were pre-run at $700 \mathrm{~V}$ for $60 \mathrm{~min}$ in TrisBorate-EDTA buffer prior to loading, then electrophoresis was carried out at $450 \mathrm{~V}$ for 12-15 h at room temperature (fragment size $\sim 400 \mathrm{bp}$ ). DNA fragments were visualised by silver staining (Promega Corporation, Southampton, UK).

Conformation sensitive gel electrophoresis (CSGE): $5 \mu \mathrm{l}$ of a wild-type control PCR product was mixed with $5 \mu l$ of patient PCR product and incubated at $98^{\circ} \mathrm{C}$ for 5 $\mathrm{min}$ and then at $65^{\circ} \mathrm{C}$ for $30 \mathrm{~min}$ to allow the formation of heteroduplexes. 5-8 $\mu \mathrm{l}$ of each sample was then mixed with $2 \mu \mathrm{l}$ of loading buffer ( $40 \%$ sucrose, $0.05 \%$ bromophenol blue, $0.05 \%$ xylene cyanol) and 3-5 $\mu \mathrm{l}$ loaded onto a $10 \%$ polyacrylamide gel (99:1 acrylamide: bisacrylamide) containing $15 \%$ formamide and $10 \%$ ethylene glycol in TrisTaurine-EDTA buffer ( $0.89 \mathrm{M}$ Tris, $0.285 \mathrm{M}$ Taurine, $2 \mathrm{mM}$ EDTA). Gels were pre-run at $750 \mathrm{~V}$ in Tris-Taurine-EDTA buffer for 60 min, the samples were loaded and electrophoresis carried out at $450 \mathrm{~V}$ for $12-16 \mathrm{~h}$. Following electrophoresis, gels were silver stained and photographed.

Sequence analysis: PCR products were purified (Bioline PCRapid Purification Kit, Bioline, London, UK) and directly sequenced using an $\mathrm{ABI} 377$ automated sequencer (PE Applied Biosystems, Warrington, UK) with the same primers used for the amplification reactions. Any mutation identified by direct sequencing was confirmed by repeat sequen- cing and/or restriction enzyme digestion if associated with the creation or loss of a specific restriction enzyme site.

\section{Structural analysis of FVII mutations:} The crystal coordinates of FVIIa and the TFFVIIa complex (12-14) were obtained from the Protein Data Bank (codes 1qfx, 1cvw and 1dan). Protein structures were visualised using the INSIGHT II 97.0 program package (Biosym/MSI, San Diego, USA) on Silicon Graphics INDY Workstations, using Crystal Eyes stereo glasses for detailed inspections. The quantitative assignment of the main-chain secondary structure of each structure was made using the DSSP program (20), where Figure 1 shows the $\alpha$-helix and $\beta$-strand contents (denoted as $\mathrm{H}$ and $\mathrm{E}$ respectively) and other types including loops and turns (T, S, B, G). The quantitative assignment of solvent-exposed residue side-chains and the side-chains of residues that make contact between FVIIa and TF in the complex was made using the COMPARER program by the Lee and Richards method $(21,22)$ using a probe of $1.4 \AA$. Sidechains were defined as exposed if their accessibilities ranged between $20-100 \%$ (values of 2 to 9 in Figure 1), and buried if these ranged between $0-19 \%$ (values of 0 and 1 in Figure 1).

\section{Results}

Phenotypic analysis: Table 1 shows the FVII:C and FVII:Ag levels for each of 27 patients from 21 unrelated families and the severity of their bleeding symptoms. Only FVII:C data obtained with recombinant 


\section{Rare $\overline{\text { Coagulation Disorders }}$}

human thromboplastin are shown. 11 out of 27 patients showed reduced levels of both FVII:C and FVII:Ag, and these are assigned as type 1 defects. In the remaining 16 patients, there was a low level of FVII:C and a normal or borderline level of FVII:Ag and these were assigned to the presence of a dysfunctional FVII molecule (type 2 defects). In 22 out of 27 patients, similar FVII:C values were obtained using three different thromboplastins (human, bovine and rabbit). However, five Iranian patients from two unrelated families (Pedigrees $J$ and $K$ ) had low FVII:C levels with rabbit thromboplastin $(<1 \%)$, mildly reduced levels with human thromboplastin (17-37\%) and normal levels with bovine thromboplastin (70-130\%). These five patients had normal or elevated levels of FVII:Ag. A total of 19 mutations were identified, of which 12 were novel and 7 had been previously reported (Table 2 ).

Novel Mutations: Nine of the 12 novel mutations were missense mutations, and three were splice-site mutations. Of the 12 families in which novel mutations were identified, seven were homozygous (Pedigrees F, $\mathrm{H}, \mathrm{Q}-\mathrm{U}$ ) and the remaining five were heterozygous (Pedigrees A, C, E, G and V). All but two of the missense mutations occurred in the catalytic SP domain of FVII. One nonSP domain mutation was Ser23Pro in the Gla domain that was found in a single patient (Pedigree A) who was heterozygous for the mutation. Although FVII:Ag is close to half-normal in this individual, as expected for a heterozygote in which no other FVII mutation or gene could be identified, FVII:C was less than $1 \%$ to indicate a dysfunctional type 2 defect. The other non-SP domain mutation was Cys135Arg, which occurs in the EGF-2 domain of FVII in patient C-1. This patient was heterozygous for this mutation, which can be a type 1 defect as both FVII:C and FVII:Ag were reduced (but see below). A second previously-reported $17 \mathrm{bp}$ deletion mutation within exon 8 (10585del17) (23) was also identified in patient $\mathrm{C}-1$. Of the seven novel SP domain mutations, four were homozygous and associated with a normal FVII:Ag level but reduced functional activity, indicating dysfunctional type 2 defects (Pedigrees H, Q-S). In the remaining three homozygous or heterozygous cases, there was a reduction in FVII function and a partial or full reduction in the FVII:Ag level, indicating type 1 or 2 defects (Pedigrees E-G).

The remaining 3 novel mutations were splice sites. In Pedigree $\mathrm{T}$, a homozygous G->A transition within intron 1a (IVS-1a G5A) was associated with a parallel reduction in both FVII:Ag and FVII:C. In Pedigree U, a homozygous G->A substitution within intron 2 (IVS-2 G1A) was associated with a severe bleeding diathesis and undetectable levels of FVII:Ag and FVII:C. In Pedigree V, a heterozygous $\mathrm{G}->\mathrm{T}$ substitution was identified within intron 6 (IVS-6 G1T). There is a disparity between FVII:Ag (30\%) and FVII:C $(<1 \%)$ in this case, which suggested the presence of an additional mutation that has not been identified.

Previously reported mutations: Of the 7 previously identified mutations, Arg304Gln 
$(23,24)$, Cys310Phe $(24,25)$ and Thr359Met (26) correspond to the SP domain, however the Thr359Met mutation is now homozygous (Pedigree P; type 1 defect), and not heterozygous as previous. The Gln100Arg and Arg152Gln mutations $(27,28)$ in the EGF-2 domain are homozygous in Pedigree B (type 1 defect) and Pedigree $D$ (type 2 defect), and not heterozygous as previous. The IVS-7 splice site mutation (29) was found in a single individual (Pedigree W), who was heterozygous for the substitution, in which the FVII:C level were consistent with a single causative mutation.

\section{Discussion}

We have used two screening methods combined with direct sequencing of PCR products to identify 19 candidate mutations in the human FVII gene in 27 kindreds, of which 12 were novel ones (Table 2). When combined with the most recent review of 35 FVII mutations (10), this makes a total of 47 . The FVII mutation website currently lists 70 mutations (February 2000), including subsequent examples of 3 of our 12 novel mutations $(30,31)$. The number of novel mutations presented here is the largest of any single study to date, and increases the known total to 79 . Since 5 novel mutations and 3 previously known mutations are homozygous, Table 1 clearly identifies the cli-
Tab. 1 - Phenotypic and clinical data on 27 patients with FVII deficiency

Kindred/ FVII:C* FVII:Ag Consanguinity Bleeding

No. $\quad(50-150 \%) \quad(70-120 \%) \quad$ Symptoms

\begin{tabular}{lllll}
\hline $\mathrm{A}-1$ & $<1 \%$ & $77 \%$ & No & Severe
\end{tabular}

B-1 $<1 \% \quad 10 \% \quad$ No $\quad$ Severe

$C-1<1 \% \quad<1 \% \quad$ No $\quad<$ Severe

D-1 $<1 \% \quad 78 \% \quad$ Yes $\quad$ Mild

E-1 $<1 \% \quad 54 \% \quad$ No $\quad$ Severe

E-2 $\quad<1 \% \quad 43 \% \quad$ No $\quad$ Mild

E-3 $<1 \% \quad 43 \% \quad$ No $\quad$ Mild

F-1 $<1 \% \quad<1 \% \quad$ Yes $\quad$ Severe

G-1 $<1 \% \quad 6 \% \quad$ No $\quad$ Severe

$\mathrm{H}-1<1 \% \quad$ Yes $\quad 135 \% \quad$ Severe

J-1 $\quad 37 \% \quad 240 \% \quad$ Yes $\quad$ None

$\mathrm{J}-2 \quad 27 \% \quad 224 \% \quad$ Yes $\quad$ Mild

J-3 $24 \% \quad 156 \% \quad$ Yes None

J-4 $17 \% \quad 106 \% \quad$ Yes $\quad$ None

K-1 $22 \% \quad 130 \% \quad$ Yes $\quad$ None

L-1 $\quad<1 \% \quad 129 \% \quad$ Yes $\quad$ Mild

M-1 $\quad<1 \% \quad 80 \% \quad$ Yes $\quad$ Mild

N-1 $\quad<1 \% \quad 104 \% \quad$ Yes $\quad$ Mild

P-1 $<1 \% \quad<1 \% \quad$ Yes $\quad$ Mild

Q-1 $\quad<1 \% \quad 80 \% \quad$ Yes $\quad$ Mild

Q-2 $\quad<1 \% \quad 130 \% \quad$ Yes $\quad$ Mild

R-1 $<1 \% \quad 132 \% \quad$ Yes $\quad$ Severe

S-1 $\quad 6 \% \quad 77 \% \quad$ Yes $\quad$ Severe

T-1 $\quad 6 \% \quad 3 \% \quad$ Yes $\quad$ Mild

U-1 $\quad<1 \% \quad<1 \% \quad$ Yes

V-1 $\quad<1 \% \quad 30 \% \quad$ No $\quad$ Mild

W1 $\quad 31 \% \quad 100 \% \quad$ No None

*VII:C obtained using recombinant human thromboplastin (tissue factor).

nical consequence of these mutations (Pedigrees B, D, F, H and P-S). In order to explain the likely effect of the missense mutations on FVII, we quantitatively identified the secondary structures and solvent 
Tab. 2 - Mutational data on 27 patients with FVII deficiency

\begin{tabular}{|c|c|c|c|c|c|}
\hline \multicolumn{2}{|c|}{ Kindred/No Mutation } & \multirow{2}{*}{$\frac{\text { Codon }}{\text { Ser23Pro }}$} & \multirow{2}{*}{$\frac{\text { Exon }}{2}$} & \multirow{2}{*}{$\frac{\text { Domain }}{\text { Gla }}$} & \multirow{2}{*}{$\frac{\text { Comments }}{\text { Heterozygous }}$} \\
\hline A-1 & TCC-CCC & & & & \\
\hline B-1 & $C A G-C G G$ & Gln100Arg* & 5 & EGF-2 & Homozygous \\
\hline \multirow[t]{2}{*}{$\mathrm{C}-1$} & 10585del17 & $223-229^{*}$ & 8 & $\mathrm{SP}$ & Compound \\
\hline & TGT-CGT & Cys135Arg & 5 & EGF-2 & heterozygote \\
\hline D-1 & $C G A-C A A$ & $\operatorname{Arg} 152 \mathrm{Gln} *$ & 6 & SP & Homozygous \\
\hline \multirow[t]{2}{*}{ E-1 } & CGC-TGC & Arg247Cys & 8 & SP & Compound \\
\hline & TGC-TCC & Cys310Phe* & & $\mathrm{SP}$ & heterozygote \\
\hline \multirow[t]{2}{*}{$\mathrm{E}-2$} & CGC-TGC & Arg247Cys & 8 & SP & Compound \\
\hline & TGC-TCC & Cys310Phe* & & SP & heterozygote \\
\hline \multirow[t]{2}{*}{ E-3 } & CGC-TGC & Arg247Cys & 8 & $\mathrm{SP}$ & Compound \\
\hline & TGC-TCC & Cys310Phe* & & SP & heterozygote \\
\hline$F-1$ & CGC-TGC & Arg277Cys & 8 & $\mathrm{SP}$ & Homozygous \\
\hline G-1 & AGC-AGG & Ser282Arg & 8 & $\mathrm{SP}$ & Heterozygous \\
\hline $\mathrm{H}-1$ & CCC-ACC & Pro303Thr & 8 & $\mathrm{SP}$ & Homozygous \\
\hline $\mathrm{J}-1$ & CGG-CAG & Arg304Gln* & 8 & SP & Homozygous \\
\hline$J-2$ & CGG-CAG & Arg304Gln* & 8 & SP & Homozygous \\
\hline$J-3$ & CGG-CAG & Arg304GIn* & 8 & $\mathrm{SP}$ & Homozygous \\
\hline$J-4$ & $C G G-C A G$ & Arg304Gln* & 8 & SP & Homozygous \\
\hline K-1 & CGG-CAG & Arg $304 G l n^{*}$ & 8 & SP & Homozygous \\
\hline $\mathrm{L}-1$ & TGC-TCC & Cys310Phe* & 8 & SP & Homozygous \\
\hline M-1 & TGC-TTC & Cys310Phe* & 8 & SP & Homozygous \\
\hline$N-1$ & TGC-TTC & Cys310Phe* & 8 & $\mathrm{SP}$ & Homozygous \\
\hline P-1 & ACG-ATG & Thr359Met & 8 & SP & Homozygous \\
\hline Q-1 & AGC-ATC & Ser363Ile & 8 & $S P$ & Homozygous \\
\hline Q-2 & AGC-ATC & Ser363Ile & 8 & SP & Homozygous \\
\hline $\mathrm{R}-1$ & TGG-TGC & Trp364Cys & 8 & SP & Homozygous \\
\hline$S-1$ & TGG-TTT & Trp364Phe & 8 & SP & Homozygous \\
\hline $\mathrm{T}-1$ & Cgt-cat & IVS1a+5 & IVS-1a & - & Homozygous \\
\hline U-1 & Gtga-âtga & IVS2+1 & IVS-2 & - & Homozygous \\
\hline$V-1$ & Ggta-gtta & IVS6+1 & IVS-6 & - & Heterozygous \\
\hline W-1 & Gtac-gtag & Splice site* & IVS-7 & - & Heterozygous \\
\hline
\end{tabular}

* Previously reported mutations.

accessibilities of residues in experimentallydetermined crystal structures for free FVIIa and the TF: FVIa complex (12-14) (Figure
1). That these crystal structures are good representations of the multidomain structures in solution was shown by scattering modelling calculations (15).

Structural interpretation of the novel mutations: The catalytic SP domain consists of two subdomains, SP1 and SP2, each of which contains a four-stranded Greek keysheet motif and a two-stranded-hairpin motif. The catalytic triad H193-D242-S344 is positioned between SP1 and SP2 (Figure 3). Six of the 12 novel mutations occur in the SP2 subdomain that interacts directly with TF, two occur in the Gla and EGF-2 domains, one occurs in the SP1 subdomain, and three are splice site mutations (Table 2).

The Ser23Pro substitution in the Gla domain results in a dysfunctional defect (Figure 2). The second mutant allele in this heterozygous patient has not been found by PCRbased mutation screening. Ser23 is conserved in the Gla domains of factors IX and X, and this mutation replaces a small exposed hydrophilic residue (Figure 1) by a bulky hydrophobic one with a restricted main-chain conformation. As the FVII:Ag 
sent in heterozygous association with a $17 \mathrm{bp}$ deletion mutation in exon 8 which prevents synthesis of FVII. Cys135 is disulphide-bridged with Cys262 in the FVII structure, and connects the light and heavy chains of FVIIa after the Arg152-Ile153 peptide bond is cleaved during activation. The physical separation of the SP domain and light chain would lead to the complete lack of functional activity of FVII. Even though it is not clear whether the low FVII:Ag assay corresponds to the rapid clearance of FVII from plasma, a low level of secretion in a misfolded FVII molecule, or a lack of epitope recognition in assays, it is not surprising that the two mutations in this patient results in a severe FVII deficiency and bleeding tendency (Table 1).

The Arg247Cys mutation is the only novel mutation that is located in the $\mathrm{N}$-terminal subdomain SP1 which makes no contacts with TF in the complex (Figures 2 and 3), so is unlikely to correspond to a dysfunctional type 2 defect. In Pedigree $\mathrm{E}$, this mutation occurs in association with a previouslydescribed homozygous mutation (Cys310Phe) $(10,24,25)$ in the SP2 subdomain (Figure 3: see below). Since the Cys310Phe mutation results in a type 2 loss of function in the homozygous Pedigrees $\mathrm{L}$, $\mathrm{M}$ and $\mathrm{N}$, the reduction to half-normal FVII levels in Pedigree $\mathrm{E}$ shows that the Arg247Cys mutation is likely to be a type 1 defect. The side-chain of Arg247 is in the protein core, being only $10 \%$ accessible and within $\beta$-strand $H$ (Figure 1). The introduction of a Cys residue in this mutation may
Fig. 2 - Ribbon view of the crystal structure of the complex between FVIIa and TF.

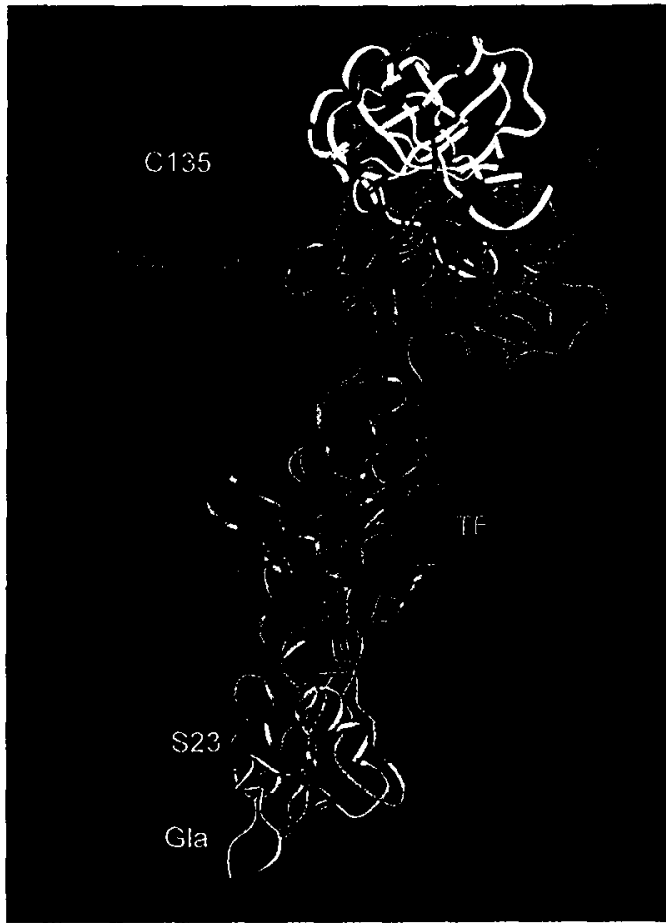

The $\alpha$-carbon atoms of the novel mutation sites (yellow; Table 2) and previously-identified ones (blue: Table 2) and the cotalytic trind (red: Figure 1) are represented by spheres. The domnins in FVIlo are identified as follows: Gla, dark grey; EGF-1 and EGF-2, green; the N-terminal and C-terminal SP subdomnins, light grey and magenta respectively. The two fibronectin type III domains in tissue factor are identified in browon.

perturb any of the 12 Cys-Cys bridges within FVII to affect the correct folding of FVII. This would cause either a lack of secretion of FVII or a short half-life in plasma, and is consistent with the assignment of a type 1 defect to the Arg247Cys mutation.

A homozygous substitution Arg277Cys was 


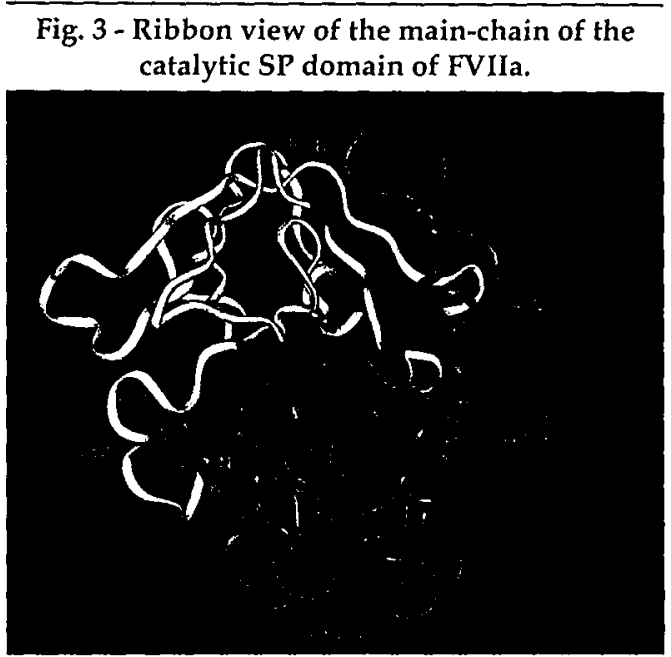

The $\alpha$-carbon atoms of the calnlytic triad H193-D242-S344 are shown as red spheres at the interface between the two subdomains of the SP domain (light grey: upper N-terminal subdomain; magenta: lower C-terminal subdomain). The novel mutation sites of this study are shown in yellow, while previously-identified ones also found in this study are shown in blue (Table 2).

identified as a type 1 defect in an Iranian patient with a severe bleeding diathesis (Table 1). The introduction of a Cys residue may cause protein misfolding and affect FVII secretion or reduce its half-life in plasma. The substitution of this residue during alanine scanning mutagenesis studies showed a combined impairment of both TF binding and proteolytic activity (33), which identifies this to be a type 1 defect. In the crystal structure of the complex, Arg277 is packed against Trp 45 of TF and forms hydrogen bonds with the Ser39 sidechain and the Gly 43 mainchain in TF (14). Unsurpri-singly, the solvent accessibility of Arg277 is much reduced from $70 \%$ in free FVIIa to $10 \%$ in the complex (Figure 1).

The Ser282Arg mutation involves a residue conserved in both factors IX and X, and corresponds to a heterozygous type 1 defect. The mutation occurs in an Iranian boy with a severe bleeding disorder, in whom the mutation on the other allele has not been identified by PCR-based mutation screening. Ser282 lies in the protein core of the SP2 subdomain of FVII within $\beta$-strand $J$ with $0 \%$ solvent accessibility (Figure 1 ). It is close to the $\mathrm{N}$-terminal residue Ile153, whose charged amino group forms an internal salt bridge with Asp343 in the oxyanion pocket next to Ser344 of the catalytic triad (Figure 3 ). The mutation of a small buried residue by a large basic one is likely to have significant steric or electrostatic effects on the oxyanion pocket. This will affect the folding of the SP domain, resulting in a low secretion or short plasma half-life for FVII.

The Pro303Thr mutation is a type 2 dysfunctional homozygous substitution in an Iranian patient with a history of recurrent and severe bleeding. Pro303 is conserved in factors IX and $\mathrm{X}$, the complement serine proteases (factor $\mathrm{D}, \mathrm{C} 1 \mathrm{r}$ and $\mathrm{C} 1 \mathrm{~s})$, and elastase and trypsin from several species $(15,34)$. Pro303 is buried with only $10 \%$ solvent accessible in the SP domain in $\beta$-strand $\mathrm{K}$, and may stabilise an adjacent turn in the protein backbone (Figure 1). In the FVIIa-TF complex, Pro303 is close to $\mathrm{TF}$ in the region where the $\mathrm{TF}$ residues Gly, Ser, Ala and Thr at positions 14 and 85-90 are absent from the crystal structure. It is likely that Pro303 is important for the stabilisation of the surface of the 


\section{Rare Coagulation Disorders}

SP domain in the complex, and this would explain the severity of the Pro303 substitution by Thr (Table 1). The adjacent residue Arg304 directly interacts with TF, however its mutation has only a mild effect on FVIIa function (see below). In confirmation of this explanation, site-directed mutagenesis of Pro303 and Arg304 showed that they are important to stabilise the complex and the proteolytic function of FVIIa (33).

Three dysfunctional mutations occur at residues 363 and 364 . The Ser363Ile mutation is homozygous in 2 members of an Iranian family with definite bleeding histories. In each case, the FVII:Ag levels were preserved but there was a reduction in FVII:C to less than $1 \%$. Two homozygous mutations were identified at residue 364 , one being Trp364Cys, and the other is a two-nucleotide substitution that gives Trp364Phe. Both mutations were associated with preservation of FVII:Ag but a reduction in FVII:C and a severe effect on bleeding. Ser363 and Trp364 are conserved residues in SP domains $(15,34)$ and occur at the $\mathrm{C}$-terminus of the $\beta$-strand $\mathrm{N}$ at the active site cleft. As both residues form four mainchain hydrogen bonds to the active site substrate analogues D-Phe-L-PheArg chloromethyl ketone or 1,4-dansyl GluGly-Arg chloromethyl ketone $(13,14)$, the effect of these mutations is most likely due to perturbations in the substrate-binding site of FVIIa, in accordance with its type 2 classification.

In relation to the three novel splice site mutations, the homozygous IVS1a+5 mutation results in the preservation of some FVII coagulant activity and is associated with a mild bleeding history. In contrast, the homozygous IVS2+1 mutation is associated with major bleeding problems (intracranial haemorrhage, muscle haematomas) and a FVII:Ag and FVII:C of less than 1\%. A similar mutation at the 5' splice site of intron 4 (IVS4+1) results in the excision of the EGF-1 domain of FVII, and is associated with a complete absence of circulating FVII (35). It is probable that a similar mechanism operates in the case of the IVS2+1 mutation. The third mutation, IVS6+1, is heterozygous, in which the FVII:C of less than $1 \%$ suggests the presence of an additional unidentified mutation. Despite a low FVII activity, the clinical phenotype was mild.

Structural interpretation of previously identified mutations: A review of 35 previously-described mutations (10) showed that 26 corresponded to amino acid substitutions found in the Gla (1 mutation), EGF-1 (3 mutations) and EGF-2 (5 mutations) domains, and the SP1 and SP2 subdomains ( 5 and 12 mutations respectively). Seven of these missense mutations were also identified in the 27 patients of the present study (Gla, 1 mutation; EGF-2, 2 mutations; SP2, 4 mutations), with an important difference in that three have now been identified in homozygous forms. The earlier discussion of structure-function aspects $(10,36)$ can now be extended in the light of recent crystal structures (12-14) and their known homozygous or heterozygous forms.

The homozygous Gln100Arg mutation in the EGF-2 domain, previously known only in 
heterozygous form (10), involves the substitution of a $0 \%$ accessible residue (Figure 1) conserved in factors IX and $\mathrm{X}$ by a large positively charged residue. Gln100 is located close to the junction of the EGF-2 domain with the SP domain (Figure 2), so the substitution is likely to perturb the protein folding of FVIIa in this critical region. This interpretation would be consistent with the assignment of this mutation as a type 1 defect (Table 1).

The homozygous Arg152Gln substitution adjacent to the SP domain coincides with the factor Xa cleavage site at Arg152-Ile153 in FVII. This would prevent the cleavage and activation of FVII, which is otherwise unaltered, so this is consistent with its type 2 assignment. Previously, this mutation had been observed in homozygous association with a second one at Arg79Gln in the EGF-1 domain, where Arg79 is conserved in factors VII, IX and X $(10,28)$. As this second mutation was absent in Kindred D-1, the clinical effect of this mutation can now be defined.

In the SP2 subdomain, the dysfunctional type 2 mutation at Arg304Gln involves a CpG dinucleotide, a recognised hotspot for mutation in the human genome. This substitution is homozygous in 2 Iranian families (Pedigrees $\mathrm{H}$ and $\mathrm{N}$ ) and has been previously reported in families from 7 additional countries. The different FVII coagulant activities measured with TF from different species is characteristic of this mutation (FVII Padua 1 ), and presumably arises from variations in the $\mathrm{TF}$ sequences that correspond to the contact area between FVIIa and TF $(37,38)$. The crystal structure of the complex shows that Arg304 binds to three $\mathrm{H}_{2} \mathrm{O}$ molecules within a hydrophilic pocket between FVIIa and TF. The likely effect of this mutation is to perturb this water structure between the two protein surfaces, thus explaining its type 2 effect.

In the SP2 subdomain, the Cys310Phe substitution was found in 3 unrelated families (Pedigrees L-N) as a homozygous mutation, and in another one (Pedigree $\mathrm{E}$ ) that was compound heterozygous for this and a second mutation Arg247Cys (see above). In the homozygous families, laboratory measurements showed normal FVII:Ag but a reduction in FVII:C to less than $1 \%$, indicating a dysfunctional defect. Cys310 is highly conserved in all serine proteases, including factors IXa and Xa, and is $0 \%$ solvent accessible in $\alpha$-helix A2 (Figure 1). It forms a disulphide bond with Cys329 near the surface of the SP domain in the only potentially mobile segment between the contact surfaces of FVIIa and $\mathrm{TF}$ (Figure 3) (14). The reduction of this disulphide bond severely impairs the interaction with TF (39). The type 2 assignment is best explained in terms of the inclusion of a bulky hydrophobic residue inside the SP domain that has altered the FVII structure in the region where it forms contacts with TF.

The Thr359Met mutation is a homozygous type 1 defect that previously had only been seen as a heterozygote (10), so its clinical phenotype has now been defined here. In the SP2 subdomain, the incorporation of a bulky hydrophobic residue at a buried location in a 


\section{Rare $\overline{\text { Coagulation Disorders }}$}

central $\beta$-strand $\mathrm{N}$ is expected to affect the packing of residues within the SP2 subdomain. Since Thr359 is packed against the surface $\alpha$-helix A1, its substitution by Met is expected to alter the position of this $\alpha$-helix, and the resulting misfolding may lead to low secretion or a short plasma half-life.

\section{Conclusion}

The large number of FVII mutations presented here, including many homozygous ones, has significantly enlarged our knowledge on gene mutations associated with FVII deficiency, the most frequent of the rare recessively-transmitted coagulation disorders. In the absence of the verification of each FVII dysfunction using expression work based on each missense mutation for functional assays and crystallisation studies, views of the experimentally-determined crystal structures of free and complexed FVIIa were used to explain the effect of each mutation. In vitro expression analyses are under way to further characterise the effects of the novel mutations. The identification of 12 novel and 9 known mutations in this study leads to a total of 79 known mutations in FVII (Figure 1; Tables 1 and 2), from which three significant conclusions can be made:

(•) The novel Arg277Cys, Pro303Thr, Ser363Ile, Trp364Cys and Trp364Phe mutations are homozygous, and their laboratory phenotypes permitted the identification of Arg277Cys as a type 1 quantitative defect and the other four as type 2 dysfunctional defects. The Gln100Arg, Arg152Gln and Thr359Met mutations were found to be homozygous ones instead of heterozygous previously, and can be identified as type 1 , type 2 and type 1 defects respectively.

$(\cdot)$ The quantitative comparison of the single-residue mutations with crystal structures for FVIIa and the FVIIa-TF complex provided good explanations for the observed type 1 and 2 classifications, with only one ambiguity in the case of Arg277Cys. These explanations clarify the assignments of the laboratory phenotypes. The type 1 defects were attributable to misfolded proteins that fail to be secreted or have short half-lives in plasma. The type 2 defects correlate with normal levels of circulating FVIIa but involve residues close to functionally important regions of FVIIa, such as at the protein surface in contact with TF in the FVIIa-TF complex.

$(\cdot)$ The location of the mutations in the FVII structure provides information on its molecular function. All four domains in FVII contribute to TF binding, where each domain contributes approximately equally to about $21 \%$ to $31 \%$ of the area in contact with TF. Functionally-defective mutations are therefore expected to occur at evolutionarily-similar rates in the four domains. This is however not observed, where the addition of 9 novel missense mutations in this study to those reviewed in (10) gives a total of 35 , of which half originates from the SP2 subdomain, and a quarter from the EGF-2 domain. It is generally thought that the association of FVIIa with TF locks the SP domain into a proteolytically-active conformation. Our localisation of defective mutations from this study provi- 
des evidence that the most important conformational changes during FVII activation are those within the C-terminal SP2 subdomain of the SP domain that makes contact with TF and leads to FVII activation, and that residue conservation is critical for this. The summary provided in Figure 1 will be useful for the classification of further FVII mutations to be identified.

\section{References}

1. Fair DS: Quantitation of factor VII in the plasma of normal and warfarin-treated individuals by radioimmunoassay. Blood 1983; 62: 784791.

2. Osterud B, Rapaport S: Activation of factor IX by the reaction product of tissue factor and factor VII: Additional pathway for initiating blood coagulation. Proc Natl Acad Sci USA 1977; 74: 5260. 5264 .

3. Bauer KA, Kass BL, ten Cate H, Hawiger JJ, Rosenberg RD: Factor IX is activated in vivo by the tissue factor mechanism. Blood 1990; 76:731736 .

4. Hagen FS, Gray CL, O'Hara P, Grant FJ, Saari GC, Woodbury RG, Hart CE, Insley M, Kisiel W, Kurachi K: Characterization of a cDNA coding for human factor VII. Proc Natl Acad Sci USA 1986; 83: 2412-2416.

5. Bajaj SP, Rapaport SI, Brown SF: Isolation and characterization of human factor VII. Activation of factor VII by factor Xa. J Biol Chem 1981; 256: 253.259.

6. O'Hara PJ, Grant FJ, Haldeman BA, Gray CL, Insley MY, Hagen FS, Murray MJ: Nucleotide

\section{Acknowledgements}

The financial support of the Katharine Dormandy Trust for Haemophilia and Allied Disorders and the Angelo Bianchi Bonomi Foundation is gratefully acknowledged. We are also grateful to $\mathrm{Dr}$ R. Sharifian, Dr M. Lak and the Iranian Haemophilia Society for their help and assistance in the identification and collection of samples.

sequence of the gene coding for human factor VII, a vitamin K-dependent protein participating in blood coagulation. Proc Natl Acad Sci USA 1987; 84: 5158-5162.

7. Berkner K, Busby S, Davie E, Hart C, Insley M, Kisiel W, Kumar A, Murray M, O'Hara P, Woodbury R: Isolation and expression of cDNAs encoding human factor VII. Cold Spring Harb Symp Quant Biol 1986; 51: 531-541.

8. Triplett DA, Brandt JT, Batard MA, Dixon JL, Fair DS: Hereditary factor VII deficiency: heterogeneity defined by combined functional and immunochemical analysis. Blood 1985; 66: 1284 . 1287.

9. Peyvandi F, Mannucci PM, Asti D, Abdoullahi M, Di Rocco N, Sharifian R: Clinical manifestations in 28 Italian and Iranian patients with severe factor VII deficiency. Haemophilia 1997; 3: 242-246.

10. Cooper DN, Millar DS, Wacey A, Banner DW, Tuddenham EGD: Inherited factor VII deficiency: Molecular genetics and pathophysiology. Thromb Haemost 1997; 78: 151.160.

11. Jenkins PV, Pasi J, Perkins SJ: Molecular modelling of ligand and mutation sites of the 
Type A domains of human von Willebrand factor and their relevance to von Willebrand's disease. Blood 1998; 91: 2032-2044.

12. Pike ACW, Brzozowski, AM, Roberts SM, Olsen $\mathrm{OH}$, Persson E: Structure of human factor VIIa and its implications for the triggering of blood coagulation. Proc. Nat. Acad. Sci. USA 1999; 96: 8.925-8930.

13. Kemball-Cook G, Johnson DJD, Tuddenham EGD, Harlos K: Crystal structure of active siteinhibited human coagulation factor VIIa (desGla). J. Struct.Biol. 1999; 127: 213-223.

14. Banner DW, D'Arcy A, Chene C, Winkler FW, Guha A, Konigsberg WH, Nemerson Y, Kirchoger D: The crystal structure of the complex of blood coagulation factor VIIa with soluble tissue factor. Nature 1996; 380: 41.44.

15. Ashton AW, Boehm MK, Johnson DJD, Kemball-Cook G, Perkins SJ: The solution structure of human coagulation factor. VIIa in its complex with tissue factor: A study of a heterodimeric receptor-ligand complex by X-ray and neutron scattering and computational modelling. Biochemistry 1998; 37: 8208-8217.

16. Lak M, Sharifian R, Peyvandi F, Mannucci PM: Symptoms of inherited factor $\mathrm{V}$ deficiency in $\mathbf{3 5}$ Iranian patients. Br J Haematol 1998; 103: 1067. 1069.

17. Coppola R, Tombesi S, Valentini F, Alborali S, Albertini A, Mannucci PM: Enzyme-linked immunosorbent assay of human factor VII based upon a monoclonal antibody that recognizes the native conformation of the protein. Thromb Res 1992; 68: 283.293 .

18. Orita M, Suzuki Y, Sekiya T, Hayashi K: Rapidand sensitive detection of point mutations and DNA polymorphisms using polymerase chain reaction. Genomics 1989; 5: 874-879.

19. Ganguly A, Rock MJ, Prockop DJ: Conformation sensitive gel electrophoresis for rapid detection of single-base differences in double-stranded PCR products and DNA fragments: Evidence for solvent-induced bends in DNA heteroduplexes. Proc Natl Acad Sci USA 1993; 90: 10325-10329.

20. Kabsch W, Sander C: Dictionary of protein secondary structure: Pattern recognition of hydrogen-bonded and geometrical features. Biopolymers 1983; 22: 2577-2637.

21. Lee B, Richards FM: The interpretation of protein structures: Estimation of static accessibility. J Mol Biol 1971; 55: 379-400.

22. Sali A, Blundell TL: The definition of topological equivalence in homologous and analogous structures: A procedure involving a comparison of local properties and relationships. $J \mathrm{Mol} \mathrm{Biol}$ 1990; 212: 403-428.

23. Bernardi F, Castaman G, Redaelli R, Pinotti M, Lunghi B, Rodeghiero F, Marchetti G: Topologically equivalent mutations causing dysfunctional coagulation factors VII (294Ala->Val) and X (334Ser->Pro). Hum Mol Gen 1994; 3:1175-1177.

24. Bernardi F, Liney DL, Patracchini $P$, Gemmati $D$, Legnani C, Arcieri P, Pinotti M, Redaelli R, Ballerini G, Pemberton S, et al: Molecular defects in CRM+ factor VII deficiencies: modelling of missense mutations in the catalytic domain of FVII. Br J Haematol 1994; 86: 610-618.

25. Marchetti G, Patracchini P, Gemmati D, De Rosa V, Pinotti M, Rodorigo G, Casonato A, Girolami A, Bernardi F: Detection of two missense mutations and characterization of a repeat polymorphism in the factor VII gene (F7). Hum Genet 1992; 89: 497-502. 
26. Arbini AA, Mannucci PM, Bauer KA: A Thr359Met mutation in factor VII of a patient with a hereditary deficiency causes defective secretion of the molecule. Blood 1996; 87: 5085 5094 .

27. Takamiya O, Kemball-Cook G, Martin DMA, Cooper DN, von Felten A, Meili E, Hann I, Prangnell DR, Lumley H, Tuddenham EGD, Mc Vey JH:

Detection of missense mutations by singlestrand conformational polymorphism (SSCP) analysis in five dysfunctional variants of coagulation factor VII. Hum Mol Genet 1993; 2: 1355 . 1359 .

28. Chaing S, Clarke B, Sridhara S, Chu K, Friedman P, Van Dusen W, Roberts HR, Blajchman M, Monroe DM, High KA: Severe factor VII deficiency caused by mutations abolishing the cleavage site for activation and altering binding to tissue factor. Blood 1994; 83: 3524-3535.

29. Pinotti M, Toso R, Redaelli R, Berrettini M, Marchetti G, Bernardi F: Molecular mechanisms of FVII deficiency: Expression of mutations clustered in the IVS7 donor splice site of factor VII gene. Blood 1998; 92: 1646-1651.

30. Peyvandi F, Mannucci PM, Jenkins PV, Perry DJ: Molecular characterisation of 22 families with factor VII deficiencies. Blood 1998; 92: Suppl. 1, Abstract 2922

31. Wulff K, Herrmann FH: Molecular analysis of FVII gene in factor VII deficiency. Thromb Haemost 1999; Supplement: 139 (Abstract)

32. Sunnerhagen M, Forsen S, Hoffren A-M, Drakenberg T, Teleman O, Stenflo J: Structure of the Ca2+-free GLA domain sheds light on membrane binding of blood coagulation proteins. Nature Struct Biol 1995; 2: 504-509.

33. Dickinson CD, Kelly CR, Ruf W:
Identification of surface residues mediating tissue factor binding and catalytic function of the serine protease factor VIIa. Proc Natl Acad Sci USA 1996; 93: 14379.14384.

34. Perkins SJ, Smith KF: Identity of the putative serine-proteinase fold in proteins of the complement system with nine relevant crystal structures. Biochem I 199.3; 295:109-114.

35. McVey JH, Boswell EJ, Takamiya O, Tamagnini G, Valente V, Fidalgo T, Layton M, Tuddenham EGD: Exclusion of the first EGF domain of factor VII by a splice site mutation causes lethal factor VII deficiency. Blood 1998; 92 : 920.926.

36. Tuddenham EGD, Pemberton S, Cooper DN: Inherited factor VII deficiency: genetics and molecular pathology. Thromb Haemost 1995; 74: 313-321.

37. O'Brien DP, Gale KM, Anderson JS, McVey JH, Miller GJ, Meade TW, Tuddenham EGD:

Purification and characterization of factor VII 304-GIn: a variant molecule with reduced activity isolated from a clinically unaffected male. Blood 1991; 78: 132-140.

38. O'Brien DP, Kemball-Cook G, Hutchinson AM, Martin DM, Johnson DJ, Byfield PG, Takamiya O, Tuddenham EGD, McVey JH: Surface plasmon resonance studies of the interaction between factor VII and tissue factor. Demonstration of defective tissue factor binding in a variant FVII molecule (FVII-R79Q). Biochemistry 1994; 33: 14162 -14169.

39. Higashi S, Matsumoto N, Iwanaga S: Conformation of factor VIIa stabilized by a labile disulfide bond (Cys310-Cys329) in the protease domain is essential for interaction with tissue factor. J. Biol. Chem. 1997; 272: 25724-25730. 


\section{Homozygous $2 \mathrm{bp}$ deletion in the human factor VII gene: a non-lethal mutation that is associated with a complete absence of circulating factor VII}

F. Peyvandi'1,2, P.M. Mannucci², P.V. Jenkins', A. Lee ${ }^{3}$, R. Coppola ${ }^{2}$, D.J. Perry ${ }^{1}$

'Haemophilin Centre and Haemostasis Unit - Department of Haematology,

Roynl Free Hospital School of Medicine, Pond Street, London.

${ }^{2}$ Angelo Bianchi Bonomi Haemophilia and Thrombosis Center, IRCCS Maggiore Hospital and University of Milan, Italy

${ }^{3}$ Department of Paediatrics, Tuen Mun Hospital, New Territories, Hong Kong, China.

Tromb Haemost 84: 635-637, 2000 


\section{Chapter 3 -Molecular studies}

\section{Abstract}

We report the case of a 5 -year-old boy with severe factor VII deficiency. The affected child presented at the age of 8 months and again at 18 months with bleeding from the gastrointestinal tract but the diagnosis of factor VII deficiency was not made until the age of 3 years. He was treated with fresh frozen plasma and subsequently factor VII concentrates and to date remains well. To identify the causative mutation, the factor VII gene was screened by SSCP and direct sequence analysis. A single homozygous $2 \mathrm{bp}$ deletion (-CT) mutation was identified in exon 1a removing nucleotides 27/28 (codons 52/53). Both parents, who were first cousins, were heterozygous for the mutation. The mutation located in the prepropeptide of factor VII, results in a complete absence of factor VII in plasma. This case indicates that a complete absence of plasma factor VII is not necessarily a lethal condition.

\section{Introduction}

Human factor VII is a vitamin K-dependent glycoprotein of 406 amino acids (1). It is synthesised by the liver and circulates in plasma as a single-chain form with a concentration of $\sim 0.5 \mu \mathrm{g} / \mathrm{ml}$. The gene for factor VII maps to chromosome 13 (13q34) and consists of 9 exons (exons 1a, 1b, $2 \longrightarrow 8$ ) and 8 introns spanning $12.8 \mathrm{~kb}$ of sequence $(2,3)$. Factor VII consists of several discrete functional domains that include the Gla domain, two epidermal-like growth factor domains and a catalytic domain (2).
Factor VII is crucial to the initiation of blood coagulation $(4,5)$. Damage to the vascular endothelium exposes tissue factor (TF)-the cellular receptor for factor VII. Exposed TF rapidly binds factor VII resulting in the formation of a TF-VII complex. Factor VII bound to TF undergoes a proteolytic cleavage (at Arg152-Ile153) resulting in the two-chain active serine protease -factor VIIa. Factor VIIa then activates factors IX and $\mathrm{X}$ leading to the generation of thrombin.

Congenital factor VII deficiency is a rare autosomally inherited, recessive bleeding diathesis that affects approximately 1:500,000 individuals (6). Factor VII deficiency, in common with many other inherited recessive disorders is more frequent in countries where consanguineous marriage occurs (7). In contrast to haemophilia A or $B$ in which the bleeding tendency correlates very well with the factor. VIII or IX level, there is a relatively poor correlation in factor VII deficiency between factor VII levels and the bleeding tendency, for reasons which are unclear.

The possibility that a complete absence of factor VII in plasma is incompatible with life is suggested by the paucity of muta. tions that can be confidently predicted to result in a total lack of circulating factor VII. McVey and colleagues recently reported a 5 ' splice site mutation within intron 4 of the factor VII gene that leads to exon skipping and the deletion of exon 4 from factor VII mRNA (8). In vitro expression studies failed to demonstrate any produc- 
tion of factor VII and the authors concluded, therefore, that the presence of this homozygous mutation was associated with a complete absence of factor VII.

The affected child died from massive intracranial haemorrhage at the age of 12 days. In this study we report for the first time a novel non-sense homozygous mutation located in exon 1a of the factor VII gene, coding for the prepropeptide sequence. This mutation leads to a complete absence of plasma factor VII but the patient remains alive.

\section{Methods}

Coagulation assays: Blood was collected into $3.8 \%$ trisodium citrate in a ratio of 1 part anticoagulant to 9 parts blood. Prothrombin times were performed using recombinant human tissue factor (Recombiplastin, Ortho Diagnostic Systems, Milan). Factor VII coagulant activity was assayed in plasma using a onestage clotting assay based upon recombinant human tissue factor and factor VII deficient plasma. This method measures factor VII activity levels as low as $0.01 \mathrm{u} / \mathrm{ml}$ (9). Factor VII antigen was measured using an immunoradiometric assay based upon the use of two previously described anti-human factor VII mouse monoclonal antibodies (10). This method can measure factor VII antigen levels as low as $0.0001 \mathrm{u} / \mathrm{ml}$.

DNA amplification: DNA was isolated from peripheral blood leukocytes and the 9 exons of the factor VII gene together with the flanking intronic sequences, amplified by polymerase chain reaction.

Amplification reactions were carried out in $100 \mu \mathrm{l}$ volumes and comprised: $100-500 \mathrm{ng}$ of DNA, 100 pmoles of each oligonucleotide primer, $200 \mu \mathrm{M}$ of each dNTP, $1.5 \mathrm{mM}$ $\mathrm{MgCl}_{2}, 50 \mathrm{mM} \mathrm{KCl}, 10 \mathrm{mM}$ Tris- $\mathrm{HCl} \mathrm{pH}$ 8.3 and 2 units of Taq DNA polymerase. Reactions were denatured at $94^{\circ} \mathrm{C}$ for 5 minutes and then 40 cycles of amplification performed. On the last cycle the extension time was increased to $10 \mathrm{minu}$ tes. (Oligonucleotide sequence data and amplification parameters are available on request.)

Single strand conformation polymorphism analysis (SSCP) and sequence analysis: PCR samples were denatured by mixing with 2 volumes of denaturation buffer ( $95 \%$ formamide, $0.05 \%$ xylene cyanole and $0.05 \%$ bromophenol blue) and incubating at $94^{\circ} \mathrm{C}$ for 10 minutes and then rapidly chilling on ice for 2 minutes. $4 \mu \mathrm{l}$ of each sample was then loaded onto a $10 \%$ polyacrylamide gel (99:1 acrylamide: bisacrylamide) containing $7.5 \%$ urea and $1 \mathrm{X}$ Tris-Borate-EDTA (TBE). Gels were pre-run at $700 \mathrm{~V}$ for 60 minutes at room temperature in $1 \mathrm{X}$ TBE prior to loading the samples.

Electrophoresis was carried out at $450 \mathrm{~V}$ for $12-15$ hours - the precise times were dependent upon the size of the PCR fragments being analysed. Following electrophoresis, DNA fragments were detected by silver staining (Promega Biotechnology, UK) and any variant bands identified. 


\begin{tabular}{lll}
\hline \multicolumn{3}{c}{ Tab. 1 - Results of Factor VII assays } \\
& $\begin{array}{ll}\text { Factor VII Antigen } \\
\text { (Normal range: }\end{array}$ & $\begin{array}{l}\text { Factor VI Activity } \\
\text { (Normal range: }\end{array}$ \\
& $0.8-1.2 \mathrm{u} / \mathrm{ml})$ & $0.8-1.2 \mathrm{u} / \mathrm{ml})$ \\
\hline Index & $<0.0001$ & $<0.01$ \\
Mother & 0.56 & 0.53 \\
Father & 0.52 & 0.43
\end{tabular}

Direct sequencing of $\mathrm{PCR}$ products was performed using an Applied Biosystems 377 DNA sequencer with the amplification primers employed as sequencing primers.

\section{Results}

Case history and coagulation studies: The index case, the offspring of a consanguineous marriage between first cousins, is a 5-year-old-male of Chinese origin. The child was born by normal vaginal delivery and there were no developmental problems associated with the neonatal or perinatal periods. At the age of 8 months and again at 18 months he presented with severe bleeding from the gastrointestinal tract. However, the diagnosis of factor VII deficiency was not made until the age of 3 years when he presented with recurrent bleeding problems-haematuria, haemarthroses, muscle and soft tissue haematomas and bleeding from the gastrointestinal tract. Many of these bleeding problems were spontaneous or occurred in relation to minor trauma. Investigations showed a prolonged prothrombin time, a normal activated partial thromboplastin time and markedly reduced factor VII activity and antigen levels at less than $0.01 \mathrm{u} / \mathrm{ml}$ and $0.0001 \mathrm{u} / \mathrm{ml}$ respectively, consistent with severe factor VII deficiency (Table 1). Screening of the father and mother showed factor VII activity levels of $0.43 \mathrm{u} / \mathrm{ml}$ and $0.53 \mathrm{u} / \mathrm{ml}$ and factor VII antigen levels of $0.52 \mathrm{u} / \mathrm{ml}$ and $0.56 \mathrm{u} / \mathrm{ml}$ respectively. The proband has four adolescent sisters but all have declined to have their factor VII levels measured. There was no family history of a bleeding diathesis.

Following diagnosis, treatment was instituted with fresh frozen plasma (FFP) with a maximum daily dose of 2 units every 12 hours. The patient received a total of 301 units of FFP and 6 units of packed red cells over the subsequent 12 months reflecting the severity of his bleeding diathesis. As a result of the problems of circulatory overload associated with the use of large volumes of FFP, replacement therapy with a plasma-derived factor VII concentrate was commenced at a dose of $500 \mathrm{u}(32 \mathrm{u} / \mathrm{kg})$ every 12 hours. Following the introduction of factor VII concentrates, his bleeding problems rapidly resolved. After 5 months of prophylactic treatment, factor VII concentrates were stopped and further treatment was given whenever the child was symptomatic. To date he remains well.

Mutational analysis: To identify the mutation in this family, the entire coding region of the factor VII gene was amplified and screened for mutations by SSCP. SSCP analysis revealed a mobility difference between control and patient in PCR fragments that encompassed exon 1a. Furthermore, the absence of a normal pattern of bands suggested that this was a 
Fig. 1 - Nucleotide sequence of exon 1 a.

G C T C C T C T G C C T T T G C T T G

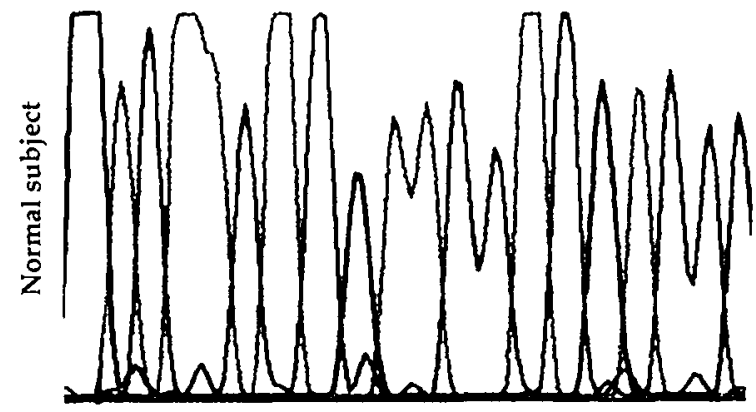

GCTCCTGCCT TCT TCT T G

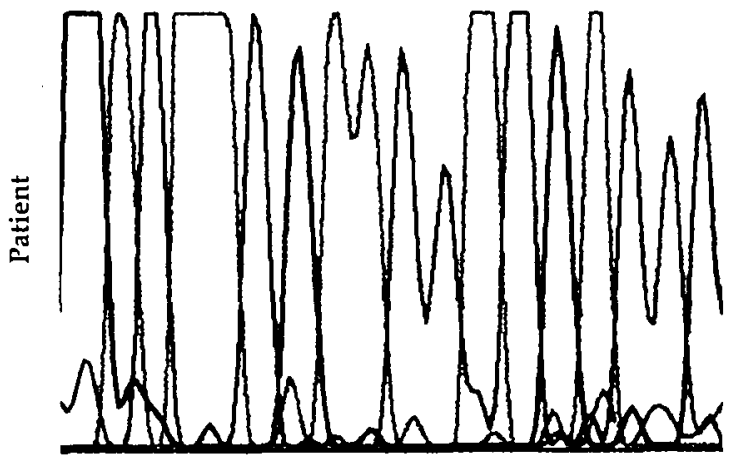

(A) Normal sequence - the ' $C T$ ' dinucleotide that is deleted is underlined. (B) Sequence from the index case showing a homozygous deleted 'CT' dimucleotide. homozygous mutation. Direct sequence analysis of this region revealed the index case to be homozygous for a $2 \mathrm{bp}$ deletion (nucleotides 27/28:-CT) in exon 1 a at codon $-52 / 51$ (Figure 1 ), a region that encodes part of the prepropeptide of factor VII. Sequence analysis of both parents confirmed that they were both heterozygous for the $2 \mathrm{bp}$ deletion mutation.

\section{Discussion}

This paper de-scribes a novel mutation in the human factor VII gene that is associated with undetectable circulating plasma factor VII. The mutation is a $2 \mathrm{bp}$ deletion (CT) in exon 1a (codon-52/-51) and is located in the prepro-leader sequence of factor VII. Factor VII is synthesised with a prepro-leader sequence of either 60 or 38 amino acids, a difference which arises from alternative splicing of exon 1a/1b (11). Ap-proxima-tely $90 \%$ of factor VII mRNA transcripts lack exon $1 \mathrm{~b}$ and contain only exon 1a. In transcripts which exclude exon $1 \mathrm{~b}$, the $2 \mathrm{bp}$ deletion results in a frameshift and the creation of a premature stop codon at residue 83 conserving only the $\mathrm{N}$-terminal 9 amino acids of the normal prepropeptide se-quence. The remaining 74 amino acids encoded by this sequence share no homology with any of the mature factor VII protein or indeed of the other vitamin $\mathrm{K}$ dependent clotting factors. In contrast, in the small number of transcripts that include both 


\section{Chapter 3 -Molecular studies}

exon $1 \mathrm{a}$ and $1 \mathrm{~b}$, the mutation results in the creation of a stop codon at position 25 but again only the $\mathrm{N}$-terminal 9 amino acids of the normal propeptide sequence are conserved.

Our current understanding of blood coagulation in man suggests that a failure to initiate coagulation through the binding of tissue factor to factor VII is likely to be incompatible with life. This theory is supported by the recently described factor VII knockout mouse which, although developing normally to term, dies shortly at/or after birth from major abdominal and intracranial haemorrhage (12). In addition, in the case reported by McVey and colleagues (8) a homozygous splice site mutation in the factor VII gene appeared to be associated with a complete absence of factor VII resulting in a fatal intracerebral haemorrhage at the age of 14 days. The authors, on the basis of this data, have concluded that the complete absence of factor VII is incompatible with life (8)

In the case we have described, bleeding symptoms did not develop until the age of 8 months and the diagnosis was not made until the age of 3 years, although the subsequent coagulation data were consistent with severe factor VII deficiency. It is unclear why there is such a marked difference in clinical manifestations between this case and that described by McVey and colleagues (8) or the factor VII knockout mouse model. The possibility that a mechanism might exist to partially correct the 2 bp deletion mutation was considered.
Transcriptional errors restoring the reading frame and/or ribosomal slippage during translation, have been shown to partially correct the molecular defect in severe haemophilia $\mathrm{A}$ and other inherited disorders, resulting in a less severe clinical phenotype $(13,14)$. Such mutations have, to date, involved the deletion of only a single nucleotide that occurs in a sequence of identical bases. In addition the correction results in the presence of functionally active protein. The $2 \mathrm{bp}$ deletion within the factor VII gene reported in this paper involves non-identical nucleotides and does not occur in a run of similar bases. In addition, the absence of any detectable factor VII antigen in plasma of the index case using a sensitive IRMA assay (capable of detecting factor VII antigen as low as $0.0001 \mathrm{u} / \mathrm{ml}$ ), would argue against this hypothesis. A second mutation within the factor VII gene to correct the frame-shift was also considered. However, such a mutation would have to occur within the pre-pro-peptide to allow efficient post-translational modification and subsequent export of the protein.

It is possible that some alternative mechanism exists that in part corrects the clinical phenotype. This may involve the activation of coagulation through factor XII or through some novel serine protease but at present this is speculation.

In summary, we report the first case of a homozygous mutation in the prepropeptide coding region of the factor VII gene. This 2 bp deletion mutation leads to the creation 
of a premature stop codon, and to the complete absence of factor VII activity and antigen. In contrast with a recent publication by McVey (8) our finding indicates that such a mutation resulting in an absence of factor VII in plasma, is not incompatible with life.

\section{References}

1. Bajaj SP, Rapaport SI, Brown SF: Isolation and characterization of human factor VII. Activation of factor VII by factor Xa. $J$ Biol Chem 1981; 256: 253-9.

2. Hagen FS, Gray CL, O'Hara P, Grant FJ, Saari GC, Woodbury RG, et al: Characterization of a cDNA coding for human factor VII. Proc Natl Acad Sci USA 1986; 83: 2412-6.

3. O'Hara PJ, Grant FJ, Haldeman BA, Gray CL, Insley MY, Hagen FS, et al: Nucleotide sequence of the gene coding for human factor VII, a vitamin K-dependent protein participating in blood coagulation. Proc Natl Acad Sci USA 1987; 84: 5158-62.

4. Edgington TS, Mackman N, Brand K, Ruf W: The structural biology of expression and function of tissue factor. Thromb Haemost 1991; 66: 67-79.

5. Camerer E, Kolstá AB, Prydz H: Cell biology of tissue factor, the principal initiator of blood coagulation. Thromb Res 1996; 81: 1-41.

6. Triplett DA, Brandt JT, Batard MA, Dixon JL, Fair DS: Hereditary factor VII deficiency: heterogeneity defined by combined functional and immunochemical analysis. Blood 1985; 66: $1284-7$.

\section{Acknowledgements}

This work was supported by the Katharine Dormandy Trust for Haemophilia and Allied Disorders and the Fondazione Angelo Bianchi Bonomi. We are grateful to Professor EGD Tuddenham for helpful suggestions and comments.

7. Peyvandi F, Mannucci PF, Asti D, Abdoullahi M, Di Rocco N, Sharifian R: Clinical manifestations in 28 Italian and Iranian Patients with Severe Factor VII Deficiency. Haemophilia 1997; 3: 242-6.

8. McVey JH, Boswell EJ, Takamiya O, Tamagnini G, Valente V, Fidalgo T, et al: Exclusion of the First EGF Domain of Factor VII by a Splice Site Mutation Causes Lethal Factor VII Deficiency. Blood 1998; 92: 920-6.

9. Poggio M, Tripodi A, Mariani G, Mannucci PM: Factor VII Clotting Assays: Influence of Different Thromboplastins and Factor VII Deficient plasmas. Thromb Haemost 1991; 65: 160.4.

10. Coppola R, Tombesi S, Valentini F, Alborali $S$, Albertini A, Mannucci PM: Enzyme-linked immunosorbent assay of human factor VII based upon a monoclonal antibody that recognizes the native conformation of the protein. Thromb Res 1992; 68: 283-93.

11. Berkner K, Busby S, Davie E, Hart C, Insley $\mathrm{M}$, Kisiel W, et al: Isolation and expression of cDNAs encoding human factor VII. Cold Spring Harb Symp Quant Biol 1986; 51 Pt 1: 531 41. 
Chapter 3 -Molecular studies

12. Rosen ED, Chan JC, Idusogie E, Clotman F, Vlasuk G, Luther T, et al: Mice lacking factor VII develop normally but suffer fatal perinatal bleeding. Nature 1997; 390: 290-4.

13. Linton MF, Pierotti V, Young SG: Readingframe restoration with an apolipoprotein $B$ gene frameshift mutation. Proc Natl Acad Sci
USA 1992; 89: 11431-5.

14. Young $M$, Inaba $H$, Hoyer LW, Higuchi $M$, Kazazian HH, Jr., Antonarakis SE: Partial correction of a severe molecular defect in hemophilia A, because of errors during expression of the factor VIII gene. Am J Hum Genet 1997; 60: 565-73. 


\section{Characterization of two naturally occurring mutations in the second epidermal growth factor-like domain of factor VII}

M. Hunault', A.A. Arbini', J.A. Carew' ${ }^{1}$, F. Peyvandi', and K.A. Bauer ${ }^{1.2}$

${ }^{1}$ Hematology-Oncology Section, Department of Medicine, Brockton-West Roxbury Department of Veterans Affairs Medical Center, West Roxbury, MA; ${ }^{2}$ Beth Israel Deaconess Medical Center, Harvard Medical School, Boston, MA;

${ }^{3}$ A. Bianchi Bonomi Hemophilia and Thrombosis Center, Department of Internal Medicine, IRCCS Ospedale Maggiore, University of Milan, Milan, Italy

Blood 93: 1237-1244, 1999 


\section{Chapter 3 -Molecular studies}

Abstract
We investigated the mechanisms responsible for severe factor VII (FVII) deficiency in homozygous Italian patients with either Gly ${ }^{97}$ Cys or Gln ${ }^{100}$ Arg mutations in the second epidermal growth factor domain of FVII. Transient expression of complementary DNA coding for the mutations in COS-1 cells showed impaired secretion of the mutant molecules. Using stably transfected Chinese hamster ovary (CHO) cells, we performed pulse-chase labeling studies, immunohistochemistry, and experiments with inhibitors of protein degradation, showing that FVII-Cys ${ }^{97}$ did not accumulate intracellularly but was degraded in a pre-Golgi, nonlysosomal compartment by a cysteine protease. In stably transfected CHO cells expressing FVII-Arg ${ }^{100}$, the level of intracellular FVII was not increased by several inhibitors of protein degradation, but FVII-Arg ${ }^{100}$ was retained in the endoplasmic reticulum for a longer period of time than wild-type FVII. FVII-Arg ${ }^{100}$ had a lower apparent molecular weight than did wild-type FVII under nondenaturing conditions, which is attributable to misfolding due to abnormal disulfide bond formation.

\section{Introduction}

Human factor VII (FVII) is a vitamin Kdependent glycoprotein that normally circulates in plasma at a concentration of 0.5 $\mu \mathrm{g} / \mathrm{mL}$.(1) FVII in association with tissue factor initiates blood coagulation by activating factor IX and factor $\mathrm{X}(2,3)$. The mature FVII molecule is a single chain of 406 amino acids and is comprised of several discrete domains including the Gla domain, two epidermal growth factor (EGF)-like domains and a large catalytic domain(4). It undergoes several post-translational modifications before its secretion by the liver including $\gamma$-carboxylation of 10 glutamic acid residues in the Gla domain, $\mathrm{N}$-glycosylation of residues $\mathrm{Asn}^{145}$ and $\mathrm{Asn}^{32 z}(5)$ and O-glycosylation of residues $\mathrm{Ser}^{52}$ and $\operatorname{Ser}^{60}$ in the first EGF domain(6). Hereditary FVII deficiency is a rare autosomal recessive bleeding disorder $(7,8)$. Patients with FVII deficiency have been classified with respect to the plasma level of FVII antigen (VII:Ag) or crossreacting material (CRM) as either $\mathrm{CRM}^{-}$(low or absent antigen), $\mathrm{CRM}^{\mathrm{R}}$ (reduced antigen), or $\mathrm{CRM}^{+}$(normal antigen). More than 30 different naturally occurring mutations in the FVII gene have been reported(9). Most are point mutations that alter FVII function, but others interfere with FVII biosynthesis. In this paper, we investigated the mechanisms responsible for FVII deficiency in two homozygous Italian patients who were $\mathrm{CRM}^{-}$and $\mathrm{CRM}^{\mathrm{R}}$ as a result of mutations in the molecule's second EGF domain.

\footnotetext{
Materials and methods Collection and processing of blood samples. Blood was collected by atraumatic venipuncture into plastic tubes containing $1 / 10$ th volume $0.129 \mathrm{~mol} / \mathrm{L}$ buffered trisodium citrate.

Plasma was obtained by centrifugation at
} 


\section{Rare Coagulation Disorders}

$2,500 \mathrm{~g}$ for 15 minutes at $4^{\circ} \mathrm{C}$, transferred into plastic tubes, and stored along with the cellular elements at $-80^{\circ} \mathrm{C}$ until use.

FVII assays. FVII coagulant activity (VII:C) and VII:Ag were measured by onestage clotting assay using recombinant human tissue factor (RecombiPlastin, Ortho Diagnostic Systems, Raritan, NJ) and an enzyme-linked immunoabsorbent assay (ELISA) (American Bioproducts $\mathrm{Co}$, Parsippany, NJ), respectively. A normal pool was constructed by mixing equal volumes of plasma from 30 healthy control subjects.

DNA isolation and in vitro amplification using polymerase chain reaction $(P C R)$. DNA was purified by standard techniques from leukocyte nuclei obtained from whole blood(10). Oligonucleotides and PCR conditions used to amplify the entire coding sequence of the FVII gene have been described in detail(11). PCR amplifications (12) were performed using a DNA Thermal Cycler (Perkin Elmer Cetus, Norwalk, CT). PCR products were generated in $20 \mu \mathrm{L}$ reaction mixtures that contained $200 \mathrm{ng}$ of genomic DNA, $0.4 \mathrm{U}$ of Taq DNA polymerase (Perkin Elmer Cetus), oligonucleotide primers at a concentration of $0.5 \mu \mathrm{mol} / \mathrm{L}$ each, dNTPs at a concentration of $100 \mu \mathrm{mol} / \mathrm{L}$ each, $1 \mathrm{mmol} / \mathrm{L} \mathrm{MgCl}_{2}$, $10 \mathrm{mmol} / \mathrm{L}$ Tris $-\mathrm{HCl}, \mathrm{pH} 8.3,50 \mathrm{mmol} / \mathrm{L}$ $\mathrm{KCl}$, and $0.01 \mathrm{mg} / \mathrm{mL}$ of autoclaved gelatin.

Cloning and sequencing of PCR fragments. Amplified PCR fragments were purified and ligated into PT7Blue T-vec- tors (Novagen, Madison, WI). Cloned inserts were sequenced by the dideoxy chain termination method on an Applied Biosystems 373A DNA Sequencer (Foster City, CA). All sequence alterations were confirmed in at least two independent clones. Sequence analyses were performed using the GCG Sequence Analysis Software Package (Genetics Computer Group, Inc, Madison, WI) from the Molecular Biology Computer Research Resource (Boston University, Boston, MA). Restriction enzyme analysis. Restriction enzyme digestion of PCR fragments was used to detect mutations that introduced or abolished a restriction site. Ten $\mu \mathrm{L}$ of PCR-amplified product were digested with $0.5 \mathrm{U}$ of enzyme in a final volume of $20 \mu \mathrm{L}$ for 16 hours. Restriction fragments were subjected to electrophoresis in nondenaturing $8 \%(\mathrm{wt} / \mathrm{vol})$ polyacrylamide gels. After completion of the electrophoretic procedure, gels were stained in $0.5 \mu \mathrm{g} / \mathrm{mL}$ ethidium bromide for 5 minutes and photographed under ultraviolet (UV) transillumination.

Antibodies. The production and purification of Mab1476,(13) a murine monoclonal antibody $(\mathrm{MoAb})$, which recognizes an epitope in the aminoterminal region of FVII, has been described(14). This antibody was used to detect FVII in pulse-chase experiments and for immunohistochemistry.

Construction of expression vectors and site-directed mutagenesis. A $2.4 \mathrm{~Kb}$ complete human FVII complementary DNA (cDNA)(4) with EcoRI/BamHI linkers at 
each end was provided by Dr Earl W. Davie (Seattle, WA).

This cDNA was cloned into the EcoRI site of the PT7-BlueT vector to obtain the plasmid PT7 ${ }^{\text {EcoRIFVIIwt }}{ }^{\text {EcoRI }}$ and subsequently modified as previously reported to obtain PT7 ${ }^{\text {sult }}$ FVIIwt ${ }^{\text {Feorl }}(14)$. The FVII cDNA was then isolated and cloned into $\mathrm{pED}-\mathrm{mtx}^{\mathrm{r}}$ provided by Dr Randal J. Kaufman (15) to obtain the plasmid pEDFVIIwt, a dicistronic messenger RNA mammalian expression vector carrying the dihydrofolate reductase (DHFR) gene at the 3 open reading frame. To investigate the influence of the Gly ${ }^{97} \mathrm{Cys}$ and Gln ${ }^{100} \mathrm{Arg}$ substitutions on FVII levels, pEDFVIICys ${ }^{97}$ and pEDFVIIArg ${ }^{100}$ were obtained by site-directed mutagenesis of PT7SalIFVIIwt ${ }^{\text {EcoRI }}$ using a commercially available kit (Transformer Site-Directed Mutagenesis Kit, Clontech, Palo Alto, CA). Oligonucleotides(5'-GAACGGCT GCTG TGAGCAGTACTGCAGTGATCACACG-3') and (5'-GAACGGCGGCTGTGAGCGTAC TGCAGTGATCACACG-3') spanning nucleotides 7817 to 7853 of the human FVII cDNA were used to introduce a $\mathrm{G}$ to $\mathrm{T}$ at position 7824 and an $A$ to $G$ at position 7834 (bold letters) coding for Gly ${ }^{97} \mathrm{Cys}$ or Gln ${ }^{100} \mathrm{Arg}$, respectively. These primers also introduced a $B c l$ I restriction site (underlined), arising from a silent GAC to GAT mutation at nucleotide 7847 , to facilitate screening for clones carrying the mutations. The mutant FVII cDNA were then inserted into the $\mathrm{pED}$ expression vector to obtain pEDFVIICys ${ }^{9 \tau}$ and pEDFVIIArgive.
Several restriction enzyme digests were performed to confirm that we had produced vectors containing the mutations. A $S a l$ I-EcoRI digest released a $2.4 \mathrm{~kb}$ fragment containing the complete FVII cDNA and $1.2 \mathrm{~kb}$ of the gene's $3^{\prime}$ untranslated region, thereby confirming that the entire cDNA had been introduced into the vector. A HindIII digest of the vector generated three fragments of 955,2735 , and $4000 \mathrm{bp}$ resulting from three sites in $\mathrm{pED}$ and none in the FVII cDNA. EcoRI digestion linearized the $7.7 \mathrm{~kb}$ construct $(5.3 \mathrm{~kb}$ pED+ insert $2.4 \mathrm{~kb} c \mathrm{cNA}$ ) by cleavage at a single site in $\mathrm{pED}$. To confirm the presence of the mutations, we amplified from the construct a $893 \mathrm{bp}$ fragment with the oligonucleotides 5'-CCCGGTCGACTCAACAGG CAGGGGCAGCACT-3' (position -94 to -74) introducing a Sal I site (bold letters) and 5'-CAGGCGGAGCAGCG-3' (position 10648-10661 in exon 8). This PCR product coded for the first 248 amino acids of FVII excluding exon $1 \mathrm{~b}$. Because the mutagenic primers introduced a $B c l$ I site in addition to the mutation, a $B c l$ I digest of the product gave two fragments of 695 and $198 \mathrm{bp}$ for the FVIIwt construct, whereas the FVIICys $^{97}$ and FVIIArg 100 constructs yielded fragments of 458,237 , and $198 \mathrm{bp}$ confirming that the mutations had been introduced. Moreover, because the $\mathrm{G}$ to $\mathrm{T}$ transversion at position 7824 resulting in Gly ${ }^{97}$ Cys introduces a $B b v$ I site, $B b v$ I digestion of the $893 \mathrm{bp}$ fragment from pEDFVIICys ${ }^{9 z}$ led to the generation of a $713 \mathrm{bp}$ product that was cleaved into pie- 
ces of 445 and $268 \mathrm{bp}$ in the presence of the mutation. As the $A$ to $G$ transversion at position 7834 resulting in $\mathrm{Gln}^{100} \mathrm{Arg}$ introduces a ${ }^{\mathrm{Bs}} \mathrm{BI}$ site, ${ }^{\mathrm{B} s \mathrm{Br}} \mathrm{BI}$ digestion of the 893 bp product from $p$ EDFVIIArg 100 generates fragments of 447 and $446 \mathrm{bp}$ fragments in the presence of the mutation.

\section{Cell culture and transfection assays.}

For transient transfection experiments, Monkey COS-1 cells (ATCC CRL1650; American Type Culture Collection, Rockville, MD) were maintained in Dulbecco's Modified Eagle's Medium (DMEM) supplemented with $10 \%(\mathrm{vol} / \mathrm{vol})$ fetal bovine serum (FBS), $2 \mathrm{mmol} / \mathrm{L} \mathrm{L}$-glutamine, $10 \mathrm{mmol} / \mathrm{L}$ HEPES $\mathrm{pH} 7.2,100$ units $/ \mathrm{mL}$ of penicillin $\mathrm{G}, 100 \mu \mathrm{g} / \mathrm{mL}$ streptomycin, and $5 \mu \mathrm{g} / \mathrm{mL}$ of vitamin $\mathrm{K} 1$ (AquaMEPHYTON, Merck \& Co Inc, West Point, PA) in a $5 \% \mathrm{CO}_{2}$ atmosphere at $37^{\circ} \mathrm{C}$. Twenty hours before transfection, COS- 1 cells were plated on $60 \mathrm{~mm}$ culture dishes at a density of $1 \times 106$ cells/dish. Five micrograms of the pEDFVII constructs was transfected into cells by Lipofectamine (GIBCO-BRL, Gaithersburg, $M D)$ according to the manufacturers' instructions. After 16 hours, medium was changed, and 36 hours later, supernatants and cell lysates were harvested and assayed for VII:C and VII:Ag. Results of transient assays are expressed as the percentage of FVIIwt and represent the mean $\pm \mathrm{SE}$.

To obtain stable cell lines expressing recombinant FVIIwt, FVIICys ${ }^{97}$, and FVIIArg ${ }^{100}$, we used DHFR-deficient
Chinese ovary (CHO) cells (CHO-DUKXB11)(16) provided by Dr Barbara C. Furie (Boston, MA). These cells were grown in alpha-modified essential medium (AMEM) supplemented with $10 \% \mathrm{FBS}, 2 \mathrm{mmol} / \mathrm{L} \mathrm{L}$ glutamine, $10 \mathrm{mmol} / \mathrm{L}$ HEPES $\mathrm{pH} 7.2,100$ units $/ \mathrm{mL}$ of penicillin $\mathrm{G}, 100 \mu \mathrm{g} / \mathrm{mL}$ streptomycin, $5 \mu \mathrm{g} / \mathrm{mL}$ of vitamin $\mathrm{K} 1,10 \mu \mathrm{g} / \mathrm{mL}$ adenosine, $10 \mu \mathrm{g} / \mathrm{mL}$ deoxy-adenosine, and $10 \mu \mathrm{g} / \mathrm{mL}$ thymidine. CHO-DUKX-B11 cells were plated on 100-mm culture dishes at a density of $3 \times 106$ cells/dish. Transfections were performed as described above with $20 \mu \mathrm{g}$ of plasmid and $45 \mu \mathrm{L}$ of Lipofectamine. Two days after transfection, cells were divided at a 1 to 8 ratio and selected for DHFR expression using medium deficient in ribonucleosides and deoxyribonucleosides. Twelve days after transfection, 24 colonies were picked at random and isolated in 12 -well $(24 \mathrm{~mm})$ plates. At day 20, when the cells achieved confluence, each well was split into two 35 $\mathrm{mm}$ dishes. Two days later, cell lysates of the wells were harvested and assayed for VII:Ag. A single clone stably transfected with each construct and expressing high levels of FVII was selected for further experiments. The rates of intracellular FVII synthesis for the selected clones expressing FVIIwt, FVIICys ${ }^{97}$, and FVIIArg 100 were $33.3 \pm 2.1,52.5 \pm 5.8$, and $47.7 \pm 5.5 \mathrm{ng} / \mathrm{mL} / \mathrm{h}$ (mean $\pm \mathrm{SEM}, \mathrm{n}=9$ ), respectively.

Metabolic labeling studies. Nearly confluent $60 \mathrm{~mm}$ dishes of $\mathrm{CHO}$ cells stably expressing recombinant FVII were used 
for pulse-chase experiments. Fresh media with FBS was added 4 hours before cells were deprived of methionine for $45 \mathrm{minu}$ tes and labeled for 15 minutes with $0.4 \mathrm{~mL}$ of methionine-free AMEM (GIBCO-BRL, Gaithersburg, MD) containing $110 \mu \mathrm{Ci}$ Expre $^{35}$ S Protein Labeling Mix ( $73 \%$ L$\left[{ }^{3 i} \mathrm{~S}\right]$ methionine and $\sim 22 \% \mathrm{~L}-\left[{ }^{35} \mathrm{~S}\right]$ cysteine; DuPont NEN Research Products, Billerica, $\mathrm{MA})$ in a $5 \% \mathrm{CO}_{2}$ atmosphere at $37^{\circ} \mathrm{C} . \mathrm{A}$ chase was then performed in $1 \mathrm{~mL}$ medium containing an excess of unlabeled $L$ methionine (GIBCO-BRL, Gaithersburg, MD) for various time periods. At each time point, medium was harvested and phenylmethyl sulfonyl fluoride (PMSF) added to a final concentration of $1 \mathrm{mmol} / \mathrm{L}$. Cell extracts were prepared in $350 \mu \mathrm{L}$ ice-cold NP-40 lysis buffer $(50 \mathrm{mmol} / \mathrm{L} \mathrm{NaCl}, 50$ $\mathrm{mmol} / \mathrm{L}$ Tris $\mathrm{pH} 8.0,1 \%(\mathrm{wt} / \mathrm{vol}) \mathrm{NP}-40$ ) supplemented with $1 \mathrm{mmol} / \mathrm{L}$ PMSF. The cell lysates were precleared overnight at $4^{\circ} \mathrm{C}$ with $50 \mu \mathrm{L}$ of $20 \%$ (vol/vol) fixed Staphylococcus aureus. Cowan I (SAC) coupled with a rabbit antimouse IgG (Sigma, St Louis, MO) in NP-40 lysis buffer. Immunoprecipitation of FVII was accomplished by incubating precleared cell lysates and conditioned media with $4 \mu \mathrm{g}$ of MoAb MC1476 for 2 hours at $4^{\circ} \mathrm{C}$. The resulting immune complexes were adsorbed with $30 \mu \mathrm{L}$ of $20 \%$ (vol/vol) Protein A Sepharose FF (Sigma) coupled 5:1 (vol/vol) with rabbit antimouse IgG antiserum in NP-40 lysis buffer. Pellets were washed four times in NP-40 lysis buffer and resuspended either in buffer for further enzy- matic digestion (see below) or in polyacrylamide gel electrophoresis (PAGE) sample buffer with or without reducing agents, and denatured by heating to $95^{\circ} \mathrm{C}$ for 5 minutes. The immunoprecipitated proteins were resolved by sodium dodecyl sulfate (SDS)-PAGE in $8 \%$ (wt/vol) gels, and analyzed by fluorography on X-OMAT-AR film (Eastman-Kodak Co, Rochester, NY) after treatment with $\mathrm{En}^{3} \mathrm{H}$ ance (DuPont NEN Research Products, Billerica, MA). To quantitate the relative amount of FVII immunoprecipitated at each time, the radioactivity incorporated into bands containing FVII was analyzed with the Umax PowerlookII Imaging Analyzer (Umax Data System Inc, Taiwan).

Immunohistochemistry. CHO cell lines expressing FVII were grown overnight at 150,000 cells/glass coverslip (Baxter Scientific products, McGawpark, IL). The coverslips were washed once in phosphatebuffered saline (PBS) and fixed for 1 hour in $3 \%(\mathrm{vol} / \mathrm{vol})$ paraformaldehyde (Fisher Scientific, Pittsburgh, PA) in PBS. The cells were sequentially washed, permeabilized for 3 minutes in $0.1 \%$ (vol $/ \mathrm{vol}$ ) Triton X-100 (Sigma), and washed three more times. They were then incubated in $0.15 \%$ (wt/vol) glycine containing $0.1 \%(\mathrm{wt} / \mathrm{vol})$ bovine serum albumin (BSA) for 15 minutes followed by anti-FVII Mab $(4 \mu \mathrm{g}$ in 0.5 $\mathrm{mL}$ of PBS containing $1 \%$ BSA) for 30 minutes. The cells were again washed three times and then incubated with fluorescein isothiocyanate (FITC)-labeled goatantimouse IgG (1/1000 in PBS containing 
1\% BSA) (Cappel, Durham, NC) for 30 minutes. After further washing, the coverslips were mounted on glass slides with Airvol (Air Products, Allentown, PA). Immunofluorescence microscopy was performed on a Zeiss axioplan fluorescence microscope at $630 \times$ magnification (Zeiss, 'Thornwood, NY).

\section{Effect of protein degradation inhibi-} tors on FVIIwt, FVIICys97, and FVIIArg 100 levels. To study the effect of various protein degradation inhibitors on FVII biosynthesis, confluent stably transfected CHO cells grown in $60 \mathrm{~mm}$ dishes were incubated with media containing either lactacystin $(10 \mu \mathrm{mol} / \mathrm{L})$ (Calbiochem, La Jolla, CA), ammonium chloride (50 $\mathrm{mmol} / \mathrm{L})$, leupeptin $(100 \mu \mathrm{mol} / \mathrm{L}), \mathrm{N}$-acetylLeu-Leu-Norleucinal $(50 \mu \mathrm{g} / \mathrm{mL})$, or brefel$\operatorname{din} \mathrm{A}(10 \mu \mathrm{g} / \mathrm{mL})$ (Sigma) dissolved according to the manufacturers' recommendations and used at previously published concentrations(17-21). Four hours later, cell lysates were harvested and assayed for VII:Ag.

Analysis of N-linked glycosylation and sialation. Immunoprecipitated proteins were incubated with $100 \mathrm{mU} / \mathrm{mL}$ Endo- $\beta$ $\mathrm{N}$-acetylglucosaminidase $\mathrm{H}$ (Endo $\mathrm{H}$ ) or $9.4 \mathrm{U} / \mathrm{mL}$ Peptide- $\mathrm{N}^{4}$-(N-acetyl- $\beta$-glucosaminyl) asparagine amidase ( $\mathrm{N}$-glycanase) for 18 hours at $37^{\circ} \mathrm{C}$ according to the manufacturer's instructions. For sialation analysis, immunoprecipitated proteins were incubated for 1 hour at $37^{\circ} \mathrm{C}$ with 4 $\mathrm{U} / \mathrm{mL}$ neuraminidase in $1 \mathrm{mmol} / \mathrm{L} \mathrm{PMSF}$, $20 \mathrm{mmol} / \mathrm{L}$ Tris-maleate $\mathrm{pH} 6.0,10 \mathrm{mmol} / \mathrm{L}$ calcium acetate, and $1.75 \%$ (vol $/ \mathrm{vol})$ NP- 40 . All enzymes were from Genzyme (Cambridge, MA). The reactions were terminated by adding 5x PAGE sample buffer, and were analyzed by SDS-PAGE.

Informed consent. Informed consent to perform research studies was obtained from the patients. The study was approved by the Human Studies Committee of the Brockton-West Roxbury VA Affairs Medical Center.

\section{Results}

Patients and genomic studies. We investigated the molecular defects in two Italian patients with FVII deficiency. Patient 1 is a 28 -year-old male with a mild hemorrhagic diathesis manifested by epistaxis and excessive bleeding after dental extractions (22). Patient 2 is a 53 -year-old woman with severe bleeding evidenced by recurrent hemarthrosis with chronic arthropathy and an episode of cerebral hemorrhage(22). The levels of VII:Ag and VII:C in the two patients were $2 \%$ and less than $1 \%$ of normal and $12 \%$ and less than $1 \%$ of normal, respectively (Table 1 ).

For each patient, we subcloned and sequenced the entire coding region and the exon/intron boundaries of the FVII gene as well as its $5^{1}$-flanking region. In patient 1 , a $\mathrm{G}$ to $\mathrm{T}$ transition at position 7824 (GGC to $\mathrm{TGC}$ ) and a $\mathrm{C}$ to $\mathrm{T}$ transition at position 7880 (CAC to CAT) in exon 5 were identified resulting in $\mathrm{Gly}^{97} \mathrm{Cys}$ and a neutral dimorphism in the codon for His ${ }^{115}$, respectively. Two previously described 
Tab. 1 - Coagulation data and genetic alterations in two italian patients with FVII deficiency

\begin{tabular}{lllllll} 
Patient & VII:Ag (\%) & VII:C (\%) & Gly97Cys & Gln100Arg & Arg353Gln & -323 Insert \\
\hline 1 & 2 & $<1$ & $+/+$ & - & $+/+$ & $+/+$ \\
2 & 12 & $<1$ & $-/-$ & $+/+$ & $-\%$ & $-/-$ \\
\hline
\end{tabular}

Presence or absence of the sequence alteration in eadt allele is denoted by + or -signs, respectively.

FVII polymorphisms known to influence FVII levels, a $\mathrm{C}$ to $\mathrm{A}$ substitution at position 10976 (CGG to $\mathrm{C} \underline{\mathrm{AG}}$ ) in exon 8 resulting in Arg ${ }^{353} \mathrm{Gln}$ and the insertion of a decanucleotide at position -323 in the 5 -flanking region of the FVII gene, were also present. In patient 2, an $\mathrm{A}$ to $\mathrm{G}$ transversion at position 7834 (CAG to CGG) in exon 5 resulting in Gln ${ }^{100} \mathrm{Arg}$ was identified. No alleles with wild-type sequence were identified in either patient. To definitively establish that the patients were homozygous, we tested for the presence of the various sequence alterations using restriction enzyme analysis. The $G$ to $T$ transversion at position 7824 , resulting in Gly ${ }^{97}$ Cys, introduces a single $B b v$ I site. Digestion of a $313 \mathrm{bp}$ PCR product spanning exon 5 with $B b v$ I generates fragments of 170 and $143 \mathrm{bp}$ in the presence of the mutation. The $A$ to $G$ transversion at position 7834 , resulting in $\mathrm{Gln}{ }^{100} \mathrm{Arg}$, introduces a $B s r \mathrm{BI}$ site and digestion with this enzyme generates fragments of 147 and $166 \mathrm{bp}$ in the presence of the mutation. Msp I restriction analysis was used to identify the $\operatorname{Arg}^{353} \mathrm{Gln}$ polymorphism(23), whereas the decanucleotide insert at position -323 was assessed by visualization of a $10 \mathrm{bp}$ difference in fragment size after EcoRI digestion of a PCR fragment spanning this region(24).
Based on the results of these restriction analyses (data not shown), pa-tient 1 was ho-mozygous for Gly" ${ }^{47}$ ys and the two polymorphisms whereas patient 2 was homozygous for only Gln ${ }^{1(1)} \mathrm{Arg}$ (Table 1).

Transient transfection assays in COS-1 cells. To investigate the influence of the Gly ${ }^{97} \mathrm{Cys}$ and $\mathrm{Gln}{ }^{100} \mathrm{Arg}$ substitutions on FVII biosynthesis, transient transfections were performed in COS-1 cells using the dicistronic $\mathrm{pED}$ vectors containing either wild-type or mutant FVII cDNAs. Assays of VII:Ag in cell lysates showed that FVIICys $^{17}$ and FVIIArg ${ }^{1(x)}$ were reduced to $38 \%$ and $54 \%$ of FVIIwt, respectively, whereas the levels in the conditioned media were decreased to $6.6 \%$ and $16.7 \%$ of FVIIwt, respectively $(n=8)$. The small amount of FVIICys ${ }^{97}$ released in to the media was functionally active as assessed by VII:C assay $(6.1 \% \pm 0.3 \%$ of $w t)$ because the level was similar to VII:Ag $(6.6 \% \pm$ $0.5 \%$ ). In contrast, the Gln ${ }^{100} \mathrm{Arg}$ mutation impaired the molecule's function because the VII:C level in the media $(2.8 \% \pm 0.2 \%)$ was considerably lower than VII:Ag (16.7\% $\pm 2.1 \%$ ) (Table 2).

Expression studies in stably transfected cell lines. Based on the results of the transient transfection experiments, it 
Tab. 2 - Transient expression assays of pEDFVIIwt, pEDFVIICys", and pEDFVIIArg ${ }^{100}$ in COS-1 Cells

\begin{tabular}{llll} 
& FVIIwt & FVIICys97 & FVIIArg100 \\
\hline Cell lysate, VIl:Ag & $100 \pm 2.8$ & $38.1 \pm 3.9$ & $54.6 \pm 3$ \\
Conditioned media, VII:Ag & $100 \pm 3$ & $6.6 \pm 0.5$ & $16.7 \pm 2.1$ \\
Conditioned media, VII:C & $100 \pm 2.9$ & $6.1 \pm 0.3$ & $2.8 \pm 0.2$ \\
\hline
\end{tabular}

FVII levels were mensured in cell lysates and conditioned medin 36 hours after 8 independent transfections of cells from a single clone transfected with each construct. Results are expressed as the percentage of FVII (mean \pm SE) produced by the wild-type construct. the cell at 240 minutes. In the conditioned media, FVIIwt was barely detectable at 30 minutes and then proceeded to accumulate (Fig 1, bottom). The levels of FVIICys ${ }^{97}$ and FVIIArg ${ }^{100}$ were much lower than that of FVIIwt at all time points. At 240 minutes, the levels of FVIICys ${ }^{97}$ and FVIIArg ${ }^{100}$ in the media were appeared that the Gly ${ }^{97} \mathrm{Cys}$ and Gln ${ }^{100} \mathrm{Arg}$ mutations led to impaired FVII biosynthesis. To study these defects, pEDFVIIwt, pEDFVIICys ${ }^{9 i}$, and pEDFVIIArg ${ }^{100}$ were transfected into DHFR-deficient CHO cells to obtain stably transfected cell lines. It can be observed that the amounts of FVII in cell lysates of the stable cell lines transfected with $\mathrm{pEDFVIICys}{ }^{3 i}$ and $\mathrm{pEDFVIIArg}{ }^{10(x)}$ were actually greater than FVIIwt. This is attributable to the selection of high-level FVII producers. After a 15 minute pulse with $\left[{ }^{35} \mathrm{~S}\right]$ methionine, the recombinant FVIIwt in cell lysates was maximal at 30 to 60 minutes and decreased as the protein was secreted (Fig 1, top). FVIICys" was synthesized at a rate similar to FVIIwt with maximal accumulation at 60 minutes, but remained in the cell for a longer period of time. Approximately, $40 \%$ of the maximal amount of intracellular FVIICys ${ }^{97}$ was still present at 240 minutes as compared with $12 \%$ for FVIIwt (Fig 1, top). FVIIArg ${ }^{100}$ was retained intracellularly even longer with maximal accumulation at 60 to 120 minutes, and $55 \%$ of the protein was retained in
$30 \%$ and $16 \%$ of FVIIwt, respectively (Fig 1, bottom).

Using immunohistochemical techniques to detect intracellular VII:Ag, we found different patterns of localization for FVIIwt, FVIICys ${ }^{97}$, and FVIIArg ${ }^{100}$. Staining of FVIIwt (Fig 2A and B) and FVIICys ${ }^{97}$ (Fig $2 \mathrm{C}$ ) was mostly perinuclear suggesting that these molecules were localized primarily in the Golgi apparatus. In contrast, FVIIArgion (Fig 2D) staining was predominantly diffuse without perinuclear enhancement, suggesting that it was retained for a longer duration of time in the endoplasmic reticulum (ER) than the other recombinant proteins.

Whereas the acquisition of Endo $\mathrm{H}$ resistance is frequently employed to monitor protein transit to the Golgi complex from the $\mathrm{ER}$, the radioactive bands that were observed for FVIICys ${ }^{97}$ and FVIIArg ${ }^{100}$ in pulse-chase experiments were generally of low intensity that precluded interpretation of these experiments (data not shown).

Effects of protein degradation inhibitors on FVII biosynthesis. We next 
analyzed the effects of various inhibitors of protein degradation on intracellular FVII levels in stably transfected cells expressing FVIIwt, FVIICys ${ }^{97}$, and FVIIArg ${ }^{100}$. Inhibitors of lysosomal degradation, including $\mathrm{NH}_{4} \mathrm{Cl}$, which inactivates lysosomal enzymes by $\mathrm{pH}$ modification, and leupeptin, which inhibits cathepsins $\mathrm{B}, \mathrm{D}, \mathrm{H}$, and $\mathrm{L}$, did not increase intracellular FVII levels (Table 3) suggesting that FVIICys ${ }^{97}$ and FVIIArg ${ }^{100}$ were not degraded in the lysosome.

Lactacystin, a potent specific inhibitor of proteasome degradation, also did not increase FVII levels (Table 3). However, ALLN, a neutral inhibitor of the cysteine proteases, calpain, and cathepsin $\mathrm{D}$, induced a significant increase in FVIICys 97 levels (147\% with ALLN versus $100 \%$ without ALLN, $\mathrm{P}=.0004$ ) without altering the levels of FVIIwt or FVIIArg ${ }^{100}$. This data therefore suggested that FVIICys ${ }^{97}$ is degraded intracellularly.

To localize the site of degradation, we investigated the effect of brefeldin A on intracellular levels of FVII in the three cell lines. Brefeldin A blocks protein transport from the ER to the Golgi complex and causes translocation of Golgi components back to the ER. After incubation with brefeldin A, FVIIwt and FVIIArg 100 increased signi- ficantly within the cells to $190 \%$ and $151 \%$ of control levels, respectively, consistent with normal translocation of these two proteins from the ER to the Golgi in the absence of the drug. In contrast, the intracellular level of FVIICys ${ }^{97}$ increased only modestly in the presence of brefeldin A to $125 \%$ of control levels, thereby suggesting that the degradation of this molecule occurred primarily in a pre-Golgi compartment. Analysis of immunoprecipitates obtained after a 45 minute pulse with 110 $\mu \mathrm{Ci}\left[{ }^{35} \mathrm{~S}\right]$ methionine and 2 hours of chase in the presence and absence of $10 \mu \mathrm{g} / \mathrm{mL}$ of brefeldin A confirmed that FVIIwt and FVIIArg ${ }^{100}$ levels in cell lysates increased to $188 \%$ and $180 \%$ of control levels respectively as measured by imaging analysis of radioactive bands, whereas FVIICys ${ }^{97}$ 
levels were unaffected $(105 \%$ versus $100 \%$ in control cells) (data not shown).

Analysis of altered mobility of FVIIArg ${ }^{100}$. In Fig 1, FVIIwt and FVIICys ${ }^{97}$ from conditioned media are visualized by nondenaturing PAGE as a single band with an apparent mol wt of $48 \mathrm{kD}$. This is slightly greater than that for the intracellular FVII species and results from post-transcriptional modifications of the protein. However, FVIIArg ${ }^{100}$ from the conditioned media appeared as a single band with a faster electrophoretic mobility than FVIIwt on nonreducing 8\% SDS-PAGE. A smaller difference in electrophoretic mobility between FVIIwt and FVIIArg ${ }^{110}$ was also observed in the cell lysates. We hypothesized that this difference in electrophoretic mobility resulted from either a change in glycosylation or alteration of the molecule's secondary structure.

To investigate $\mathrm{N}$-linked glycosylation, radiolabeled FVII was immunoprecipitated and incubated with Endo-H or N-Glycanase which respectively cleaves either high-mannose and certain hybrid-type carbohydrates at the GlcNAc $\beta 1-4$ GlcNAc linkage to leave a single GlcNAc residue attached to asparagine (25) or all N-linked carbohydrates by hydrolyzing the asparginyl-oligosaccharide bond. (26) As the secretion of FVIIwt and FVIIArg ${ }^{100}$ occur at different rates, we eva-

48

33
Fig. 1 - Pulse-chase labeling experiments in CHO cells transfected with pEDFVIIwt, pEDFVIICys", and pEDFVIIArg ${ }^{100}$.

WT 100 97 time $30601201802403060120180240 \quad 3060120180240$ (min)

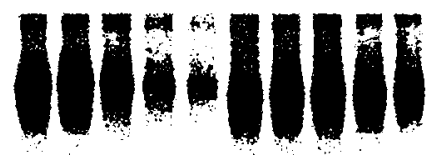

3

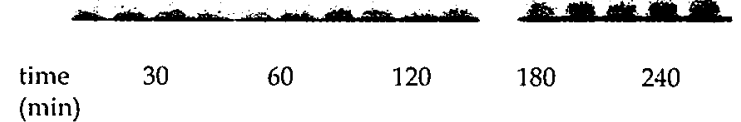

wt 97100 wt 97100 wt 97100 wt 97100 wt 97100

77

48
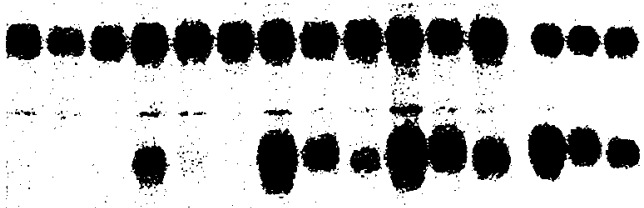

33

After a 15-minute pulse with $\left.{ }^{35} S\right]$ methionine, the cells were chased for 30,60,120, 180, and 240 minutes. Equivalent amounts of cell lysate (top) or conditioned media (bottom) for FVIhwt (wt), FVIICys 97 (97) and FVIIArg ${ }^{100}$ (100) were immunoprecipitated using a Mab against FVII and analyzed by $8 \%$ SDS-PAGE under nonreducing conditions. The location of molecular weight markers in $K D$ is denoted at the left-hand side of the figure. In the conditioned media (bottom), the $77 \mathrm{kD}$ band was nonspecific as it was observed with equal intensity in untransfected $\mathrm{CHO}$ cells (data not showon).

luated lysates from the two stably transfected cell lines at different chase times. After a 15 -minute pulse with $\left[{ }^{35} \mathrm{~S}\right]$ methionine and 120 minutes of chase time, FVIIwt migrated more rapidly after digestion with either Endo $\mathrm{H}$ or N-Glycanase, reflecting the removal of $\mathrm{N}$-linked high mannose oligosaccharides from the 
Fig. 2 - Immunohistochemical localization of wild-type and mutant FVII molecules in stably transfected $\mathrm{CHO}$ cells.
A

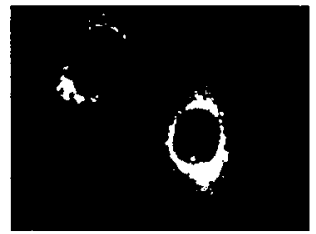

B

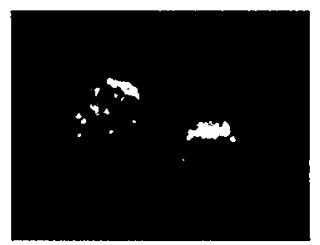

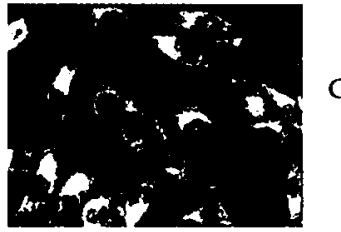

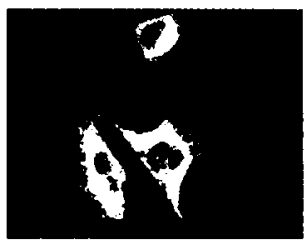

FVIItwt $(A, B)$ and FVIICys ${ }^{97}$ (C) were mostly localized in the perinuclear aren, wherens FVIIArg ${ }^{100}$ (D) was present diffusely throughout the cytoplasm without perinuclear enhancement. Untransfected CHO cells did not react with either the anti-FVII Mab or the fluorescent second antibody indicating that the observed labeling was specific for FVII (data not shown).
FVIIArg ${ }^{100}$ migrated with a similar electrophoretic mobility (Fig $3 \mathrm{C}$ ), thereby suggesting that disulfide bond formation of the FVII molecule was affected by the Gln ${ }^{100}$ Arg substitution. Similar results were obtained after reduction with $5 \%(\mathrm{vol} / \mathrm{vol}) \beta-$ Mercaptoethanol (data not shown).

\section{Discussion}

We investigated the mechanisms responsible for FVII deficiency in two unrelated Italian patients with a bleeding diathesis. Sequencing of the coding sequences and intron/exon boundaries of the FVII gene showed that they were homozygous for different mutations within the coding region for exon 5. Patient 1 had a $G$ to $\mathrm{T}$ mutation at position 7824 and patient 2 had an $\mathrm{A}$ to $\mathrm{G}$ mutation at position 7834 resulting in $\mathrm{Gly}^{97} \mathrm{Cys}$ and Gln ${ }^{100} \mathrm{Arg}$, respectively. These two mutations were previously reported in association with other mutations in doubly heterozygous patients.(27-29)Patient 1 , who was homozygous for $\mathrm{Gly}^{97} \mathrm{Cys}$, was also homozygous for two polymorphisms known to reduce FVII levels, $\mathrm{Arg}^{353} \mathrm{Gln}$ in exon 8 and the decanucleotide insert in the $5^{\prime}$ flanking region of the FVII gene. $(23,30,31)$ To study the mechanism by which the two mutations reduce FVII levels, we performed transient expression studies in COS-1 cells with cDNA encoding FVIIwt, FVIICys ${ }^{97}$, and FVIIArg ${ }^{100}$ and showed that the secretion of the two mutant proteins 
Fig. 2 - Analysis of the altered electrophoretic mobility of FVIIArg ${ }^{100}$.
(A) Lysate

Endo H NGly

WT 100 WT 100 WT 100

77

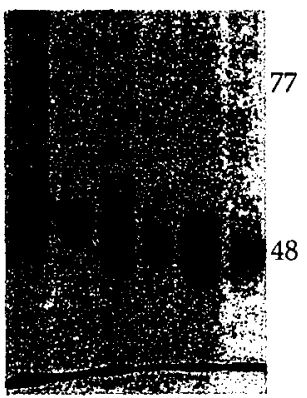

(B)MEDIA Neura

(C) MEDIA

Control DTT WT 100 WT 100 WT 100 WT 100

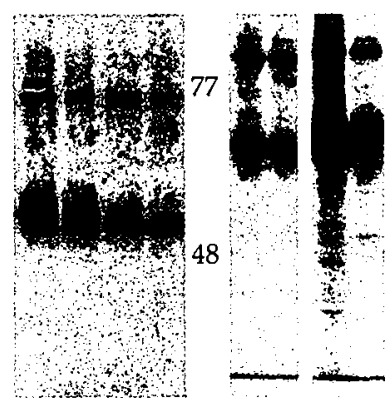

After a 15-minute pulse with [sS] methionine, stably transfected cells expressing FVIlwot and FVIIArg 100 were chased for 60 minutes and 120 minutes, respectively, to analyze FVII in cell lysates. In the conditioned media, FVIhwt and FVIIArg100 were both investigated after 180 minutes of chase. FVIhot (wot) and FVIIArg100 (100) were immunoprecipitated using a MoAb against FVII. (A) Equivalent amounts of cell lysate weere analyzed by $8 \%$ SDS-PAGE before (-) or after trentment with Endo $H$ and N-Glycanase (N-Gly). (B) Conditioned media were analyzed before (-) or after treatment with neuraminidase (Neura) by $10 \%$ SDSPAGE. (C) Conditioned medin were evalunted under nonreducing conditions (control) or after reduction by $100 \mathrm{mmol} / \mathrm{L}$ Dithiothreitol (DTT). The $77 \mathrm{kD}$ band was nonspecific because it was also observed in conditioned media from untransfected $\mathrm{CHO}$ cells (data not showm). Molecular weight markers in $k D$ are indicated on the left.

was impaired. The levels of VII:Ag and VII:C in the conditioned media were reduced concordantly for FVIICys ${ }^{97}$, whereas a higher level of VII:Ag relative to VII:C was observed for FVIIArg ${ }^{100}$. The results were similar to those in the patients' plasmas. We also observed that the intracellular levels of VII:Ag were reduced in transient transfection assays performed with the mutant cDNA.
To study the intracellular processing of the mutant proteins, we performed pulse-chase experiments and immunohistochemical staining of stably transfected CHO cells expressing FVIICys ${ }^{97}$ and FVIIArg ${ }^{100}$ in comparison to FVIIwt. Our results showed that the proteins did not accumulate intracellularly in spite of major secretion defects. A potential mechanism to account for reduced amounts of FVII protein in the cells is degradation. Intracellular degradation of abnormal proteins can result from lysosomal proteolysis or from pre-Golgi or ER degradation, which has been termed the "quality control function" of the $\operatorname{ER}(32,33)$. Protein degradation within the ER is a complex, poorly understood process and occurs either within the ER lumen or on the cytoplasmic side. Some of the proteolytic events are adenosine triphosphate (ATP)dependent and several of the enzymes involved in this process are sensitive to serine protease inhibitors. Some proteins with an abnormal conformation are degraded by a soluble ATP. dependent pathway in which conjugation occurs between the abnormal protein and multiple molecules of ubiquitin followed by hydrolysis by a $26 \mathrm{~S}$ proteolytic enzyme complex. The proteolytic core of this structure is the $20 \mathrm{~S}$ proteasome, which has been localized to the cytoplasmic surface of the ER by immunoelectron microscopy (34). 
To investigate potential mechanisms of intracellular degradation, we examined the biosynthesis of FVIICys ${ }^{97}$ using inhibitors of lysosomal $\mathrm{pH}\left(\mathrm{NH}_{4} \mathrm{Cl}\right)$, lysosomal proteolytic enzymes (leupeptin), and the 20Sproteasome (lactacystin). We also evaluated the effect of ALLN, a common inhibitor of neutral $\mathrm{Ca}^{2+}$-dependent cysteine proteases, which inhibits the ubiquitin-proteasome pathway (35). The intracellular level of FVIICys $^{97}$ did not change in the presence of inhibitors of lysosomal function (ie, $\mathrm{NH}_{4} \mathrm{Cl}$ and leupeptin) or lactacystin, whereas a significant increase was observed with ALLN. These data indicate that FVIICys ${ }^{97}$ degradation does not occur in lysosomes and involves a cysteine protease, which is, however, independent of the proteasome pathway.

Brefeldin A inhibits protein secretion in a pre-Golgi compartment such that proteins destined for secretion remain in the ER(36). Whereas the level of FVIIwt rose by $90 \%$ of baseline in the presence of brefel$\operatorname{din} \mathrm{A}$, the intracellular level of FVIICys ${ }^{97}$ increased by less than $30 \%$. The Gly ${ }^{97} \mathrm{Cys}$ mutation is in the second EGF domain of FVII and results in substitution of a small nonpolar side chain by a polar side chain. Based on the crystal structure of activated FVII bound to the extracellular domain of tissue factor(37), Gly ${ }^{97}$ helps position the $\mathrm{Cys}^{98}$-Cys ${ }^{112}$ loop to facilitate intramolecular disulfide bonding. We postulate that the resulting alteration in protein conformation causes FVIICys ${ }^{97}$ to undergo degradation in a pre-Golgi compartment.
For FVIIArg ${ }^{100}$, pulse-chase experiments showed that the mutant protein was retained for a longer time interval in stably transfected CHO cells than FVIIwt and the level was not increased by the various inhibitors of protein degradation. In the presence of brefeldin $\mathrm{A}$, the levels of FVIIArg ${ }^{100}$ increased by $51 \%$ as compared to FVIIwt that increased by $90 \%$. This data coupled with the immunohistochemical demonstration that FVIIArg ${ }^{100}$ is present diffusely throughout the cytoplasm is consistent with retention of a substantial portion of the mutant protein in the ER.

The more rapid electrophoretic mobility of FVIIArg ${ }^{100}$ as compared with FVIIwt sug. gested that FVIIArg ${ }^{100}$ might be incompletely glycosylated or have an abnormal tertiary structure. To investigate alterations in N-linked glycosylation and sialation, radiolabelled FVIIwt and FVIIArg ${ }^{100}$ from conditioned media were treated with Endo $\mathrm{H}, \mathrm{N}$-Glycanase, and neuraminidase. The difference in electrophoretic mobility remained between FVIIwt and FVIIArg ${ }^{100}$ after digestion with the three enzymes, implying that $\mathrm{N}$-linked glycosylation and sialation of FVIIArg ${ }^{100}$ were unaffected. We did not evaluate whether O-linked sugars on residues $\operatorname{Ser}^{52}$ and $\operatorname{Ser}^{60}$ of FVII $(6,38)$ were altered because FVIIAla ${ }^{52}$, a mutant molecule lacking glycosylation at this residue, has been reported to have the same electrophoretic mobility as FVIIwt(38). Because the second EGF domain contains three intramolecular disulfide bonds $\left(\mathrm{Cys}^{91}-\mathrm{Cys}^{102}, \mathrm{Cys}^{98}-\mathrm{Cys}^{112}\right.$, and $\mathrm{Cys}^{114}-\mathrm{Cys}^{127}$ ), 
we compared the electrophoretic mobility of FVIIwt and FVIIArg 100 under reducing as well as non-reducing conditions. After reduction, the difference in electrophoretic mobility between the two molecules was no longer present, leading us to speculate that FVIIArg ${ }^{101}$ does not undergo normal disulfide bonding during its biosynthesis. To confirm this, chemical determination of the disulfide bonding pattern of FVIIArg ${ }^{100}$ would need to be performed and the results compared with those for FVIIwt. The mutation replaces a neutral GIn residue with a larger positively-charged Arg, which may sterically interfere with Tyr ${ }^{118}$ and electrostatically interfere with the positively-charged side chain of $\mathrm{His}^{15}(37)$. We therefore postulate that the Gln ${ }^{100} \mathrm{Arg}$ mutation in FVII results in a protein with an abnormal conformation that remains in the ER for an extended period during its biosynthesis and reduces its secretion.

Whereas defective biosynthesis is a major defect conferred by the Gln ${ }^{100} \mathrm{Arg}$ mutation, a small amount of dysfunctional protein is secreted as evidenced by the low specific activity of the FVII (ie, ratio of VII:C to VII:Ag) that is present in the patient's plasma as well as conditioned medium of transfected COS- 1 cells. Our data is in agreement with studies of FVIIArg ${ }^{100}$ reported by Kemball-Cook et al(39), who showed that the activated form of the mutant recombinant protein had markedly diminished affinity for tissue factor and, in complex with soluble tissue factor, had less than $5 \%$ of the ability of FVIIwt to activate factor X. Orning et al (40) have also provided data that the peptide sequence, Glu 99 . Gln ${ }^{100}$. Tyr ${ }^{101}$, in the second EGF domain of FVII, inhibits the ability of FVIIwt to mediate tissue factor-dependent factor $X$ activation. Based on the crystal structure of the FVIIa-tissue factor complex, Gln ${ }^{100}$ is located at the interface of the second EGF and the protease domain, but is not in contact with tissue factor.

Whereas Gly ${ }^{97} \mathrm{Cys}$ and Gln ${ }^{100} \mathrm{Arg}$ have previously been reported in double heterozy. gotes with FVII deficiency, this is the first report of homozygous patients with these mutations. The severe clinical phenotype of patient 2 with Gln ${ }^{100} \mathrm{Arg}$ is consistent with studies showing a major secretion defect as well as markedly impaired function of the small amount of FVII that is released from cells. It is unclear why patient 1 with Gly ${ }^{97} \mathrm{Cys}$ does not have a similarly severe bleeding diathesis. Because it is not possible to obtain sufficient FVIICys ${ }^{97}$ protein to perform detailed biochemical studies, we cannot evaluate whether a very small amount of circulating FVII protein posseses sufficient biologic function to attenuate the bleeding diathesis.

\section{Acknowledgement}

The authors thank Dr Michael Yaffee (Beth Israel Deaconess Medical Center, Boston, MA) for his assistance in the analysis of the coordinates of FVIIa from the FVIIa-soluble tissue factor crystal structure. 


\section{References}

1. Fair DS: Quantitation of factor VII in the plasma of normal and warfarin-treated individuals by radioimmunoassay. Blood 62:784, 1983

2. Bauer KA, Kass BL, ten Cate H, Hawiger JJ, Rosenberg RD: Factor IX is activated in vivo by the tissue factor mechanism. Blood 76:731, 1990

3. Osterud B, Rapaport S: Activation of factor $\mathbf{X}$ by the reaction product of tissue factor and factor VII: Additional pathway for initiating blood coagulation. Proc Natl Acad Sci USA 74: 5260,1977

4. Hagen FS, Gray CL, O'Hara P, Grant FJ, Saari GC, Woodbury RG, Hart CE, Insley M, Kisiel W, Kurachi K, Davie EW: Characterization of a cDNA coding for human factor VII. Proc Natl Acad Sci USA 83: 2412, 1986

5. Thim L, Bjoern S, Christensen M, Nicolaisen EM, Lund-Hansen T, Pedersen AH, Hedner U: Amino acid sequence and posttranslational modifications of human factor VIIa from plasma and transfected baby hamster kidney cells. Biochemistry 27: 7785, 1988

6. Nishimura H, Kawabata S, Kisiel W, Hase S, Ikenaka T, Shimonishi Y, Iwanaga S:

Identification of a disaccharide (Xyl-Glc) and a trisaccharide (Xyl $\left.{ }^{2}-\mathrm{Glc}\right) \mathrm{O}$-glycosidically linked to a serine residue in the first epidermal growth factor-like domain of human factors VII and IX and protein Z and bovine protein Z. J Biol Chem 264: 20320, 1989

7. Ragni MV, Lewis JH, Spero JA, Hasiba U: Factor VII deficiency. Am J Hematol 10:79, 1981

8. Triplett DA, Brandt JT, McGann Batard MA,
Schaeffer Dixon JL, Fair DS: Hereditary factor VII deficiency: Heterogeneity defined by combined functional and immunochemical analysis. Blood 66:1284,1985

9. Cooper D, Millar D, Wacey A, Banner D, Tuddenham E: Inherited factor VII deficiency: Molecular, genetic and pathophysiology. Thromb Haemost 78:151, 1997

10. Kunkel LM, Smith KD, Boyer SH, Borgaonkar DS, Wachtel SS, Miller OJ, Breg WR, Jonew HW, Rary JM: Analysis of human Y chromosome-specific reiterated DNA in chromosome variants. Proc Natl Acad Sci USA 74:1245, 1977

11. Arbini AA, Bodkin D, Lopaciuk S, Bauer KA: Molecular analysis of Polish patients with factor VII deficiency. Blood 84:2214, 1994

12. Saiki RK, Gelfand DH, Stoffel S, Scharf SJ, Higuchi R, Horn GT, Mullis KB, Erlich HA: Primer-directed enzymatic amplification of DNA with a thermostable DNA polymerase. Science 239:487, 1988

13. Broze GJ Jr: Monoclonal anti-human factor VII antibodies. Detection in plasma of a second protein antigenically and genetically related to factor VII. $J$ Clin Invest 76:937, 1985

14. Arbini AA, Mannucci PM, Bauer KA: A $\mathrm{Thr}^{359}$ Met mutation in factor VII of a patient with a hereditary deficiency causes defective secretion of the molecule. Blood 87:5085, 1996

15. Kaufman RJ, Davies MV, Wasley LC, Michnick D: Improved vectors for stable expression of foreign genes in mammalian cells by use of the untranslated leader sequence from EMC virus. Nucleic Acids Res 
19:4485, 1991

16. Chasin LA, Urlaub G: Isolation of Chinese hamster cell mutants deficient in dihydrofolate reductase activity. Proc Natl. Acad Sci USA 77:4216, 1980

17. Jensen T, Loo M, Pind S, Williams D, Goldberg A, Riordan J: Multiple proteolytic systems including the proteasome, contribute to CFTR processing. Cell 83:129, 1995

1 8. Lukacs G, Mohamed A, Kartner N, Chang X, Riordan J, Grinstein S: Conformational maturation of CFTR but not its mutant counterpart (?F508) occurs in the endoplasmic reticulum and require ATP. EMBO $J$ 13:6076, 1994

19. Pipe S, Kaufman R: Factor VIII C2 domain missense mutations exhibit defective trafficking of biologically functional proteins. $J$ Biol Chem 271:25671, 1996

20. Field M, Moran P, Li W, Keller G, Caras I: Retention and degradation of proteins containing an uncleaved glycosylphosphatidylinositol signal. J Biol Chem 269:10830, 1994

21. Qu D, Teckman J, Omura S, Perlmutter D: Degradation of a mutant secretory protein, $\alpha$ 1-antitrypsin $\mathrm{Z}$, in the endoplasmic reticulum requires proteasome activity. $J$ Biol Chem 271:22791, 1996

22. Peyvandi F, Mannucci $P$, Asti D, Abdoullah M, Di Rocco N, Sharifian R: Clinical manifestations in 28 Italian and Iranian patients with severe factor VII deficiency. Hemophilia 3:242, 1997

23. Hunault M, Arbini A, Lopaciuk S, Carew J, Bauer K: The Arg ${ }^{353}$ Gln polymorphism reduces the level of coagulation factor VII: In vivo and in vitro studies. Arterioscler Thromb Vasc Biol 17:2825, 1997
24. Hunault M, Arbini A, Carew J, Bauer K: Mechanism underlying factor VII deficiency in Jewish populations with the $\mathrm{Ala}^{244} \mathrm{Val}$ mutation. $\mathrm{Br} J$ Haematol (in press)

25. Tarentino A, Maley F: Purification and properties of an endo-beta- $\mathrm{N}$-acetylglucosaminidase from Streptomyces griseus. $J$ Biol Chem 249:811, 1974

26. Tarentino A, Gomez C, Plummer 'TJ: Deglycosylation of aspargine-linked glycans by peptide: N-glycosidase F. Biochemistry 24:4665, 1985

27. Bernardi F, Patracchini P, Gemmati D, Ferrati M, Arcieri P, Papacchini M, Redaelli R, Baudo F, Mariani G, Marchetti G: Molecular analysis of factor VII deficiency in Italy: a frequent mutation (FVII Lazio) in a repeated intronic region. Human Genet 92:446, 1993

28. Kuppuswamy M, Sabharwal A, Birktoft J, Bajaj S: Molecular characterization of human factor VII Kansas (GK704): Substitution of Gln 100 by Arg in one allele and of Arg304 by GIn possibly in the other allele. Thromb Haemost 69:1292, 1993

29. Takamiya O, Kemball-Cook G, Martin DMA, Cooper DN, von Felten A, Meili E, Hann I, Prangnell DR, Lumley $\mathrm{H}$, Tuddenham EGD, McVey JH: Detection of missense mutations by single-strand conformational polymorphism (SSCP) analysis in five dysfunctional variants of coagulation factor VII. Hum $\mathrm{Mol}$ Gen 2:1355, 1993

30. Humphries S, Temple A, Lane A, Green F, Cooper J, Miller G: Low plasma levels of Factor VIIc and antigen are more strongly associated with the 10 base promoter $(-323)$ insertion than the glutamine 353 variant. Thromb 
Haemostas 75:567, 1996

31. Pollak ES, Hung HL, Godin G, Overton GC, High KA: Functional characterization of the human factor VII 5' flanking region. $J$ Biol Chem 271:1738, 1996

32. Buscà $R$, Martinez $M$, Vilella $E$, Pognonec $P$, Deeb S, Auwerx J, Reina M, Vilaró S: The mutation Gly ${ }^{142}$ Glu in human lipoprotein lipase produces a missorted protein that is diverted to lysosomes. J Biol Chem 271:2139, 1996

33. Bonifacino J, Klausner R: Degradation of proteins retained in the endoplasmic reticulum. Ciechanover A, Schwartz AL (eds), vol 15. New York, NY, 1994.

34. Rivett A, Mason G, Murray R, Reidlinger J: Regulation of proteasome structure and function. Mol Biol Report 24:9, 1997

35. Rock K, Gramm C, Rothstein L, Clark K, Stein R, Dick L, Hwang D, Goldberg A: Inhibitors of the proteasome block the degradation of most cell proteins and the generation of peptides presented on MHC class I molecules. Cell 78:761, 1994

36. Fujiwara T, Oda K, Yokota S, Takatsuki A,
Ikehara Y: Brefeldin A causes disassembly of the golgi complex and accumulation of secretory proteins in the endoplasmic reticulum. $J$ Biol Chem 263:1854, 1988

37. Banner D, D'Arcy A, Chene C, Winkler F, Guha A, Konigsberg W, Nemerson Y, Kirchlofer D: The crystal structure of the complex of blood coagulation factor VIIa with soluble tissue factor. Nature 380:41,1996

38. Bjoern S, Foster DC, Thim L, Wiberg FC, Christensen M, Komiyama Y, Pedersen AH, Kisiel W: Human plasma and recombinant factor VII: Characterization of $\mathrm{O}$-glycosylations at serine residues 52 and 60 and effects of site directed mutagenesis of serine 52 to alanine. $J$ Biol Chem 266:11051, 1991

39. Kemball-Cook G, Johnson D, Takamiya $O$, Banner D, Mc Vey J, Tuddenham E: Coagulation factor VII Gln ${ }^{100} \mathrm{Arg}$. $J$ Biol Chem 273:8516, 1998

40. Orning L, Stephens R, Petersen L, Hamers $\mathrm{M}$ : A peptide sequence from the EGF-2 like domain of FVII inhibits TF-dependent FX activation. Thromb Res 86:57, 1997 


\section{Abnormal secretion and function of}

\section{recombinant human factor VII as the result of modification to a calcium binding site caused by a 15 base pair insertion in the factor VII gene}

F. Peyvandi ${ }^{123}$, J.A. Carew ${ }^{1}$, D.J. Perry ${ }^{3}$, M. Hunault ${ }^{1}$, U. Khanduri', S.J. Perkins, ${ }^{5}$ P. M. Mannucci', and K.A. Bauer ${ }^{1}$

${ }^{1}$ Hematology Section, Department of Medicine, Boston VA Healthcare System, Haroard Medical School, Boston, MA, USA

${ }^{2}$ Angelo Bianchi Bonomi Hemophilia and Thrombosis Center and Fondazione Luigi Villa, IRCCS Maggiore Hospital and University of Milan, Italy ${ }^{3}$ Hemophilia Centre and Hemostasis Unit, Department of Hematology, Royal

Free and University College Medical School, Pond Street, London, UK

'Department of Hematology, College of Medicine, Sultan Qaboos University-Sultanate of Oman

${ }^{5}$ Department of Biochemistry and Molecular Biology, Royal Free and University College Medical School, Rowland Hill Street, London, UK

Blood (accepted for publication) 


\section{Summary}

We report a case of a novel insertion type mutation in the factor VII (FVII) gene that results in severe FVII deficiency with FVII coagulant activity (FVII:C) of $<1 \%$ and factor VII antigen levels (FVII:Ag) of $10 \%$. DNA analysis revealed a homozygous $15 \mathrm{bp}$ inframe insertion type mutation at nucleotide 10554 within the catalytic domain of FVII. This insertion consists of a duplication of the residues Leu213 to Asp217 (Leu, Ser, Glu, His, Asp), probably arising by slipped mispairing between 2 copies of a direct repeat (GCGAGCACGAC) separated by $4 \mathrm{bp}$. Molecular graphics analyses of FVIIa showed that the insertion is located at the surface of the catalytic domain in an exposed loop stabilized by extensive salt-bridge and hydrogen bond formation at which the calcium binding site is located. The insertion may interfere with protein folding during FVII biosynthesis and/or diminish functional activity through the loss of calcium binding. To explore these two hypotheses, wildtype FVII (FVIIWT) and mutant FVII (FVIIMT) cDNAs were expressed transiently in COS1 cells and stably in Chinese hamster ovary cells (CHO). In lysates of cells transfected with either the FVIIWT or FVIIMT constructs, the FVII:Ag levels were equivalent. However the amount of FVII:Ag secreted by cells transfected with FVIIMT was $5-10 \%$ of that secreted by cells transfected with FVIIWT. Using stably transfected $\mathrm{CHO}$ cells, pulse chase studies demonstrated that FVIIMT did not accumulate intracellularly. A part of this recombinant protein was degraded in PreGolgi compartment as demonstrated by using different inhibitors of protein degradation. Accordingly, only small amounts of FVII with not detectable procoagulant activity were secreted into conditioned media. These results verify both the hypotheses derived from inspection of the FVIIa crystal structure, and demonstrate that both a secretion and a functional defect is the mechanism whereby this insertion causes FVII deficiency.

\section{Introduction}

Factor VII (FVII) has a central role in the initiation of blood coagulation. This glycoprotein circulates in blood as a single-chain zymogen composed of 406 amino acid residues (1) with a molecular weight of $50 \mathrm{kD}$. FVII, after the formation of a one-to-one stoichiometric complex with its cell surface receptor and cofactor tissue factor (TF) and in the presence of calcium ions, is rapidly cleaved to its active form, FVIIa. This activation occurs through proteolytic cleavage at a single site (Arg152-Ile153)(2,3). FVIIa converts zymogen factors $\mathrm{X}$ and IX to the corresponding active enzymes (2). FVIIa is composed of an N-terminal light chain (152 amino acids) and a C-terminal heavy chain (254 amino acids) linked by a disulfide bond. The light chain contains an amino terminal $\gamma$-carboxy-glutamic acid-rich domain, followed by two epidermal growth factor (EGF)-like modules. The heavy chain consists of the catalytic domain. The FVII gene is $12.8 \mathrm{~kb}$ in length and is located $2.8 \mathrm{~kb}$ away from the factor $\mathrm{X}$ gene on the long arm of chromosome 
13(4). The mature protein is encoded by exons 2 to 8 .

FVII deficiency is a rare recessive bleeding disorder with a relatively poor correlation between FVII coagulant activity and hemorrhagic symptoms(5). Several missense mutations and a few small deletions and insertions in the human FVII gene have been reported $(6,7)$, but no insertion type mutation or mutations affecting the FVII calcium site in the catalytic domain have yet been documented (see the FVII mutation database at http://europium.csc.mrc.ac.uk). Here, using expression studies, we describe and characterize the first case of FVII deficiency caused by a homozygous insertion type mutation consisting of a duplication of a $15 \mathrm{bp}$ segment within exon 8 (Leu213Asp217) in the catalytic domain (\{73-77\}: chymotrypsinogen numbering is denoted throughout by curved brackets). Crystal and solution scattering structures are available for FVIIa and its complex with $\mathrm{TF}(8-11)$. We show, using molecular graphics analysis, that the insertion is proximate to the calcium binding site of the catalytic domain, and propose that this is responsible for the complete loss of FVIIa activity. In vitro transient and stable expression studies demonstrated reduced levels of FVII:Ag in conditioned media, supporting the hypothesis of a secretion defect caused by the insertion mutation. This mutation probably does not interfere with FVII synthesis, but is associated with various defects including abnormal folding, intracellular degradation, secretion failure and loss of proteolytic activity. To our know- ledge, this is the first instance of a FVII deficiency caused by a perturbation at its calcium-binding site in the catalytic domain.

\section{Materials and methods}

Patient. The patient, born from a consanguineous marriage, is a 5 year old female from Oman. The first bleeding episode was noted after female circumcision. Hematuria occurred in her first year of life and several episodes of epistaxis and hematuria ocurred at age 3 . These bleeding episodes were severe enough to require transfusions of fresh frozen plasma and red cells. Informed consent to perform the research studies was obtained from the patient's family.

Collection and processing of blood samples. Blood was collected by atraumatic venepuncture into plastic tubes containing $1 / 10$ th volume $0.129 \mathrm{~mol} / \mathrm{L}$ buffered trisodium citrate. Plasma was obtained by centrifugation at $2500 \mathrm{Xg}$ for $15 \mathrm{~min}$ at $4^{\circ} \mathrm{C}$, transferred into plastic tubes, and stored along with leukocytes at $-80^{\circ} \mathrm{C}$ until use.

Factor VII assays. Plasma FVII:C was measured by a one-stage prothrombin timebased assay, using human recombinant tissue factor RecombiPlastin, OrthoDiagnostic System, Raritan, NJ) and FVII deficient plasma (Dade International, Miami, FL). Plasma FVII:Ag was measured using an enzyme-linked immunoabsorbent assay (ELISA) using murine monoclonal antibodies against FVII(12). A normal plasma pool was constructed by mixing equal volumes of plasma from 40 healthy subjects, 20 men and 20 women (not pregnant and not taking oral 


\section{Chapter 3 -Molecular studies}

contraceptives). In the expression studies, levels of recombinant FVII:C and FVII:Ag were determined using the functional assay described above and ELISA (American Bioproducts Co., Parsippany, NJ) using a polyclonal rabbit anti-serum against human FVII, respectively.

\section{DNA isolation and in vitro amplifica-} tion using PCR. Genomic DNA was isolated from peripheral blood leukocytes by established techniques(13). The coding regions, intron/exon boundaries, and $490 \mathrm{bp}$ of 5' flanking region of the FVII gene were amplified by polymerase chain reaction (PCR) and analyzed for mutations by single-strand conformational polymorphism (SSCP)(14). PCR amplifications were carried out in 100 $\mu \mathrm{l}$ volumes comprised of 100-500 ng of DNA, 100 pmoles of each oligonucleotide primer, $200 \mathrm{mmol} / \mathrm{L}$ of each dNTP, $1.5 \mathrm{mmol} / \mathrm{L}$ $\mathrm{MgCl}_{2}, 50 \mathrm{mmol} / \mathrm{L} \mathrm{KCl}, 10 \mathrm{mmol} / \mathrm{L}$ Tris- $\mathrm{HCl}$ $\mathrm{pH} 8.3$, and 2 units of Taq polymerase (Perkin-Elmer Cetus). Reactions were denatured at $94^{\circ} \mathrm{C}$ for $5 \mathrm{~min}$, then 40 cycles of amplification were performed, with a $10 \mathrm{~min}$ extension time in the last cycle. For SSCP analysis, $1 \mu \mathrm{l}$ of each final PCR product was mixed with $5 \mu \mathrm{l}$ of denaturation buffer $(95 \%$ formamide, $0.05 \%$ xylene cyanol, $0.05 \%$ bromphenol blue), denatured for $10 \mathrm{~min}$ at $94^{\circ} \mathrm{C}$ and then placed on ice for $2 \mathrm{~min}$. 3-4 $\mu \mathrm{l}$ of each denatured sample were loaded onto a $10 \%$ polyacrylamide gel (99:1 acrylamide: bisacrylamide) in Tris-borate EDTA buffer (0.09 M Tris-borate, $2 \mathrm{mM}$ EDTA), supplemented with $7.5 \%$ urea. Following electrophoresis DNA fragments were visualized by silver staining (Promega Corp., Southampton, UK). PCR fragments showing abnormal SSCP migration were purified by Bioline PCRapid Purification kit (Bioline, London, UK) and directly sequenced using an ABI 377 automated DNA sequencer (Perkin-Elmer Applied Biosciences, Warrington, UK).

Antibodies. The production and purification of Mab1476, a murine monoclonal antibody, which recognizes an epitope in the amino terminal region of FVII, has been described (15). This antibody was used to detect FVII in pulse chase experiments.

\section{Structural analysis of the mutant pro-} tein. The crystal coordinates of the TF-FVIIa complex and unbound FVIIa at resolutions of 2.0-2.8 $\AA$ (9-11) were obtained from the Protein Data Bank (PDB codes 1dan, 1qfx and 1cvw). Protein structures were visualized using INSIGHT II software (MSI, San Diego, CA) on Silicon Graphics INDY Workstations in conjunction with Crystal Eyes stereo glasses. The FVIIa secondary structures and sidechain solvent accessibilities are as reported previously(7). The rigid body fragment assembly method in the HOMOLOGY and DISCOVER modules (MSI) was used to model the insertion. For reason of their positions in the exposed surface loop, His216 \{76\} and Asp219 \{79\} were fixed and used to define the insertion point, and Asp217 $\{77\}$ and Gly218 $\{78\}$ were deleted. The seven-residue fragment DLSEHDG was inserted by standard homology modelling methods(16). A precalculated $\mathrm{C} \alpha$ distance matrix identified known loops in the 
Tab. 1 - Effect of inhibitors of protein degradation and Brefeldin $A$ on intracellular levels of FVIIWT and FVIIMT.

\begin{tabular}{lll} 
& FVIIWT (\%) & FVIMT (\%) \\
\hline Media alone & $95( \pm 5)$ & $116( \pm 4)$ \\
$\mathrm{NH}_{4} \mathrm{Cl}(50 \mathrm{mM} / \mathrm{L})$ & $121( \pm 4)$ & $115( \pm 3)$ \\
Leupeptin $(100 \mu \mathrm{mol} / \mathrm{L})$ & $87( \pm 18)$ & $99( \pm 16)$ \\
Brefeldin $\mathrm{A}(10 \mu \mathrm{g} / \mathrm{mL})$ & $150( \pm 3)$ & $88( \pm 24)$ \\
\hline
\end{tabular}

Confluent $\mathrm{CHO}$ cells expressing recombinmt FVIIWT and FVIIMT were incubated for $4 \mathrm{~h}$ in fresh media containing $10 \%$ FBS in the presence or absence of agents. The results report the levels of FVII:Ag in cell lysates, expressed as the percentage of FVII:Ag (iment $\pm S E$ ) from 3 independent experiments. The $p$ values (see text) were calculated by the t-test.

Protein Data Bank that best fitted the corresponding $\mathrm{C} \alpha$ distance matrix based on the positions of His216 \{76\} and Asp219 \{79\} and other flanking residues in FVIIa. Sidechain atoms were automatically generated for the inserted region using template structures and general rules for residue exchanges. The final inserted loop structure showed no steric overlap with the remaining FVIIa structure and was refined using 300 steps of steepest descent energy minimisation.

Cloning of the Insertion Mutation. The $15 \mathrm{bp}$ insertion mutation identified at the very beginning of exon 8 was inserted into the FVIIWT cDNA by overlapping PCR (Figure 1). For the first PCR reaction, the FVIIWT CDNA was used as a template. The upstream primer extended from position 8906 to 8937 in exon 6, including the underlined Xba I restriction site (CCATGTGGAAA AATACCTA TTCTAGAAAAAAG). The downstream primer began at position 9726 , the junction of exons 7 and 8 (CCAG-
CACCGCGACAAATT TCTCCAGTTC) and included silent mutations (underlined) in codons 202 to 204 which introduced an Apo I restriction site (AGGAACCTG to AGAAATTTG). For the second PCR reaction, the template was the PCR product of exon 8 from the patient's genomic DNA. The upstream primer for this reaction included a 5 ' extension of 29 bases of exon 7 sequence (position 9698 to 9726 ) containing the silent mutations, as well as the first 30 bases of exon 8 (positions 10543 to 10572) sequence and $15 \mathrm{bp}$ of insertion (lower c a s e) : ( GA A C T G G G A A A T T G ATCGCGGTGCTGGGCGAGCACGACCTC AGCGAGCACGAC c tcagcgagcacgacGGGG). The downstream primer extended from position 10927 to 10905 within exon 8 (GGTTGCGCAGCCCTGGCCCCAGC). For the third PCR reaction, the products of the first and second reactions, and the upstream primer from reaction 1 and downstream primer from reaction 2 were used to generate the overlapping PCR fragment containing the insertion. The presence of the mutation was confirmed by Apo I digestion.

The construction of plasmid pT7SalIFVIIWTEcoRI has been described previously (17). The product of the third PCR reaction was purified, digested with Xba I and Kpn I, then ligated into this vector which had been digested with the same enzymes, to make the clone pT7-SalIFVIIMTEcoRI. Cloned inserts were sequenced. Sequencing confirmed the correct sequence including the insertion mutation.

Construction of expression vectors. 
SalIFVIIWT ${ }^{\text {Ecork }}$ and SallFVIIMTEcoRI fragments were prepared from the corresponding pT7 vectors, and ligated into the expression plasmid, $\mathrm{pED}-\mathrm{mtx}^{\mathrm{r}}$ provided by Dr. Randal J. Kaufman. The resulting plasmids, pEDFVIIWT and pEDFVIIMT, are dicistronic mRNA mammalian expression vectors carrying the WT or MT FVII cDNAs at the 5' open reading frame and the DHFR CDNA at the 3 ' open reading frame(17).

Cell culture and transfection assays. For transient transfection experiments, African green monkey COS-1 cells (ATCC CRL1650) were maintained in Dulbecco's Modified Eagle's Medium (DMEM) supplemented with $10 \%$ (vol/vol) fetal bovine serum (FBS), $2 \mathrm{mmol} / \mathrm{L} \mathrm{L}$-glutamine, $10 \mathrm{mmol} / \mathrm{L}$ HEPES pH 7.2, 100 units $/ \mathrm{mL}$ of penicillin G, 100 $\mu \mathrm{g} / \mathrm{mL}$ streptomycin and $5 \mu \mathrm{g} / \mathrm{mL}$ of vitamin K1 (Phytonadione, Abbott Laboratories, North Chicago, IL) in a $5 \% \mathrm{CO}_{2}$ atmosphere at $37^{\circ} \mathrm{C}$. Twenty hours prior to transfection, COS- 1 cells were plated on $100 \mathrm{~mm}$ culture dishes at a density of $3 \times 106$ cells/dish. Fifteen $\mu \mathrm{g}$ of the pEDFVIIWT or pEDFVIIMT constructs were transfected into cells by Lipofectamine (GIBCO-BRL, Gaithersburg, MD) according to the manufacturers' instructions. After $16 \mathrm{~h}$, medium was changed, and $36 \mathrm{~h}$ later supernatants and cell lysates were harvested and assayed for FVII:C and FVII:Ag.

To obtain stable cell lines expressing recombinant FVIIWT and pEDFVIIMT, dihydrofolate reductase (DHFR) deficient CHO cells (CHO-DUKX-B11)(18) provided by Dr. Barbara C. Furie (Boston, MA) were tran- sfected with the $\mathrm{pED}$ expression vectors. These cells were grown in alpha modified essential medium (AMEM) supplemented with $10 \% \mathrm{FBS}, 2 \mathrm{mmol} / \mathrm{L}$ L-glutamine, 10 $\mathrm{mmol} / \mathrm{L}$ HEPES $\mathrm{pH} 7.2,100$ units $/ \mathrm{mL}$ of penicillin $\mathrm{G}, 100 \mu \mathrm{g} / \mathrm{mL}$ streptomycin, 5 $\mu \mathrm{g} / \mathrm{mL}$ of vitamin $\mathrm{K} 1,10 \mu \mathrm{g} / \mathrm{mL}$ adenosine, $10 \mu \mathrm{g} / \mathrm{mL}$ deoxy-adenosine, and $10 \mu \mathrm{g} / \mathrm{mL}$ thymidine. CHO-DUKX-B11 cells were plated on $100-\mathrm{mm}$ culture dishes at a density of $3 \times 10^{6}$ cells/dish. Transfections were performed as described above with $15 \mu \mathrm{g}$ of either pEDFVIIWT or $\mathrm{pEDFVIIMT}$ plasmid and 45 $\mu \mathrm{L}$ of Lipofectamine. Two days after transfection, cells were divided at a 1 to 8 ratio and selected for DHFR expression using medium deficient in ribonucleosides and deoxyribonucleosides. Twelve days after transfection, 14 colonies were picked at random and cultured in 12-well (24-mm) plates. At day 20 when the cells achieved confluence, each well was split into two $35-\mathrm{mm}$ dishes. At $90 \%$ confluence, cell lysates were prepared and assayed for FVII:Ag by ELISA.

Metabolic labeling studies. Nearly confluent $100-\mathrm{mm}$ dishes of transiently transfected COS- 1 cells or stably transfected $\mathrm{CHO}$ cells expressing recombinant FVII were used for pulse chase experiments. Fresh media with FBS was added $4 \mathrm{~h}$ before cells were deprived of methionine for $30 \mathrm{~min}$ and labeled for $15 \mathrm{~min}$ with $2 \mathrm{~mL}$ of methionine-free AMEM (GIBCO-BRL, Gaithersburg, MD) containing $400 \mu \mathrm{Ci}$ Expre ${ }^{35} \mathrm{~S}$ Protein Labeling Mix ( 73\% L- $\left.{ }^{35} \mathrm{~S}\right]$ methionine and $22 \%$ L- $\left[{ }^{35} \mathrm{~S}\right]$ cysteine; DuPont NEN Research Products, Billerica, MA) in a $5 \%$ 


\section{Rare $\overline{\text { Coagulation Disorders }}$}

$\mathrm{CO}_{2}$ atmosphere at $37^{\circ} \mathrm{C}$. A chase was then performed in $2 \mathrm{~mL}$ medium containing an excess of unlabeled L-methionine (GIBCOBRL, Gaithersburg, MD) for various time periods. At each time point, medium was harvested and PMSF added to a final concentration of $1 \mathrm{mmol} / \mathrm{L}$. Cell extracts were prepared in $600 \mu \mathrm{L}$ ice-cold NP-40 lysis buffer $(50 \mathrm{mmol} / \mathrm{L} \mathrm{NaCl}, 50 \mathrm{mmol} / \mathrm{L}$ Tris $\mathrm{pH} 8.0$, $1 \%$ (wt/vol) NP-40) supplemented with 1 $\mathrm{mmol} / \mathrm{L}$ PMSF. The cell lysates were precleared overnight at $4^{\circ} \mathrm{C}$ with $100 \mu \mathrm{L}$ of $20 \%$ (vol/vol) fixed Staphylococcus Aureus Cowan I (SAC) coupled with a rabbit anti-mouse IgG (Sigma, St. Louis, MO) in NP-40 lysis buffer. Immunoprecipitation of FVII was accomplished by incubating precleared cell lysates and conditioned media with $25 \mu \mathrm{g}$ of monoclonal antibody $\mathrm{MC} 1476$ for $4 \mathrm{~h}$ at $4^{\circ} \mathrm{C}$. The resulting immune complexes were adsorbed with $70 \mu \mathrm{L}$ of $20 \%(\mathrm{vol} / \mathrm{vol})$ Protein A Sepharose (Sigma, St. Louis, MO) coupled $5: 1(\mathrm{vol} / \mathrm{vol})$ with rabbit anti-mouse IgG antiserum in NP-40 lysis buffer. Pellets were washed four times in NP-40 lysis buffer and resuspended either in buffer for further enzymatic digestion (see below) or in polyacrylamide gel electrophoresis (PAGE) sample buffer with or without reducing agents, and denatured by heating to $95^{\circ} \mathrm{C}$ for $5 \mathrm{~min}$. The immunoprecipitated proteins were resolved by SDS-PAGE in $8 \%(\mathrm{wt} / \mathrm{vol})$ gels, and the radioactivity incorporated into FVII bands was analyzed using a Bio-Rad model 501 PhosphorImager and radiography on $\mathrm{X}$ OMAT-AR film (Eastman-Kodak Co., Rochester, NY).
In vitro transcription/translation of FVIIWT and FVIIMT. One $\mu \mathrm{g}$ of pT7FVIIWT and pT7-FVIIMT were linearized by EcoR I digestion and incubated in rabbit reticulocyte coupled transcription/ translation reactions (Promega Corp., Madison, WD) for $90 \mathrm{~min}$ at $30^{\circ} \mathrm{C}$. Twenty $\mu \mathrm{Ci}$ of translation grade methionine (DuPont-New England Nuclear, Billerica, MA) was included in the reactions to label the synthesized FVII protein, and a control reaction to which no plasmid DNA had been added was run in parallel. Aliquots of the reactions were electrophoresed on a $12 \%$ polyacrylamide gel under denaturing conditions.

Effect of protein degradation inhibitors on FVIIWT and FVIIMT levels. To study the effect of protein degradation inhibitors on FVII biosynthesis, confluent stably transfected CHO cells grown in $100-\mathrm{mm}$ dishes were incubated with media containing ammonium chloride $(50 \mathrm{mmol} / \mathrm{L})$, leupeptin $(100 \mu \mathrm{mol} / \mathrm{L}), \mathrm{N}$-acetyl-Leu-Leu-Norleucinal $(50 \mu \mathrm{g} / \mathrm{ml})$ or Brefeldin A (10 $\mu \mathrm{g} / \mathrm{ml})$ (Sigma, St. Louis, MO) dissolved according to the manufacturers' recommendations and used at previously published concentrations(1923). After $4 \mathrm{~h}$, cell lysates were harvested and assayed for FVII:Ag.

\section{Results}

Coagulation assays and genomic studies. The coagulation assays performed on the 5 year old patient from Oman revealed severe FVII deficiency with a FVII:C of less than 1\% of FVII:C and FVII:Ag of $10 \%$. The asymptomatic parents had FVII:C levels of 
Fig. 1 - Introduction of the 15bp insertion mutation into FVII cDNA by three overlapping PCR reactions.
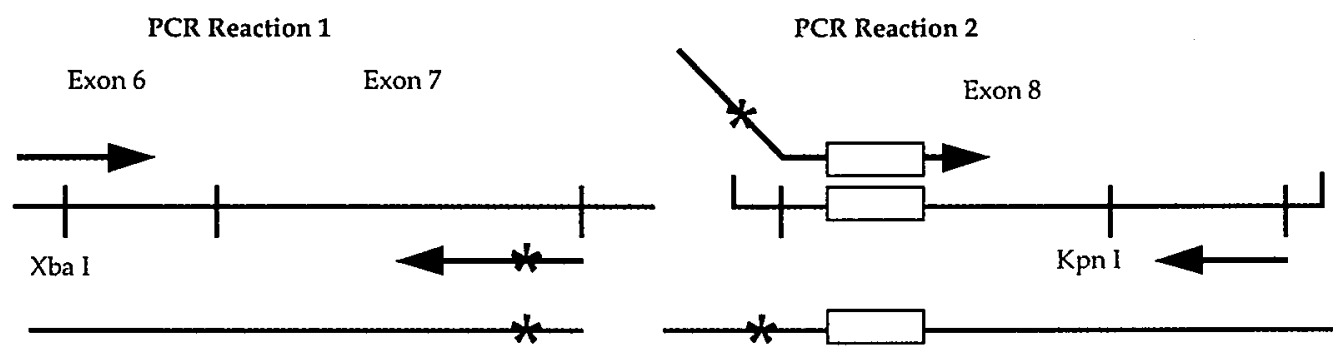

PCR Reaction 3

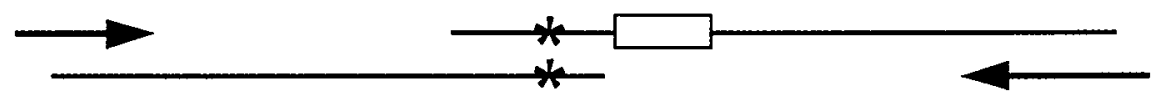

The arrowus $(\rightarrow)$ for the primers show directionality, the asterisk $(*)$ shows the introduced Apo I site and the box $(\square)$ represents the $15 b p$ insertion. The details of the three PCR reactions including templates, positions of the primers on FVII and restriction sites are included in text.

$50 \%$ (mother) and $60 \%$ (father). 'To determine the molecular abnormality causing FVII deficiency in the patient, the entire coding region and $490 \mathrm{bp}$ of promoter region of the FVII gene were amplified and screened by SSCP and heteroduplex analysis. An abnormally migrating fragment was detected in exon 8 by SSCP analysis. Sequence analysis of this fragment demonstrated a homozygous insertion-type mutation located at nucleotide 10554. This insertion was an in-frame 15 base pair (5 codon) duplication from Leu213 $\{73\}$ to Asp217 $\{77\}$ inclusive (CTC AGC GAG CAC GAC) and was located between codons 217 and 218.

\section{Structural analysis of the mutant FVIIa.} The superimposition and viewing of the crystal structure for the FVIIa-TF complex and two additional structures for unbound FVIIa (PDB codes 1dan, 1qfx and 1cvw) showed that the Leu213-Asp217 $\{73-77\}$ sequence had identical conformations at a surface loop in the first subdomain of the catalytic serine protease domain. They occur within a sequence 210-EHDLSEHDGDEQSRR-224, in which 10 residues possess charged sidechains and half are buried from solvent. A network of buried hydrogen bonds and salt bridges occur within this loop, which is highly exposed to solvent and adjacent to the 
Fig. 2 - Molecular graphics views of the 15bp insertion mutation (Leu213-Asp217ins) in the FVII catalytic domain.
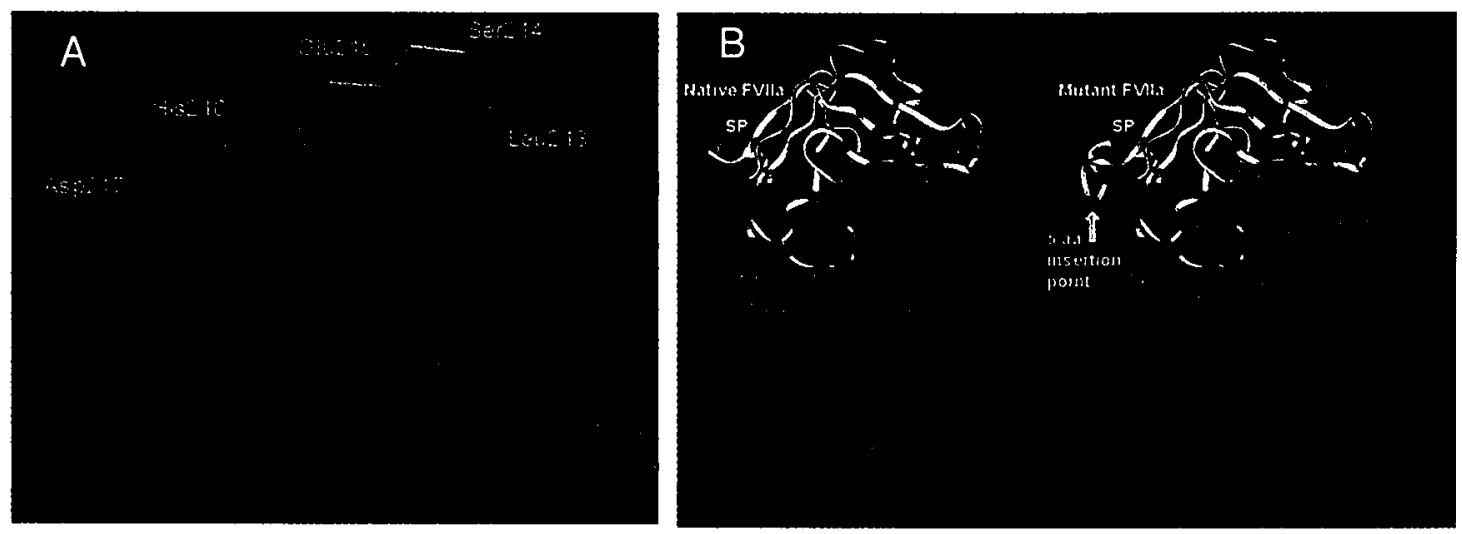

(a) In native FVIla (PDB code 1cow), the polypeptide mainchain backbone is shown in light blue with the exception of that for the insertion residues Let213-Asp217 which is in yellow. The calcium ion is shown in magenta, with its six ligands being the sidechain carboxyl oxygen atoms of Glu210 and Glu220, the mainchain carbonyl oxygen atoms of Asp212 and Glu215, and two water molecules. With the exceptions of Glu210 and Glu220, the sidechains are not showon.

(b) Comparison of native FVlla (left) wilh a model of FVlla containing the 15bp insertion mutation (right) (PDB code 1dan). The two structures are shown in ribbon views, where the N-terminal and C-terminal subdomains of the catalytic domain are shown in white and magento respectively. The EGF-1 and EGF-2 domains are shown in green, and are proximate to the two TF domains at the bottom (not shown). The insertion mutation is shown as a yellow ribbon, while the catalytic triad is represented by three red spheres on the opposite side of the domain to that of the 15bp insertion.

active site cleft between the two subdomains of the catalytic domain. The loop is followed by the long $\beta$-strand $G$ with many buried sidechains that passes over the top of the domain surface and ends at Asp242 \{102\} of the His-Asp-Ser catalytic triad.(7) The insertion of five residues at this location is therefore expected to disrupt the correct formation of the loop and the insertion of $\beta$-strand $G$ into the protein surface, and may lead to misfolded protein that may be degraded or not secreted. In addition to the possibility of misfolding, the insertion coincides with a calcium binding site formed by direct metal contacts with the sidechains of Glu210 $\{70\}$ and
Glu220 $\{80\}$ and with the mainchain oxygen atoms of Asp212 \{72\} and Glu215 \{75\}. Two water molecules fill the two remaining calcium coordination sites (Figure 2a). All six oxygen-calcium bond lengths range between 2.1-2.4 $\AA$ (PDB code 1cvw). The insertion will directly affect the Glu215-calcium interaction, as Figure 2a shows that the correct mainchain conformation on the loop from Asp212 $\{72\}$ to Glu215 $\{75\}$ is critical for this calcium-binding site. It is also likely that the $15 \mathrm{bp}$ insertion will disrupt the Glu220 interaction with calcium. In order to visualize the possible effects of the Leu213-Asp217 insertion on FVIIa, its sequence was added 
to the crystal structure of FVIIa by homology modelling methods. This was most simply achieved by the deletion of His216 \{76\} and Asp217 $\{77\}$, and reorienting these two residues outwards in order to permit the subsequent addition of the five additional amino acid residues. Figure $2 b$ showed that the loop could be readily incorporated into the FVIIa structure without steric problems. This indicated that mutant FVIIa might form a folded protein, although it was not possible to comment on the probability of this correct folding taking place.

Expression studies. To investi-
Fig. 3 - FVII:Ag expressed by COS-1 cells following transient transfection.

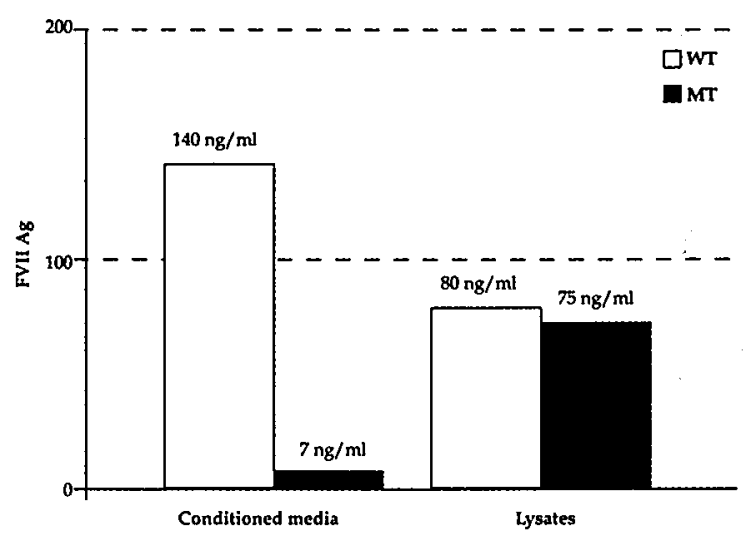

The concentrations of FVII:Ag in culture media and lysates of cells transfected with either $p E D F V I W T$ (open bars) or $p E D F V I M T$ (filled bars) were determined by ELISA after $36 \mathrm{hr}$, as described in Methods. The values shown are the mean from 6 replicate dishes. The concentration of FVII:Ag is expressed in $n g / m l$. gate the influence of the insertion mutation, the pEDFVIIWT and pEDF. VIIMT vectors were expressed in COS- 1 cells by transient transfection. ELISA assays of the cell lysates demonstrated that FVII:Ag levels of WT $\left(80 \mathrm{ng} / \mathrm{ml}\right.$ in $3 \times 10^{6}$ cells plated in $36 \mathrm{~h})$ and $\mathrm{MT}\left(75 \mathrm{ng} / \mathrm{ml}\right.$ in $3 \times 10^{6}$ cells plated in $36 \mathrm{~h}$ ) were similar. However, the FVII:Ag levels in the conditioned media of $\mathrm{MT}$ was significantly reduced to $5 \%(7 \mathrm{ng} / \mathrm{ml})$ of WT (140 ng/ml) (Figure 3). No Factor VII procoagulant activity was detectable in the conditioned media of cells transfected with FVIIMT (FVII: $\mathrm{C}<1 \%$ ), consistent with the result obtained by assay of the patient's plasma. Recombinant FVIIWT , in contrast, had normal procoagulant activity that was similar to the level of FVII:Ag.

To compare the synthesis of FVIIWT and

FVIIMT proteins, in vitro transcription/translation assays were performed. This experiment showed that, when both the mRNA and the nascent protein were protected from degradation, equivalent amount of FVIIWT and FVIIMT proteins were produced. It was noted that the FVIIMT protein, containing the additional 5 amino acids, migrated more slowly than the FVIIWT protein under denaturing conditions (Figure 4).

We then investigated FVII biosynthesis and secretion in CHO cells stably transfected with pEDFVIIWT cDNA or pEDFVIIMT cDNA. Follo-wing a $15 \mathrm{~min}$ pulse with ${ }^{35} \mathrm{~S}$ methionine, a chase was performed at 0,30 , 60,120 and $240 \mathrm{~min}$. At each time point, the recombinant FVIIWT in cell lysates was immunoprecipitated with Mab1476. 


\section{Rare Coagulation Disorders}

Detectable levels of FVIIWT were maximal at 60-120 min and decreased after this time as a consequence of protein secretion.

Approximately equal amo-unts of intracellular protein appeared to be synthesized for FVIIWT and FVIIMT. (Fig.5a: lane 1-5, 6-10) No intracellular accumulation was observed for FVIIMT (Figure 5a lane 1-10). However, in the conditioned media, FVIIMT was barely detectable at $120 \mathrm{~min}$ (Fig.5b lane 7) and there was only a very small amount (5 to $10 \%$ of FVIIWT) after $240 \mathrm{~min}$ (Fig.5b. lane 8). The same difference in electrophoretic mobility between FVIIWT and FVIIMT in the transcription/ translation experiment was also present in the immunoprecipitation analysis (Fig. 5a and $5 \mathrm{~b}$ ).

Effects of protein degradation inhibitors on FVII biosynthesis. Because metabolic labelling studies indicated that the FVIIMT protein was neither accumulating within the cell nor being secreted, we hypothesized that it might undergo intracellular degradation. We analyzed by ELISA the effects of various inhibitors of protein degradation on the intracellular FVII levels in stably transfected CHO cells (Table 1). $\mathrm{NH}_{4} \mathrm{Cl}$, a general inhibitor of lysosomal proteolysis, modestly increased WT FVII:Ag levels $(p=0.001)$ but not MT FVII:Ag $(p=0.74)$. Also treatment with leupeptin, which inhibits cathepsins $B, D, H, L$, did not change FVII:Ag levels significantly, demonstrating that FVIIMT is not likely to be degraded in the lysosome. We also investigated the effect of Brefeldin A on intracellular levels of FVII:Ag. Brefeldin A is a compound which blocks protein transport from the endoplasmic reticulum to the Golgi complex and causes retrograde translocation of Golgi components back to the endoplasmic reticulum. Intracellular levels of FVIIWT were increased by $50 \%$ after treatment with Brefeldin $A(p<0.0001)$, but there was no significant difference for levels of FVIIMT $(p=0.12)$. This result suggests that partial degradation of the mutant protein occurs in a preGolgi compartment.

\section{Discussion}

The vast majority of mutations in the FVII gene are missense mutations, but a few nonsense mutations and small deletions and insertions have also been reported(6,7). We report a novel homozygous insertion type mutation that causes a severe deficiency of FVII. The insertion was localized between 


\section{Chapter 3 -Molecular studies}

Fig. 5 - Pulse-chase of cell lysate and conditioned media of the cells stably transfected with pEDFVIIWT or pEDFVIIMT.

A

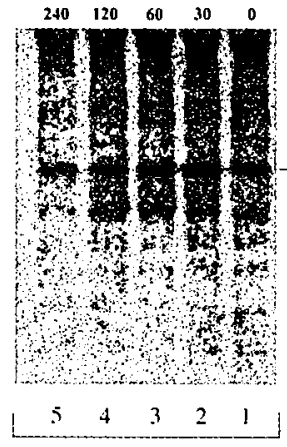

MT $\begin{array}{lllll}240 & 120 & 60 & 30 & 0\end{array}$

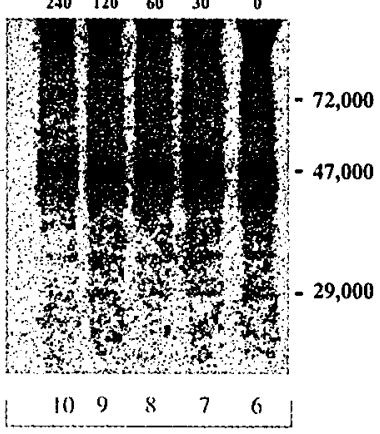

WT

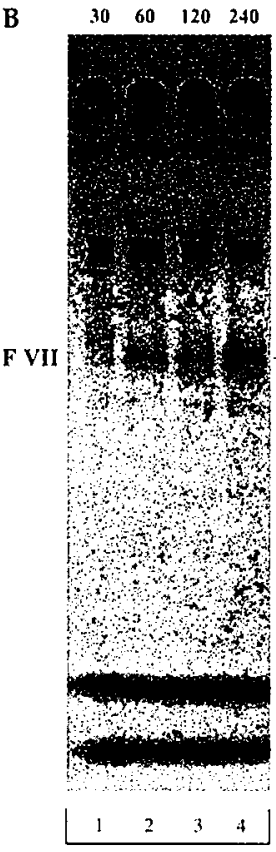

WT

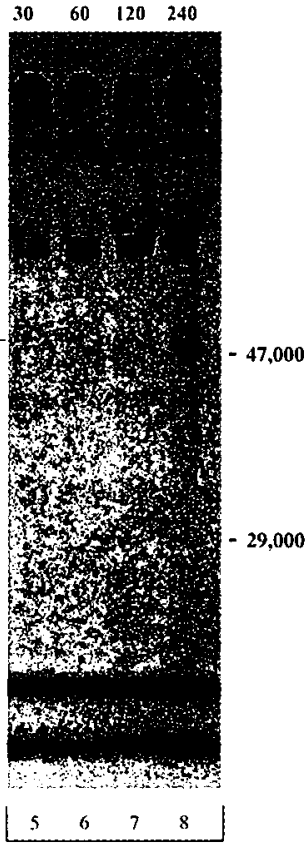

MT

After 15 min of pulse with S35 methionine, cells were chased for 30,60, 120 and 240 min. Equivalent amounts of cell lysate (A) and conditioned media (B) for both WT and MT constructs were immunoprecipitated using Mab1476 against FVII and analyzed by $8 \%$ SDS-PAGE under non reducing conditions. The molecular weight marker is localized at the right side of the figures.

codons 217-218 leading to a duplication of codons 213 to 217 . This mutation appears to be a classic case of slipped mispairing between two copies of a direct repeat (gcg agc acg ac) separated by 4 bp in which the wild type evolved by internal duplication, thereby setting up the possibility of a mutation caused by slipped mispairing. Computer views of the 5 amino acid insertion in the
FVIIa crystal structure revealed that the insertion occurs at the calcium binding site in the catalytic domain. The six calcium-oxygen ligands are the same as those reported for bovine trypsin(24). As the intracellular concentration of calcium is $1.5 \mathrm{mM}$ and its plasma concentration is $2.5 \mathrm{mM}(25)$, FVII is expected to interact with calcium as soon as it is synthesized. This report describes expe- 


\section{Rare Coagulation Disorders}

riments that characterize the first mutation directly affecting this FVII calcium binding site, and the lack of detectable procoagulant activity in FVIIMT stresses the importance of this site for the normal function of FVII.

Similar intracellular levels of FVII:Ag measured by ELISA or detected by immunoprecipitation confirmed the normal synthesis of FVIIMT. In contrast, the reduced levels of FVII:Ag observed in conditioned media supported our hypothesis of a secretion defect caused by the insertion mutation. After 240 min of chase, very small amounts of labelled FVIIMT were detected in the conditioned media.

However no intracellular FVII accumulation was seen suggesting the additional possibility of intracellular degradation. Thus, we chose to block various pathways of protein biosynthesis and transportation using $\mathrm{NH}_{4} \mathrm{Cl}$ (an inhibitor of lysosomal degradation) and leupeptin (an inhibitor of cathepsins $\mathrm{B}, \mathrm{D}, \mathrm{H}$ and $\mathrm{L}$ ). These inhibitors did not markedly change intracellular FVII:Ag levels. However treatment with Brefeldin A, an agent that usually blocks protein transport from the endoplasmic reticulum to the Golgi complex and causes translocation of Golgi components back to the endoplasmic reticulum, caused the intracellular level of FVIIWT to increase by $56 \%$, whereas no significant difference was seen for FVIIMT.

The small amount of FVIIMT protein secreted by transfected cells was not proteolytically active in a one-stage coagulation assay, and this confirmed the phenotype of the patient. The lack of activity in secreted FVIIMT is well explained in terms of the direct perturbation of two calcium binding sites at the mainchain carbonyl atoms of Asp212 and Glu215. The insertion of five residues implies that the loop mainchain structure will be modified and that many of the sidechain interactions between buried residue pairs involving His216, Asp217, Asp219, Glu220, Glu221 and Arg223 will no longer be possible. Thus the insertion is expected to disrupt the sidechain positions of the two other calcium binding ligands at Glu210 and Glu220. In agreement with the modelling, alanine scanning mutagenesis has shown that mutations in the sidechains of Glu210, Asp212, Leu213 and Glu220 lead to marked decreases in proteolytic function without affecting TF binding(26). Mutants involving Glu220 reduced the coagulant activity of FVII to $0.1 \%(27)$. Even though the homology modelling shows that it was possible to add a surface loop to the surface of FVII, the correct formation of folded mutant FVIIa may be difficult to achieve for reason of the extensive sidechain interactions in this loop region. If so, this would lead to the misfolding of the catalytic domain of FVIIMT. Accordingly FVIIMT may either be secreted at lower levels or be abnormally degraded.

This explanation would account for the observed reduction in the FVIIMT:Ag level when this was measured using two monoclonal antibodies specific for the FVIIa light chain $(9,12)$.

In conclusion, we report the first insertion 
mutation in the FVII gene and the first naturally-occurring mutation to be associated with the FVII calcium binding site in the catalytic domain. This mutation is associated with various defects including abnormal folding, intracellular degradation, secretion failure and lack of detectable procoagulant activity.

\section{References}

1.Hagen FS, GrayCL,O'HaraPetal: Characterization of a cDNA coding for human factor VII. Proc Natl Acad Sci USA.1986; 83: 2412-16.

2. Bauer KA, Kass BL, ten Cate, Hawiger JJ, Rosenberg RD: Factor IX is activated in vivo by tissue factor mechanism. Blood.1990; 76: 731 . 736

3. Osterud B, Rappaport S: Activation of factor IX by the reaction product of tissue factor and factor VII additional pathway for initiating blood coagulation. Proc Natl Acad Sci USA. 1977; 74: 5260-4.

4. O'Hara PJ, Grant FJ, Haldeman BA et al: Nucleotide sequence of the coding region for human factor VII, a vitamin $K$ dependent protein parteciping in blood coagulation. Proc Natl Acad Sci USA. 1987; 84: 5158-5162

5. Peyvandi F, Mannucci PM, Asti D, Abdoullahi M, Di Rocco N, Sharifian R: Clinical manifestation in 28 Italian and Iranian patients with severe factor VII deficiency. Haemophilia. 1997; 3: $242-46$

6. Cooper DN, Millar DS, Wacey A, Banner DW, Tuddenham EGD: Inherited factor VII defi-

\section{Acknowledgements}

The financial support of the Katharine Dormandy Trust for Haemophilia and Allied Disorders and the Medical Research Service of the Department of Veterans Affairs is gratefully acknowledged. We also thank Dr P. V. Jenkins and Mr J. Hinshelwood for assistance with the molecular graphics modelling.

ciency: molecular genetics and pathophysiology. Thromb Haemost. 1997; 78: 151-60.

7. Peyvandi F, Jenkins PV, Mannucci PM, et al: Molecular characterisation and three-dimensional structural analysis of mutations in 21 unrelated families with inherited Factor VII deficiency. Thromb Haemost 2000; August, 2000

8. Ashton AW, Boehm MK, Johnson DJD, Kemball-Cook G, Perkins SJ: The solution structure of human coagulation factor VIIa in its complex with tissue factor: A study of a heterodimeric receptor-ligand complex by $\mathrm{X}$-ray and neutron scattering and computational modelling. Biochemistry. 1998; 37: 8208-17

9. Banner DW, D'Arcy A, Chene C, et al: The crystal structure of the complex of blood coagulation factor VIIa with soluble tissue factor. Nature 1996; 380: 41-6.

10. Pike ACW, Brzozowski, AM, Roberts SM, Olsen $\mathrm{OH}$, Persson E: Structure of human factor VIIa and its implications for the triggering of blood coagulation. Proc Natl Acad Sci USA. 1999; 96: 8925.30

11. Kemball-Cook G, Johnson DJD, Tuddenham EGD, Harlos K: Crystal structure of active 


\section{Rare Coagulation Disorders}

site-inhibited human coagulation factor VIIa (des-Gla). J Struct Biol. 19991; 27: 213-223.

12. Coppola R, Tombesi S, Valentini F, Alborali S, Albertini A, Mannucci PM: Enzyme-linked immunosorbent assay of human factor VII based upon a monoclonal antibody that recognizes the native conformation of the protein. Thromb Res.1992; 68: 283-93.

13. Kunkel LM, Smith K.D, Boyer SH, et al: Analysis of human $\mathrm{Y}$ chromosome-specific reiterated DNA in chromosome variants. Proc Natl Acad Sci USA.1997; 74: 1245-9.

14. Orita M, Suzuki Y, Sekiya T, Hayashi K: Rapid and sensitive detection of point mutations and DNA polymorphisms using polymerase chain reaction. Genomics. 1989; 5: 874-9.

15. Broze GJ: Monoclonal antihuman factor VII antibodies: Detection in plasma of a second protein antigenically related to factor VII. J Clin Invest. 1985; 76: 937-46.

16. Jenkins PV, Pasi J, Perkins SJ: Molecular modelling of ligand and mutation sites of the Type A domains of human von Willebrand factor and their relevance to von Willebrand's disease. Blood. 1998; 91: 2032-44.

17. Arbini AA, Mannucci PM, Bauer KA: A Thr ${ }^{359}$ Met mutation in factor VII of a patient with a hereditary deficiency causes defective secretion of the molecule. Blood. 1996; 87: 5085-94.

18. Chasin LA, Urlaub G: Isolation of Chinese hamster cell mutants deficient in dihydrofolate reductase activity. Proc Natl Acad Sci USA.1980; 77: 4216-20.

19. Jensen T, Loa M, Pind S, Williams D, Goldberg A, Riordan J: Multiple proteolytic system including the proteasome, contribute to CFTR processing. Cell.1995; 83;129.35.

20. Lukacs G, Mohamed A, Kartner N, Chang $X$, Riordan J, Grinstein S: Conformational maturation of CFTR but not its mutant counterpart $(\triangle \mathrm{F} 508)$ occurs in the endoplasmic reticulum and require ATP. EMBO J. 1994;13:6076-86.

\section{Pipe S, Kaufman R: Factor VIII C2} domain missense mutations exhibit defective trafficking of biologically functional proteins. J Biol Chem.1996; 271: 25671-6.

22. Field M, Moran P, Li W, Keller G, Caras I: Retention and degradation of proteins containing an uncleaved glycosylphosphatidylinositol signal. $J$ Biol Chem.1994; 269: 10830-7.

23. Qu D, Teckmen J, Omura S, Perlmutter D: Degradation of a mutant secretory protein, al-antitrypsin $\mathrm{Z}$, in the endoplasmic reticulum requires proteasome activity. $J$ Biol Chem.1996; 271: 2791-95.

24. Bode $W$, Schwager $P$ : The single calcium binding site of crystalline bovine $\beta$-trypsin. FEBS Lett. $1975 ; 56: 139-143$

25. Kumar PJ, Clark ML (Eds): Clinical Medicine, Second Edition, Bailliere-Tindall, London, 1990

26. Dickinson CD, Kelly. CR, Ruf W: Identification of surface residues mediating tissue factor binding and catalytic function of the serine protease factor VIIa. Proc Natl Acad Sci USA.1996; 93: 14379.84.

27. Wildgoose P, Foster D, Schiødt J, Wiberg FC, Birktoft JJ, Petersen LC: Identification of a calcium binding site in the protease domain of human blood coagulation factor VII.

Evidence for its role in factor VII-tissue factor interaction. Biochemistry. 1993; 32: 114-9. 


\title{
Molecular analysis of the ERGIC-53 gene in 35 families with combined factor V-factor VIII deficiency
}

\author{
M. Neerman-Arbez, K.M. Johnson, M.A. Morris, J.H. McVey, \\ F. Peyvandi, W.C. Nichols, D. Ginsburg, C. Rossier, S.E. Antonarakis, \\ and E.G.D. Tuddenham
}

Department of Genetics and Microbiology, Division of Medical Genetics, University of Geneva Medical School

Haemostasis Research Group, MRC Clinical Sciences Centre, Imperial College School of Medicine, London, UK

Division of Medical Genetics, Cantonal Hospital of Geneva, Switzerland

Bonomi Haemophilia and Thrombosis Center, IRCCS Maggiore Hospital and University of Milano, Italy Department of Medicine, Howard Hughes Medical Institute, University of Michigan, Ann Arbor, MI

Blood 93; 2253-2260, 1999 


\section{Abstract}

Combined factor V-factor VIII deficiency (F5F8D) is a rare, autosomal recessive coagulation disorder in which the levels of both coagulation factors V and VIII are diminished. The F5F8D locus was previously mapped to a $1-\mathrm{cM}$ interval on chromosome $18 \mathrm{q} 21$. Mutations in a candidate gene in this region, ERGIC-53, were recently found to be associated with the coagulation defect in nine Jewish families.

We performed single-strand conformation and sequence analysis of the ERGIC-53 gene in 35 F5F8D families of different ethnic origins. We identified 13 distinct mutations accounting for 52 of 70 mutant alleles.

These were 3 splice site mutations, 6 insertions and deletions resulting in translational frameshifts, 3 nonsense codons, and elimination of the translation initiation codon. These mutations are predicted to result in synthesis of either a truncated protein product or no protein at all.

This study revealed that F5F8D shows extensive allelic heterogeneity and all ERGIC-53 mutations resulting in F5F8D are "null."

Approximately $26 \%$ of the mutations have not been identified, suggesting that lesions in regulatory elements or severe abnormalities within the introns may be responsible for the disease in these individuals. In two such families, ERGIC-53 protein was detectable at normal levels in patients' lymphocytes, raising the further possibility of defects at other genetic loci.

\section{Introduction}

Combined factor V-factor VIII deficiency (F5F8D) (MIM 227310) is a rare, recessive coagulation disorder characterized by reduction in levels of both factor $V$ and factor VIII, to less than $20 \mathrm{U} / \mathrm{dL}(1-4$.) The severity ranges from mild (factor $\mathrm{V}$ and VIII levels of 10 to $20 \mathrm{U} / \mathrm{dL}$ ) to moderate (levels 5 to 10 $\mathrm{U} / \mathrm{dL})(5)$. Linkage of the F5F8D locus to human chromosome $18 \mathrm{q}$ was reported in nine nonAshkenazi Jewish families by homozygosity mapping(6) and by classical linkage analysis in 19 families of Irani, Pakistani, and Algerian origin(7). The same locus was, therefore, implicated in different ethnic groups. The difference in clinical severity and the lack of a specific haplotype in the second group of families(7), in contrast to two distinct founder haplotypes reported by Nichols et al(6), suggested the existence of allelic heterogeneity, ie, that more than one mutation was responsible for the disease in this sample of families. Critical recombination events localized the F5F8D gene to an interval of approximately $1 \mathrm{cM}$, between markers D18S849 and D18S1103(7). ERGIC-53, which had been previously mapped to this region(8) and codes for a $53-\mathrm{kD}$ transmembrane protein resident in the endoplasmic reticulum-Golgi intermediate compartment(9), was shown by mutation analysis to be the gene responsible for F5F8D(1). Two mutations were identified. All Sephardic Jewish patients from five families tested were homozygous for a donor splice site mutation leading to premature protein truncation, and all 
patients from four Middle Eastern Jewish families had a single base pair insertion at codon 30. In Epstein-Barr virus (EBV) transformed cell lines from these patients, Western blotting and immunofluorescence analysis indicated complete absence of ERGIC-53 expression. (1) To investigate the molecular origin of this coagulation disorder we have studied 35 additional F5F8D families from different ethnic backgrounds by single-strand conformational analysis (SSCA) and sequencing of polymerease chain reaction (PCR) products of exons 1-13 and flanking intronic sequences of the ERGIC-53 gene. As expected from our previous haplotype analysis, 7 numerous mutations in the ERGIC-53 gene were found to be responsible for the disease. All 13 identified discrete mutations were predicted to lead to a deficiency or absence of functional protein. These mutations accounted for a total of 52 of 70 mutant alleles (74\%). In addition, a number of polymorphisms were identified, some of which result in amino acid changes.

\section{Materials and methods}

Description of families. Blood was collected from 16 families from Iran, 6 families of Pakistani origin, 8 from Italy, 2 of Chinese origin, and 1 each from Algeria, Britain, and South Africa (Table 1). Informed consent was obtained from all families. The majority of Iranian and Pakistani families were consanguineous (19 of 22) involving first cousin marriages. Factor V and factor VIII assays were performed by a one-stage procedure by using congenitally deficient plasma substrates and normal pooled plasma as reference (10). The levels of factor V:C and factor VIII:C detected in the plasma of affected individuals are shown in Table 1.

DNA isolation and PCR amplification. Genomic DNA was purified from blood leukocytes, according to standard protocols. The ERGIC-53 gene structure was determined by PCR and sequence analysis as described in another report (Nichols et al(11), this issue). For the mutation screening, one affected patient from each family (35 individuals) and four normal individuals were used. The ERGIC-53 gene was analyzed by PCR amplification of all 13 exons, including intron-exon junctions (with the exception of the intron 7-exon 8 junction). The primers used for the PCR amplifications $\left(5^{\prime}>3^{\prime}\right)$ are shown in Table 2.

Single-strand conformational analysis. Each sample was analyzed independently with either small- or large-format polyacrylamide gels: (a) PCR was performed from genomic DNA in a total volume of $15 \mu \mathrm{L}$, containing $2.6 \mathrm{pmol}$ of each primer, 1.3 $\mu \mathrm{mol} / \mathrm{L}$ of each dNTP, and $0.25 \mathrm{U}$ Taq polymerase. After denaturation at $94^{\circ} \mathrm{C}$, the amplification program consisted of 10 touchdown cycles of 30 seconds denaturation at $94^{\circ} \mathrm{C}, 30$ seconds annealing between 60 and $50^{\circ} \mathrm{C}$, and 30 seconds elongation at $72^{\circ} \mathrm{C}$ followed by 20 cycles ( 30 seconds $94^{\circ} \mathrm{C}, 30$ seconds $50^{\circ} \mathrm{C}, 30$ seconds $72^{\circ} \mathrm{C}$ ). Ten additional cycles were then performed in a new reaction on an aliquot $(2 \mu \mathrm{L})$ of the first $\mathrm{PCR}$ to reduce the amount of genomic DNA 
Tab. 1 - Identified Mutations, Geographical Origin, and Clinical Characteristics of F5F8D Patients

\begin{tabular}{|c|c|c|c|c|}
\hline Patient & $\begin{array}{l}\text { Origin } \\
\text { (Consanguinity) }\end{array}$ & $\begin{array}{l}\text { Phenotype } \\
\text { Factor V/VIlI }\end{array}$ & Mutation & ERGIC-53 Protein \\
\hline \multirow[t]{2}{*}{$\mathrm{A} 1$} & $\operatorname{Iran}(\mathrm{C})$ & $13 / 14$ & $912-913$ ins A (cd 305) & ND \\
\hline & & & 912-913insA (cd 305) & \\
\hline \multirow[t]{2}{*}{ A2 } & $\operatorname{lran}(C)$ & $7 / 7$ & $822 \mathrm{G}>\mathrm{A}(\mathrm{IVS} 7 \mathrm{DS}-1)$ & -* \\
\hline & & & $822 G>A$ (IVS7 DS -1) & \\
\hline \multirow[t]{2}{*}{$\mathrm{A} 3$} & $\operatorname{Iran}(\mathrm{C})$ & $14 / 13$ & 912-913insA (cd 305) & ND \\
\hline & & & 89-90insG (cd 30) & \\
\hline \multirow[t]{2}{*}{ A4 } & $\operatorname{Iran}(\mathrm{C})$ & $10 / 11$ & IVS9 $+2 \mathrm{~T}>\mathrm{G}$ & ND \\
\hline & & & IVS9 $+2 T>G$ & \\
\hline \multirow[t]{2}{*}{ A5 } & $\operatorname{Iran}(\mathrm{C})$ & $5 / 10$ & $?$ & ND \\
\hline & & & $?$ & \\
\hline \multirow[t]{2}{*}{ A6 } & $\operatorname{Iran}(\mathrm{C})$ & $14 / 13$ & $822 \mathrm{G}>\mathrm{A}($ (IVS7 DS -1$)$ & ND \\
\hline & & & $822 \mathrm{G}>\mathrm{A}$ (IVS7 DS - 1 ) & \\
\hline \multirow[t]{2}{*}{ A7 } & $\operatorname{Iran}(\mathrm{C})$ & $7 / 7$ & $?$ & ND \\
\hline & & & $?$ & \\
\hline \multirow[t]{2}{*}{ A8 } & $\operatorname{Iran}(\mathrm{C})$ & $5 / 6$ & 1214-1218delAAATG (cd 406) & ND \\
\hline & & & 1214-1218delAAATG (cd 406) & \\
\hline \multirow[t]{2}{*}{ A9 } & $\operatorname{Iran}(\mathrm{C})$ & $18 / 8$ & $822 \mathrm{G}>\mathrm{A}($ IVS7 DS -1$)$ & ND \\
\hline & & & $822 G>A($ IVS7 DS - 1 ) & \\
\hline \multirow[t]{2}{*}{ A10 } & $\operatorname{Iran}(\mathrm{C})$ & $12 / 15$ & 23delG (cd 8) & ND \\
\hline & & & 23delG (cd 8) & \\
\hline \multirow[t]{2}{*}{ A11 } & $\operatorname{Iran}(C)$ & $18 / 17$ & 89-90insG (cd 30) & ND \\
\hline & & & 89-90insG (cd 30) & \\
\hline \multirow[t]{2}{*}{ A12 } & $\operatorname{Iran}(C)$ & $2.5 / 2.2$ & $822 \mathrm{G}>\mathrm{A}$ (IVS7 DS - 1 ) & $-*$ \\
\hline & & & $822 \mathrm{G}>\mathrm{A}$ (IVS7 DS -1) & \\
\hline \multirow[t]{2}{*}{ A13 } & $\operatorname{Iran}(\mathrm{C})$ & $4.6 / 5.5$ & $?$ & ND \\
\hline & & & $?$ & \\
\hline \multirow[t]{2}{*}{ A14 } & Iran & $10 / 6$ & $?$ & ND \\
\hline & & & $?$ & \\
\hline \multirow[t]{2}{*}{ A16 } & Iran & $9 / 13.5$ & $\mathrm{R} 202 X(\mathrm{CGA}>\mathrm{TGA})$ & ND \\
\hline & & & $\mathrm{R} 202 \mathrm{X}(\mathrm{CGA}>\mathrm{TGA})$ & \\
\hline \multirow[t]{2}{*}{ A17 } & $\operatorname{Iran}(\mathrm{C})$ & $5 / 7.5$ & $\mathrm{R} 202 \mathrm{X}(\mathrm{CGA}>\mathrm{TGA})$ & ND \\
\hline & & & $\mathrm{R} 202 X(\mathrm{CGA}>\mathrm{TGA})$ & \\
\hline \multirow[t]{2}{*}{ A18 } & Pakistan (C) & $10 / 15$ & $K 302 X(A A A>T A A)$ & $-*$ \\
\hline & & & $\mathrm{K} 302 \mathrm{X}(\mathrm{AAA}>\mathrm{TAA})$ & \\
\hline \multirow[t]{2}{*}{ A19 } & Pakistan (C) & $14 / 14$ & $\mathrm{R} 456 \mathrm{X}(\mathrm{CGA}>\mathrm{TGA})$ & -* \\
\hline & & & $\mathrm{R} 456 \mathrm{X}(\mathrm{CGA}>\mathrm{TGA})$ & \\
\hline
\end{tabular}




\begin{tabular}{|c|c|c|c|c|}
\hline Patient & $\begin{array}{l}\text { Origin } \\
\text { (Consanguinity) }\end{array}$ & $\begin{array}{l}\text { Phenotype } \\
\text { Factor V/VIII }\end{array}$ & Mutation & ERGIC-53 Protein \\
\hline \multirow[t]{2}{*}{ A20 } & Pakistan (C) & $8 / 6$ & $\mathrm{~K} 302 \mathrm{X}(\mathrm{AAA}>\mathrm{TAA})$ & $-^{\star}$ \\
\hline & & & $\mathrm{K} 302 \times(\mathrm{AAA}>\mathrm{TAA})$ & \\
\hline \multirow[t]{2}{*}{ A21 } & Italy & $10 / 11$ & $?$ & +0 \\
\hline & & & $?$ & \\
\hline \multirow[t]{2}{*}{ A22 } & ltaly & $8 / 24$ & $?$ & $-{ }^{*}$ \\
\hline & & & $?$ & \\
\hline \multirow[t]{2}{*}{ A24 } & Italy & $17 / 26$ & M1T (ATG>ACG) & ND \\
\hline & & & M1T (ATG>ACG) & \\
\hline \multirow[t]{2}{*}{ A25 } & Italy & $9 / 10$ & $\operatorname{M1T}($ ATG $>A C G)$ & $-^{\star}$ \\
\hline & & & M1T (ATG>ACG) & \\
\hline \multirow[t]{2}{*}{ A26 } & Pakistan (?) & $18 / 18$ & $\mathrm{~K} 302 \mathrm{X}(\mathrm{AAA}>\mathrm{TAA})$ & ND \\
\hline & & & $\mathrm{K} 302 \mathrm{X}(\mathrm{AAA}>\mathrm{TAA})$ & \\
\hline \multirow[t]{2}{*}{ A27 } & China & $7 / 9$ & R456X (CGA>TGA) & $-{ }^{\star}$ \\
\hline & & & $\mathrm{R} 456 \times(\mathrm{CGA}>\mathrm{TGA})$ & \\
\hline \multirow[t]{2}{*}{ A28 } & UK & & $?$ & ND \\
\hline & & & $?$ & \\
\hline \multirow[t]{2}{*}{ A29 } & South Africa & $11 / 22$ & $?$ & +0 \\
\hline & & & $?$ & \\
\hline \multirow[t]{2}{*}{$\mathrm{A} 30$} & Pakistan (C) & $6 / 3$ & $\mathrm{~K} 302 \mathrm{X}(\mathrm{AAA}>\mathrm{TAA})$ & ND \\
\hline & & & $\mathrm{K} 302 \mathrm{X}(\mathrm{AAA}>\mathrm{TAA})$ & \\
\hline \multirow[t]{2}{*}{ A.31 } & Pakistan (C) & $14 / 18$ & $\mathrm{~K} 302 \mathrm{X}(\mathrm{AAA}>\mathrm{TAA})$ & ND \\
\hline & & & $\mathrm{K} 302 \mathrm{X}(\mathrm{AAA}>\mathrm{TAA})$ & \\
\hline \multirow[t]{2}{*}{ A33 } & Italy & & $?$ & ND \\
\hline & & & $?$ & \\
\hline \multirow[t]{2}{*}{ A34 } & Italy & $9 / 27$ & IVS5 + $1 \mathrm{G}>\mathrm{T}$ & ND \\
\hline & & & IVS5 + $1 \mathrm{G}>\mathrm{T}$ & \\
\hline \multirow[t]{2}{*}{ A35 } & Italy & $6 / 23$ & IVS5 +1 G>T & ND \\
\hline & & & IVS5 +1 G>T & \\
\hline \multirow[t]{2}{*}{ A.36 } & Italy & $1.4 / 2.7$ & 1208-1209insT (cd 403) & ND \\
\hline & & & 1208-1209insT (cd 403) & \\
\hline \multirow[t]{2}{*}{ A37 } & China (?) & $17 / 19$ & R456X (CGA>TGA) & ND \\
\hline & & & R456X (CGA>TGA) & \\
\hline \multirow[t]{2}{*}{ B1 } & Algeria (C) & & 31delG (cd 11) & ND \\
\hline & & & $1 \mathrm{delG}(\mathrm{cd} 11)$ & \\
\hline
\end{tabular}

F5F8D levels were mensured as described in Materials and Methods. Western blot nalysis of ERGIC-53 protein levels was as described (see Materials and Methods and Fig 3).

Abbreviation: ND, not determined. * Indicates no ERGIC-53 protein detected. ${ }^{\circ}$ Indicates normal ERGIC-53 levels. 
Tab. 2 - Primers Used for PCR Amplifications ( $\left.5^{\prime}>3^{\prime}\right)$

\begin{tabular}{lll} 
Exon & Forward & Reverse \\
\hline 1 & TCG CGT TCC AGA ATC CAAG & TCA GCA CAC CAG GGT AGC \\
2 & CAG TTT GGA AAT GTA CAT TGA G & GGG AAC AGT TAG AGG CTA G \\
3 & CTA GCC TCT AAC TGT TCC C & CTC ACA GCC TAA CTC TGT TG \\
4 & TGT AAG TCA CTT CAT AGT AC & CAA TGT ATT TCA TAA GGA TTC C \\
5 & TGA AAA GCT GAG TGT CTT GT & GAA AAG TGA TAC TGT AAC ATT G \\
6 & GAA ACA AAA CTG AAT AGT AGT C & ACA AGT CTA CAT ATC CCT AA \\
7 & AGA GTG CCA TTG CCT TTA CC & CAA ACC TAA GTT AGT CTT CC \\
8 & CAC CAG ATA AAG AAA TTT CG & AGG CAA CAC AGA GAC TCA AG \\
9 & CAC TTT GGT CAC TTA CGT TA & TCT ATG AGC ACA TAG TAC AG \\
10 & GGG AAG TAA AGA AGA AGG GC & AAT CAC ATA ACA CAC AAA CG \\
11 & GTG ATT TTA TTG TAT CAA GAG & AGT ATG AGT TCT TCC TTT CC \\
12 & GGG GAT AGA AGG TTT TCT GG & GAA CAT AGA TAA CTT AGT TG \\
13 & CTG TTC ATT TCA GTT CAC AT & AAT TCC CTC AAA ACG ACA TC
\end{tabular}

versus amplified product before SSCA. PCR products were denatured with an equal volume of denaturation buffer $(95 \%$ formamide, $0.05 \%$ xylene cyanol, $0.05 \%$ bromophenol blue) for 10 minutes at $94^{\circ} \mathrm{C}$. A 6- $\mu \mathrm{L}$ sample of each was then loaded on a 12.5\% GeneGel Excel (Pharmacia Biotech, St Albans, UK). Electrophoresis was at $600 \mathrm{~V}$ at $12^{\circ} \mathrm{C}$ for 3 hours (for fragments of approximately $300 \mathrm{bp}$ : ie, exons 1 , $2,6,7,9,11,12,13$ ) or 2 hours (for fragments of approximately $200 \mathrm{bp}$ : ie, exons 3 , $4,5,8,10)$. The gels were stained by DNA silver staining (Pharmacia Biotech). SSCA variants were purified and directly sequenced with the primers used for the amplification with a semiautomated sequencer (ABI 377; Perkin-Elmer Applied Biosystems, Foster City, CA), using standard protocols. Mutant alleles of heterozygous patients were cloned by using TA cloning (Invitrogen, La Jolla, CA) and puri- fied and sequenced as previously described. (b) PCR was performed from genomic DNA in a total volume of $50 \mu \mathrm{L}$ of $50 \mathrm{mmol} / \mathrm{L}$ $\mathrm{KCl}, 10 \mathrm{mmol} / \mathrm{L}$ Tris- $\mathrm{HCl} \mathrm{pH} 8.8,1.5$ $\mathrm{mmol} / \mathrm{L} \mathrm{MgCl}_{2}, 0.1 \%$ Triton X-100 containing $150 \mathrm{ng}$ of each primer, $200 \mu \mathrm{mol} / \mathrm{L}$ of each dNTP and $1 \mathrm{U}$ of Red Hot DNA polymerase (Advanced Biotechnologies, Epsom, UK). After denaturation at $94^{\circ} \mathrm{C}$ for 7 minutes, 30 cycles of denaturation: $94^{\circ} \mathrm{C}, 1$ minute; annealing: either $50^{\circ} \mathrm{C}$ or $55^{\circ} \mathrm{C}, 1$ minute; extension: $72^{\circ} \mathrm{C}, 3$ minutes were performed followed by a final extension at $72^{\circ} \mathrm{C}$ for 10 minutes. PCR products were labeled by the incorporation of $\alpha^{33} \mathrm{Pd}$-ATP ( $56 \mathrm{kBq} / 50 \mu \mathrm{L}$ reaction, $377-110 \mathrm{Tbq} / \mathrm{mmol}$; Amersham Life Science, Little Chalfont, UK). SSCA was performed as described by Michaelides et al(12) on a 40-cm polyacrylamide gel run at $4^{\circ} \mathrm{C}$. PCR products were purified by filtration by using a Microcon 100 spin column (Amicon, Stonehouse, UK) 
before direct sequencing with the thermosequenase dye terminator cycle sequencing kit (Amersham Life Science) according to the manufacturer's instructions and analyzed on an Applied Biosystems 373A DNA automated sequencer (Perkin-Elmer Applied Biosystems, Warrington, UK). The primers used for PCR and direct sequence analysis were as in Table 2, with the exception of $\left(5^{\prime}>3^{\prime}\right)$ exon 1, F: TCGCGTTCCA GAATCCAAG, R:AGCA-CACCAGGGTA GCCG; exon 6, F: AGTCATAAAATGGA TCGATTG, R: TTCCCAATAAAACACAC CTC; and exon 8, F: TGTT-AACCTTTCCG TAGTGG, R: GCTAGGCAA-CACAGACT CAA.

Allele-specific PCR. The $822 \mathrm{G}>$ A mutation was analyzed by allele-specific PCR amplification using the following primers: $\left(5^{\prime}>3^{\prime}\right)$ : GTAATCTCCTATGGAAC'TTTT and either the wild-type TTGAAAATATG TAAAA-TTACT or mutant TTGAAAATATGTTTGTAAAAT-TACC. After denaturation at $94^{\circ} \mathrm{C}$ for 7 minutes, 30 cycles of denaturation: $94^{\circ} \mathrm{C}, 1$ minute; annealing: $53^{\circ} \mathrm{C}, 1$ minute; extension: $72^{\circ} \mathrm{C}, 3$ minutes were performed followed by a final exten. sion at $72^{\circ} \mathrm{C}$ for $10 \mathrm{~min}$. The products were analyzed by electrophoresis on $2 \%$ agarose gels.

Analysis of intragenic polymorphic markers. The G3R polymorphism was analyzed by restriction digestion of the exon 1 PCR product with BamH1 (G3, BamH1 site; R3, no BamH1 site). Similarly, the $R 14 \mathrm{Q}$ polymorphism was analyzed by restriction digestion of the exon 1 PCR product with EagI (R14 EagI site; Q14, no EagI site). The R117 polymorphism was studied by SSCA of the exon 2 PCR product.

RT-PCR analysis. Polyadenylated RNA was isolated from EBV transformed lymphocytes and first-strand cDNA synthesis performed according to standard techniques (Amer-sham Pharmacia Biotech, St Albans, UK) with $200 \mathrm{ng}$ of an ERGIC-53 exon 8 specific antisense primer: 5'-TTTATCCAATTCTTG-TTGAAAG$3^{\prime}$. Five microliters of the reaction was used for PCR amplification with an ERGIC-53 exon 6 specific oligonucleotide primer: 5'-AATGATCAATAATGGCTTTACA- $3^{\prime}$ and the exon 8 specific primer used for the cDNA synthesis under the following conditions: (a) Initial denaturation $95^{\circ} \mathrm{C}, 5$ minutes then 25 cycles of denaturation, $94^{\circ} \mathrm{C}, 30$ seconds; (b) Annealing, $57^{\circ} \mathrm{C}, 30$ seconds; (c) Elongation, $72^{\circ} \mathrm{C}, 30$ seconds, and (d) A final elongation step at $72^{\circ} \mathrm{C}, 10$ minutes. A further $5 \mu \mathrm{L}$ of the reverse transcription (RT) was used for PCR amplification of GAPDH by using the following oligonucleotides: 5'-T-GAGTACGTC GTGGAGTCCAC-3' and 5'-ACCAGGAAAT GAGCTTGACA-3'. The products were analyzed by $2 \%$ agarose gel electrophoresis.

Western blot analysis. ERGIC-53 protein was detected by Western blot analysis as previously described (1) on EBV transformed cell lines from affected and carrier individuals in families A18, A19, A20, A21, $\mathrm{A} 22, \mathrm{~A} 25, \mathrm{~A} 27$, and $\mathrm{A} 29$. 


\section{Results}

A total of 35 patients, ie, one affected individual per family, were analyzed for mutations in the ERGIC-53 gene. Each of the 13 exons and the adjacent intron-exon boundaries of the ERGIC- 53 gene were amplified by PCR and analyzed in two laboratories by SSCA with both small and large format polyacrylamide gels. Representative SSCA patterns of nine mutations are shown in Fig 1. In families for whom no mutation was identified by SSCA, each exon (complete with the flanking intronic sequences) was sequenced.

Many variant SSCA patterns were identified. For each discrete pattern, the appropriate fragment was subjected to nucleotide sequencing. In all cases, a particular SSCA pattern was associated with a unique sequence difference. All heterozygous sequence variants were characterized by direct DNA sequencing of both strands of the PCR products and, in some cases, the PCR products were cloned and sequenced.

A total of 13 definite mutations, representing 52 of 70 F5F8D alleles, were identified (Table 1, Fig 2). We have confirmed the high degree of allelic heterogeneity suggested by our previous haplotype analysis(7), which is in marked contrast to the founder effect observed in Jewish families by Nichols et al $(1,6)$. The majority of the patients in whom mutations were identified are true homozygotes rather than compound heterozygotes (25 of 26), largely because of the high degree of consanguinity found in the parents of patients with this rare, autoso-
Fig. 1 - Examples of SSCA for nine discrete mutations in ERGIC-53. SSCA was performed according to protocol 1 in Materials and Methods. In each panel, the abnormal pattern caused by the mutation is in the middle lane surrounded by two controls.

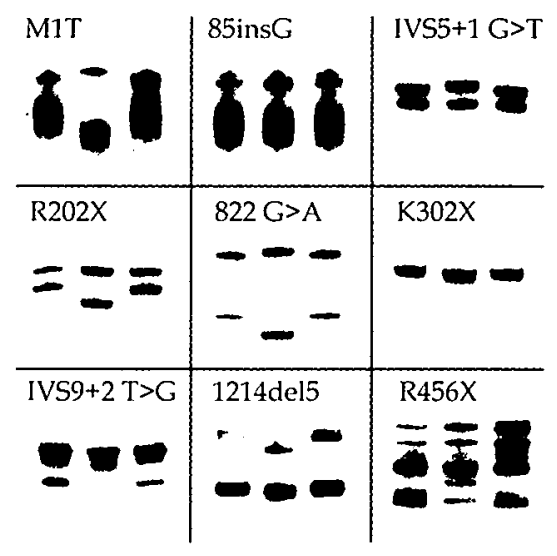

mal recessive disease (Table 1).

Nonsense mutations. Three different nonsense mutations were found, in exons 5,8 , and 11, accounting for a total of $20 \mathrm{~F} 5 \mathrm{~F} 8 \mathrm{D}$ alleles (27\% of all mutant alleles) (Table 1 , Fig 2). One of these, K302X (AAA > TAA), was homozygous in five of the six Pakistani families studied. The other two, R202X and R456X, were CGA to TGA mutations in accordance with the known $\mathrm{CpG}$ to $\mathrm{TpG}$ hypermutability(13). The R456X was found in both Chinese and Pakistani families on a different haplotype (A19 homozygous for R117R cgg; A27 homozygous for R117R cga) showing recurrence of this mutation.

Deletions and insertions. A total of six small deletions and insertions leading to disruption of the reading frame and prema. 
Fig. 2 - Schematic representation of the ERGIC-53 gene showing mutations causing combined F5F8D (above the gene) and normal polymorphisms (below). Exons, indicated by rectangles, are numbered from 1 to 13 and are drawn to scale. The coding portion of the gene is shaded, with the white portion of exon 1 representing the $5^{\prime}$ UTR and the white portion of exon 13 the $3^{\prime}$ UTR, theexactsizeof whichisunknown.

The introns are indicated by narrow lines and are not to scale.

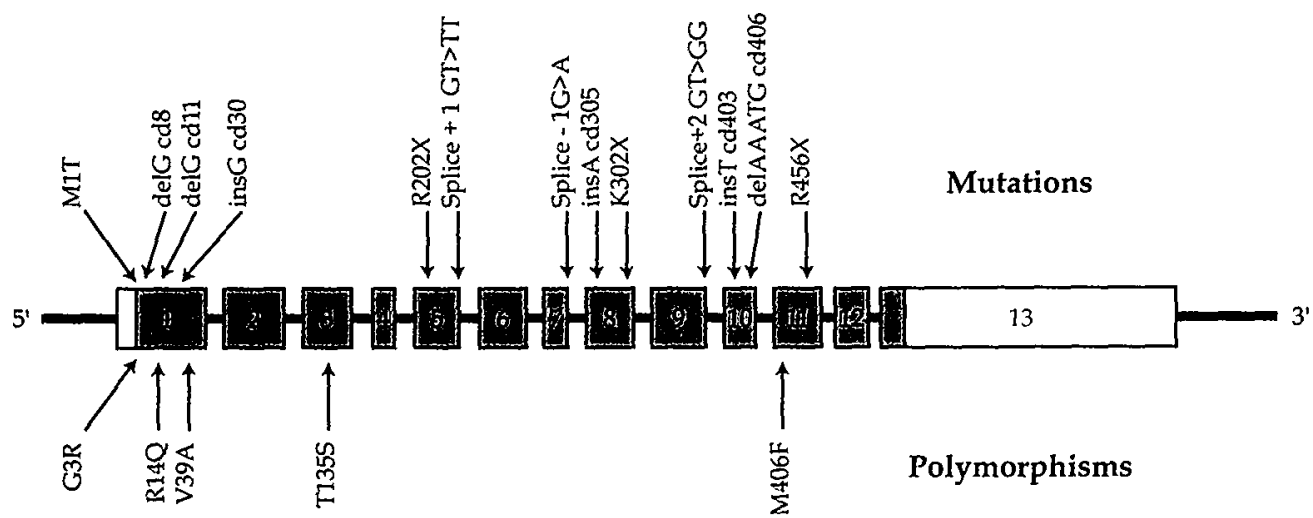

ture termination of translation were identified, on 14 different mutant alleles (Table 1, Fig 2). These were in exon $1,23 \mathrm{del} G$ (in a G4 tract), 31delG (in a G3 tract), 89-90insG (in a G4 tract); in exon 8, 912-913insA (in an A8 tract); in exon 10, 1208-1209ins T, and 1214-1218delAAATG (deletion of one of two copies of a repeated pentanucleotide). The 89-90insG mutation, which we found in two Iranian families, is the common mutation of Middle Eastern Jewish families(1).

Missense mutation in the initiator ATG. A mutation of particular interest was found in the translation initiation codon in two Italian families from our study (Table 1, Fig 2 ), and four Italian families in the report by Nichols et al(11). This ATG > ACG mutation is predicted to abolish translation since the next in frame ATG in the coding sequence is found in exon 6 , thus leading to the complete absence of ERGIC-53, as confirmed by Western blotting.

Splice site mutations. Two different splice site mutations predicted to result in severe abnormality of RNA processing and one putative splice site mutation were identified in three different exons accounting for a total of 14 F5F8D alleles (Table 1, Fig 2). In intron 5, a $\mathrm{G}>\mathrm{T}$ substitution at the invariant $\mathrm{GT}$ dinucleotide of the donor splice site (GT > TT) was found in homozygosity in families A34 and A35, both from Italy. In intron 9 , the donor splice site invariant dinucleotide GT was mutated to GG in both alleles of the affected members of family $\mathrm{A} 4$ from Iran. Both of these mutations are 
Fig. 3 - (A) Cartoon representation of intron 6-intron 8 of the ERGIC-53 gene. The primers used for the RT-PCR analysis are indicated by an arrow and the asterisk indicates the position of the IVS7-1 mutation. Potential RT-PCR products resulting from normal splicing, inclusion of intron 7 or skipping of exon 7 are shown. (B) Agarose gel electrophoresis of the RT-PCR products after amplification of polyadenylated RNA with ERGIC-53 exon 6-exon 8 specific primers and glyceraldehyde 3-phosphate dehydrogenase (GAPDH) specific primers. The GAPDH amplification was a control for mRNA integrity. The cDNA synthesis was primed with the exon 8 specific primer and oligo dT. Lane $M$, markers; lane 1, individual A2 (homozygous $822 \mathrm{G}>\mathrm{A}$ ); lane 2, individual A12 (homozygous $822 \mathrm{G}>\mathrm{A}$ ); lane 3, human endothelial cell line; lane 4, unaffected individual; lanes 5, 6, and 7, affected individuals with the M1T mutation; lane 8 , no DNA control. The arrow marks the normally spliced product. The asterisk marks the incorrectly spliced product. (C) DNA sequence chromatograms of: 1, the incorrectly spliced product, resulting from skipping of exon 7, observed in RT-PCR of polyadenylated lymphoblastoid RNA from individual A12; 2, the major product observed in RT-PCR of polyadenylated RNA from a human endothelial cell line.

The exon boundaries are indicated by an arrow.

A

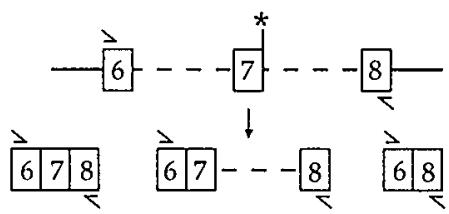

B

$\begin{array}{lllllllll}M & 1 & 2 & 3 & 4 & 5 & 6 & 7 & 8\end{array}$

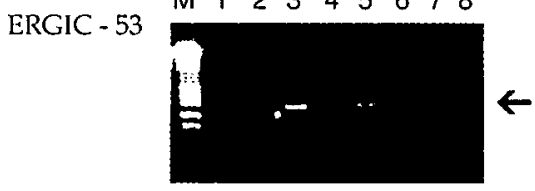

$\mathrm{C}^{1}$

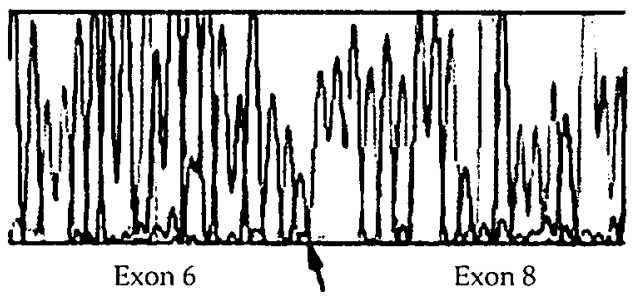

expected to result in abnormal splicing of the ERGIC-53 mRNA(14). Indeed, a different mutation in the same donor splice site of intron 9 (GT > GC) was previously identified in five Sephardic Jewish families, resul-
$\begin{array}{llllllll}M & 1 & 2 & 3 & 4 & 5 & 6 & 78\end{array}$

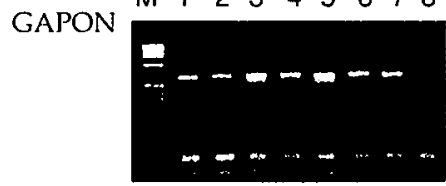

2

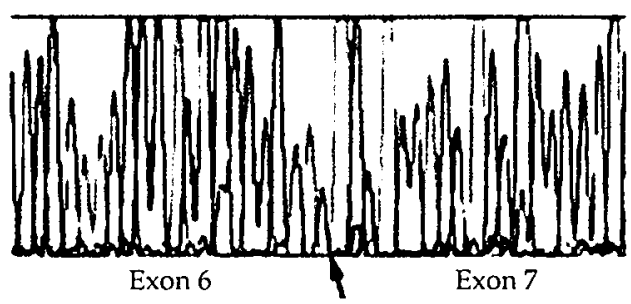

ting in an apparently complete block of splicing of this intron(1).

Another modification, a $\mathrm{G}>\mathrm{A}$ change in the last nucleotide of exon $7(822 \mathrm{G}>\mathrm{A})$, ie, in the -1 position of the donor splice site con- 
sensus sequence of intron 7 was found in homozygosity in four Iranian families: A2, A6, A9, and A12 (Table 1, Fig 2). This mutation does not change the amino acid corresponding to the modified codon as both CCG and CCA code for proline. However, it is possible that abnormal splicing occurs at least in some mRNA molecules because the sequence surrounding the splice site is modified. We screened the DNA of 24 unaffected and the remaining 13 affected Iranians by allele-specific PCR; none carried the mutation.

To determine the consequences of this mutation on ERGIC-53 mRNA we isolated polyadenylated RNA from lymphoblastoid cell lines from patients: A2, A12 (both homozygous $822 \mathrm{G}>\mathrm{A}$ ), A24 and A25 (homozygous M1T), and one unaffected individual. cDNA synthesis was primed by using an oligonucleotide corresponding to the antisense sequence of exon 8. RT-PCR between exons 6 and 8 followed by sequencing of the products confirmed that in $\mathrm{A} 2$ and A12, exons 6 and 8 were directly contiguous after the skipping of exon 7; no normal cDNA was present. No skipping of exon 7 was observed in the other tested individuals (Fig 3). Skipping of exon 7 leads to absence of ERGIC-53 protein in lymphoblasts (Table 1, A2 and A12).

Polymorphisms. The SSCA and nucleotide sequence analysis showed several common polymorphisms in the ERGIC-53 gene that result in amino acid substitutions. These substitutions are not associated with nor do they cause F5F8D because they were found in homozygosity in normal individuals, or in affected alleles in which another, deleterious, mutation was also present. These polymorphisms are R14Q (CGG to CAG), V39A (GTC to GCC), T153S (ACT to TCT), and M410L (ATG to TTG) (Fig 2). In addition there is a common CGA to CGG polymorphism at the Arg codon 117 that does not result in an amino acid substitution. Furthermore, a deletion of $2 \mathrm{Ts}$ at nucleotides 16-17 of IVS4 was also commonly observed. These polymorphisms may be useful in linkage studies involving chromosome 18q21. In our study, these polymorphisms allowed us to confirm the compound heterozygosity (ie, two different mutations on the two ERGIC-53 alleles) observed in the Iranian patient A3 (Table 1) because this patient was also heterozygous for the R14Q and $\mathrm{R} 117$ polymorphisms.

In Iranian family A14, there was a nucleotide substitution $G$ to $A$ at codon 3 resulting in an amino acid substitution glycine to arginine. This substitution is within the hydrophobic 30 -amino acid signal sequence. This substitution was not present in the DNA of any other affected individual from the Iranian sample and was not present in 24 unaffected Iranian individuals tested.

Western blot analysis of ERGIC-53 protein levels. Western blot hybridization confirmed the absence of detectable ERGIC-53 protein for two nonsense mutations (K302X, $\mathrm{R} 456 \mathrm{X}$ ) and one missense mutation (M1T), (Table 1 and Fig 4). It also showed the presence of detectable ERGIC-53 protein in individuals A21 and A29, two patients with 
Fig. 4 - Western blot analysis of ERGIC-53 protein levels in selected families with F5F8D (see Table 1 for the nature of the ERGIC-53 mutation present in each affected individual). $\mathrm{N}$ indicates a normal control, lanes $\mathrm{C} 1$ and $\mathrm{C} 2$ are two different mutations from reference 1 (C1: 86-89insG; C2 IVS9 + 2

$\mathrm{T}>\mathrm{C}$ ). The arrow indicates the position of the ERGIC-53 protein band. Normal levels of ERGIC53 protein were also found in two unaffected family members from family A19.

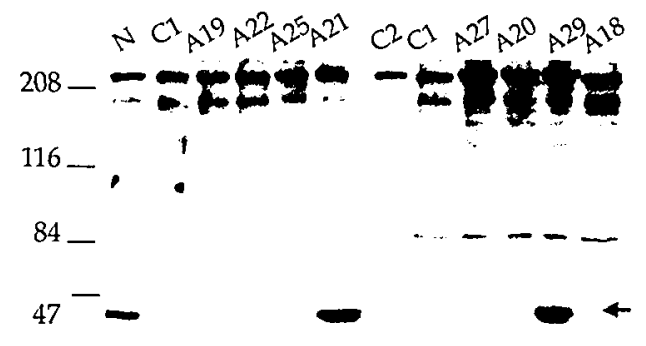

no detectable mutation in the ERGIC-53 coding sequence and flanking intron-exon boundaries.

\section{Discussion}

In this study we have analyzed the ERGIC53 gene in 35 families with F5F8D. We have confirmed that mutations in the ERGIC-53 gene are definitely responsible for the deficiency in $74 \%$ of the families analyzed. In contrast to the two distinct founder mutations found to be responsible for the disorder in Sephardic and Middle Eastern Jewish families, we identified 13 distinct mutations accounting for 52 mutant alleles in F5F8D families of multiple ethnic origins. There were 3 different splice site mutations, 6 insertions and deletions resulting in translational frameshifts, 3 nonsense mutations, and a missense mutation in the initiator methionine. In addition we also identified several amino acid polymorphisms.

One of the splice site mutations, found in homozygosity in four Iranian families but absent in 74 other Iranian alleles tested, was situated at position - 1 of the donor splice site consensus sequence of intron 7 (822G $>$ A). At this position in the consensus donor splice site, $\mathrm{G}$ is found in $78 \%$ and $\mathrm{A}$ in only $10 \%$ of mammalian genes; therefore, we confirmed by RT-PCR analysis that this modification leads to exon skipping and loss of the open reading frame. There are 56 known $\mathrm{G}$ to $\mathrm{A}$ mutations in the 1 nucleotide of the donor splice site in human genes associated with disorders(14) (Human Gene Mutation Database; http://www.uwcm.ac.uk/uwcm/-mg/hgmd0.html, including factor V, factor VII, factor VIII, and factor IX. Abnormal splicing was studied in several of these cases and the resulting exon skipping ranged from $30 \%$ to $100 \%$. In addition, use of cryptic donor splice sites has been reported as resulting in translational frameshift and abnormal protein $(14,16)$.

One of the sequence differences, G3R, which was found in homozygosity in one Iranian family (A14) but was absent in 80 other Iranian alleles tested, is within the 30 amino acid signal sequence and may be either a polymorphism or a causative mutation. This position is not highly conserved. For example, the rat sequence contains valine at position 3 (Genbank no. U44129). The G3R substitution does not change the probability that the first 30 amino acids is a 
signal peptide (http://psort.nibb.ac.jp; http://www.cbs.-dtu.dk/services/SignalP). However, it is now recognized that signal sequences have a more complex structure than previously anticipated, allowing for multiple and independent interactions with the translocation machinery(17) (see Note Added in Proof).

There appears to be little or no correlation between the precise mutation and the severity of the $\mathrm{F} 5 \mathrm{~F} 8 \mathrm{D}$ phenotype because (a) all identified mutations are predicted to lead to an absence of mature protein and (b) some recurrent mutations were found in association with strikingly different levels of factor $\mathrm{V}$ and factor VIII (compare, for example, families A6 and A12 or families A26 and A30).

The human ERGIC-53 is a $53-\mathrm{kD}$ transmembrane resident protein of the ER-Golgi intermediate compartment, a distinctive vesicular organelle in the secretory pathway(18). The protein is homologous to leguminous lectins, presenting mannoseselective and calcium-dependent binding(1921). Additional ERGIC-53 homologues have been identified in the rat, Xenopus laevis, and Caenorhabdi-tis elegans $(22,23)$ (Genbank accession no. Z81097). The importance of ERGIC-53 protein in the efficient secretion of the coagulation factors $V$ and VIII has clearly been established by its causative role in F5F8D (data presented in this report, the accompanying report by Nichols et al(11), and reference 1). Factor $V$ and factor VIII are homologous proteins that share a conserved domain structure, having deri- ved from a common ancestor molecule, with the $\mathrm{A}$ and $\mathrm{C}$ domains of the two factors showing $40 \%$ sequence identity $(24,25)$. Both factor $V$ and factor VIII are subject to extensive posttranslational modification, which includes the addition of multiple oligosaccharide residues, predominantly in the B-domain. Therefore, ERGIC-53 most probably interacts with the B-domains of factor $\mathrm{V}$ and factor VIII via a lectin like linkage. All of the mutations in ERGIC-53 described to date are null mutations. However, there is still some factor V and factor VIII activity in the plasma of the affected individuals, suggesting that there may be several bypass mechanisms for the transport of factor $V$ and factor VIII from the ER to the Golgi. ERGIC-53 may also be required for the secretion of many other glycoproteins whose loss is not sufficient to cause a clinically recognizable phenotype. Although we have identified approximately $74 \%$ of the mutations responsible for $\mathrm{F} 5 \mathrm{~F} 8 \mathrm{D}$ in our patient sample, $26 \%$ of the mutations have not been identified despite screening by SSCA with two different experimental conditions and sequencing the entire coding sequence and intron-exon boundaries of the ERGIC-53 gene. These results are similar to those reported by Nichols et al (11) in the accompanying report, with no mutations found in the ERGIC-53 gene in 8 of 19 families. A number of explanations are possible for this incomplete detection. The missing mutations may be located within intronic regions that were not analyzed in the current study, leading, for example, to aberrant splicing or 
other RNA anomalies, or in regulatory regions situated up to several hundred kilobases away from the ERGIC-53 gene. Such mutations could only be identified by detailed investigation of ERGIC-53 transcripts in the remaining families.

However, a number of observations strongly support an alternative explanation, which is the existence of mutations at other, currently unidentified, loci. First, in all but one of the consanguineous families in whom we have identified ERGIC-53 mutations, as expected the patients are true homozygotes. In contrast, in two of the three consanguineous (first-cousin marriage) families in whom no mutations were identified, the affected individuals are heterozygous for the ERGIC-53 gene according to intragenic and flanking polymorphisms(7) (families A5: heterozygous for R14Q and R117, and A13: heterozygous for R14Q and M410L).

Secondly, affected individuals from another two families with no identified ERGIC-53 mutations (A21 and A29) have normal levels of ERGIC-53 according to Western blotting. The existence of further loci responsible for F5F8D is currently under investigation.

\section{Note added in proof}

Immunofluorescence analysis of cells expressing introduced genes for ERGIC-53 with wild-type or mutated (G3R) leader sequences showed no difference in signal peptide cleavage or distribution of protein. Hence, G3R cannot be the cause of disease in family A14. (Hans-Peter Hauri, personal communication, Basel, Switzerland.)

\section{Acknowledgment}

We thank all members of these families for their cooperation and for donating blood samples for our study. We are grateful to $\mathrm{Dr}$ L. Tengborn, Salgrenska University Hospital, Göteborg, Sweden; Dr E.A.C. Chalmers, Royal Hospital for Sick Children, Glasgow, UK; Dr S.D. Wright, Watford General Hospital, Watford, UK; Dr P. Giangrande, Oxford Haemophilia Centre, Oxford, UK; Dr M. Makris, Sheffield Haemophilia and Thrombosis Centre, Sheffield, UK; Dr L.A. Parapia, Bradford Royal Infirmary, Bradford, UK; Dr J. Wilde, Haemophilia Unit, University Hospital, Birmingham, UK; Dr M.J. Strevens, Walsgrave Hospital, Coventry, UK; Dr Steven P. Field, South African Blood Transfusion Service, Johannesburg, South Africa. Prof L.C. Chan, University of Hong Kong, Hong Kong; Dr M. Morfini, Haemophilia Centre, Florence, Italy; Dr A. Gringeri, Haemophilia and Thrombosis Centre, Milan, Italy; Dr J. Reynaud, Hopitaux de St-Etienne, France, for the collection of families, and to Drs S. Zeinali, M. Akhtari, M. Lak, and R. Sharifan, Haemophilia Center and Haematology Department, Imam Khomeini Hospital, Tehran, Iran for their generous assistance to EGDT and FP. We also thank Dr H-P. Hauri (Biozentrum, Basel, Switzerland) for the gift of the anti-ERGIC-53 antibody and ERGIC-53 cDNA. We thank Dr Philip Chandler for his help in establishing lymphoblastoid cell lines and Dr Anni Schönbörner for DNA extractions. 


\section{References}

1. Nichols WC, Seligsohn U, Zivelin A, Terry VH, Hertel CE, Wheatley MA, Moussalli MJ, Hauri H-P, Ciavarella N, Kaufman RJ, Ginsburg D: Mutations in the gene for ERGIC-53, a protein of the endoplasmic reticulum-Golgi intermediate compartment, cause combined deficiency of coagulation factors $\mathrm{V}$ and VIII. Cell 93:61, 1998

2. Seligsohn U, Ramot B: Combined factor V and factor VIII deficiency: Report of four cases. Br J Haematol 16:475,1969

3. Mazzone D, Fichera A, Pratico G, Sciacca F: Combined congenital deficiency of factor $\mathrm{V}$ and factor VIII. Acta Haematol 68:337, 1982

4. Ozsoylu S: Combined congenital deficiency of factor V and factor VIII. Acta Haematol 70:207, 1983

5. Seligsohn U: Combined factor $V$ and factor VIII deficiency, in Seghatchian J, Savidge GT (eds): Factor VIII-von Willebrand factor. New York, NY, CRC, 1989, p 89.

6. Nichols WC, Seligsohn U, Zivelin A, Terry VH, Arnold ND, Siemieniak DR, Kaufman RJ, Ginsburg D: Linkage of combined factors $V$ and VIII deficiency to chromosome $18 q$ by homozygosity mapping. $J$ Clin Invest 99:596, 1997

7. Neerman-Arbez M, Antonarakis SE, Blouin J-L, Zeinali S, Afshar Y, Tuddenham EGD: The locus for combined factor V-factor VIII deficiency (F5F8D) maps to 18q21, between D18S849 and D18S1103. Am J Hum Genet 61:143, 1997

8. Arar C, Mignon C, Mattei M, Monsigny M, Roche A, Legrand A: Mapping of the MR60/ERGIC-53 gene to human chromosome 18q21.3-18q22 by in situ hybridization. Mamm Genome 7:791, 1996

9. Schindler R, Itin C, Zerial M, Lottspeich F, Hauri H-P: ERGIC-53, a membrane protein of the ER-Golgi intermediate compartment, carries an ER retention motif. Eur J Cell Biol 61:1, 1993

10. Dacie JV, Lewis SM: Practical Haematology (ed 8). Edinburgh, UK, Churchill Livingstone, 1995, p 326.

11. Nichols WC, Terry VH, Wheatley MA, Yang A, Zivelin A, Ciavarella N, Stefanile C, Matsushita T, Saito H, de Bosch NB, Ruiz-Saez A, Torres A, Thompson AR, Feinstein DI, White GC, Negrier C, Vinciguerra C, Aktan M, Kaufman RJ, Ginsburg D, Seligsohn U: ERGIC-53 gene structure and mutation analysis in 19 combined factors $\mathrm{V}$ and VIII deficiency families. Blood 93:2261, 1999

12. Michaelides K, Schwaab R, Lalloz MRA, Schmidt W, Tuddenham EGD: Mutational analysis: New mutations, in McPherson MJ, Hames BD, Taylor GR (eds): PCR2. A Practical Approach. Oxford, UK, IRL, Oxford University Press, 1995, $p$ 255.

13. Youssoufian $\mathrm{H}$, Kazazian $\mathrm{HH}$ Jr, Phillips DG, Tsiftis G, Brown VA, Antonarakis SE:

Recurrent mutations in haemophilia A give evidence for $\mathrm{CpG}$ mutation hotspots. Nature 324:380, 1986

14. Krawczak M, Reiss J, Cooper DN: The mutational spectrum of single base-pair substitutions in mRNA splice junctions of human genes: Causes and consequences. Hum Genet 90:41,1992

15. Krawczak M, Cooper DN: The Human 
Gene Mutation Database. Trends Genet 13:121, 1997

16. Sakuraba H, Eng CM, Desnick RJ, Bishop DF: Invariant exon skipping in the human alpha-galactosidase A pre-mRNA: A $g+1$ to $t$ substitution in a 5 '-splice site causing Fabry disease. Genomics 12:643, 1991

17. Belin D, Bost S, Vassalli JD, Strub K: A two-step recognition of signal sequences determines the translocation efficiency of proteins. EMBO J 15:468, 1996

18. Schweizer A, Fransen JAM, Matter M, Kreis TE, Ginsel L, Hauri H-P: Identification of an intermediate compartment involved in protein transport from endoplasmic reticulum to Golgi apparatus. Eur J Cell Biol 53:185, 1990 19. Fiedler $K$, Simons $K$ : A putative novel class of animal lectins in the secretory pathway homologous to leguminous lectins. Cell 77:625, 1994

20. Arar C, Carpentier V, Le Caer JP, Monsigny M, Legrand A, Roche AC: ERGIC-53, a membrane protein of the endoplasmic reticulumGolgi intermediate compartment, is identical to MR60, an intracellular mannose-specific lectin of myelomonocytic cells. $J$ Biol Chem 270:3551, 1995

21. Itin C, Roche AC, Monsigny M, Hauri H.P: ERGIC-53 is a functional mannose-selective and calcium-dependent human homologue of leguminous lectins. Mol Biology Cell 7:483, 1996

22. Lahtinen U, Hellman U, Wernstedt C, Saraste J, Pettersson RF: Molecular cloning and expression of a 58-kDa cis-Golgi and intermediate compartment protein. $J$ Biol Chem 271:4031, 1996

23. Saraste J, Palade GE, Farquhar MG: Antibodies to rat pancreas Golgi subfractions: Identification of a 58-kD cis-Golgi protein. J Cell Biol 105:2021, 1987

24. Gitschier J, Wood WI, Goralka TM, Wion KL, Chen EY, Eaton DH, Vehar GA, Capon DJ, Lawn RM: Characterization of the human factor VIII gene. Nature 312:326, 1984

25. Cripe LD, Moore KD, Kane WH: Structure of the gene for human coagulation factor $\mathrm{V}$. Biochemistry 31:3777, 1992 


\section{chapter 4}

\section{Therapeutic \\ Recommendations}




\section{Rare $\overline{\text { Coagulation Disorders }}$}

\subsection{Fibrinogen deficiency}

On the basis of our clinical experience plasma levels of $40-50 \mathrm{mg} / \mathrm{dL}$ are sufficient for normal hemostasis, because patients with higher levels do not bleed spontaneously nor after surgical trauma. In the past, cryoprecipitate was the preferred form of replacement therapy. Virucidal methods cannot be currently applied to "wet" cryoprecipitate, so that even using the most stringent screening tests this fraction carries a risk of transmission of bloodborne viruses. Fibrinogen concentrates treated with virucidal methods are commercially available and convenient to use at doses of $20-30 \mathrm{mg} / \mathrm{kg}$ body weight but are expensive (Table 1). Recently, a method has been developed that allows to add to plasma pooled from at least 2500 donors a virucidal mixture made of an organic solvent and a detergent (1). Since the application of this virucidal method to plasma-derived coagulation factor concentrates used in patients with hemophilia A and B no case of hepatitis $B$ and $C$ nor of HIV infection has been recorded in these patients over a period of 15 years (2). Whether this safety record also applies to solvent/detergent plasma remains to be demonstrated. It is reasonable to expect the same levels of safety towards $\mathrm{HIV}, \mathrm{HBV}$ and $\mathrm{HCV}$ that the method provides to plasma-derived concentrates used in hemophilia A and B. However, concerns remain about non-enveloped viruses that are not inactivated by solvent/detergent, particularly the hepatitis $A$ virus and parvovirus B19. The relatively high cost of solvent/detergent plasma ( 3 to 4 times that of plain fresh-frozen plasma) may be a serious obstacle for its use in developing countries use. Another virucidal method applicable to plasma is based on its illumination with visible light in the presence of a photosensitizing dye such as methylene blue (3). This method, which has the advantage of being applicable to single plasma units, has not been extensively validated by in vivo studies.

\subsection{Prothrombin deficiency}

Even though the series of Iranian patients with prothrombin deficiency is definitely the largest ever reported, our clinical experience is insufficient to make firm recommendations on treatment. The long plasma half-life of the protein (72 hours) and the relatively low levels necessary for normal hemostasis (20-30 per cent) (Table 1) make the infusion of fresh-frozen plasma the most inexpensive and safe therapeutic option, specially if plasma is virally inactivated. Factor IX complex concentrates usually contain substantial amounts of prothrombin (roughly one unit of prothrombin per unit of factor IX). Doses of 20-30 U/kg, repeated as necessary according to the type and severity of bleeding episodes, are usually adequate. These concentrates carry a risk of thrombotic complications, whereas the risk of transmission of bloodborne infections is minimal since the adoption of virucidal methods (for review, see 2 ).

\subsection{Factor V deficiency}

Factor $V$ is the only inherited coagulation disorder that must be treated with plasma, 


\section{Tab. 1 - Treatment of rare coagulation disorders}

\begin{tabular}{|c|c|c|c|}
\hline $\begin{array}{l}\text { Deficient } \\
\text { Factor }\end{array}$ & $\begin{array}{l}\text { Hemostatic } \\
\text { Levels }\end{array}$ & $\begin{array}{l}\text { Plasma } \\
\text { Half-life }\end{array}$ & $\begin{array}{l}\text { Recommended therapy } \\
\text { (in order of priority) }\end{array}$ \\
\hline Fibrinogen & $40-50 \mathrm{mg} / \mathrm{dL}$ & 3 days & $\begin{array}{l}\text { - Fresh-frozen plasma (FFP) } \\
(15-20 \mathrm{ml} / \mathrm{kg}), \text { preferably virus-inactivated } \\
\text { Fibrinogen concentrate }(20-30 \mathrm{mg} / \mathrm{kg})\end{array}$ \\
\hline Prothrombin & $20-30 \%$ & 3 days & $\begin{array}{l}\text { - FFP }(15-20 \mathrm{ml} / \mathrm{kg}) \\
\text { Factor IX complex concentrate }(20-30 \mathrm{U} / \mathrm{kg})\end{array}$ \\
\hline Factor V & $10-15 \%$ & 36 hours & - FFP(15-20 ml $/ \mathrm{kg})$, preferably virus-inactivated \\
\hline Combined factor V and VIII & $10-15 \%$ & - & - As for factor $V$ \\
\hline Factor VII & $10-15 \%$ & $4-6$ hours & - Factor VII concentrate ( $30-40 \mathrm{U} / \mathrm{kg}$ every 12 hours) \\
\hline Factor X & $10-15 \%$ & 40 hours & $\begin{array}{l}\text { - FFP }(15-20 \mathrm{ml} / \mathrm{kg}) \\
\text { Factor IX complex concentrate }(20-30 / \mathrm{kg})\end{array}$ \\
\hline
\end{tabular}

because no concentrate is currently available. With a half-life of 36 hours and minimal hemostatic levels of the deficient factor of 10-20 per cent (Table 1), attention must be made to avoid fluid overload when repeated infusions are needed. In our experience, single daily dosages of $15-20 \mathrm{ml} / \mathrm{kg}$ are usually adequate to control most spontaneous hemorrhages in soft tissues and mucosal tracts. A frequent symptom such as epistaxis can usually be controlled by local measures and antifibrinolytic amino acids, so that replacement therapy can be avoided. In a few surgical cases, prolonged treatment with large amounts of plasma caused fluid overload. Hence, a factor V concentrate is warranted.

\subsection{Factor VII deficiency}

Factor VII has a very short plasma half life (4-6 hours) (Table 1). The need of two-three daily infusions to keep factor VII above the hemostatic levels of 10-15 per cent renders difficult the treatment with plasma and warrants the use of concentrates. Virallyinactivated plasma concentrates containing almost exclusively factor VII are produced by at least two commercial manufactures (Table 2) and two daily doses of $30-40 \mathrm{U} / \mathrm{kg}$ have been successfully used by us to handle major surgery without fluid overload. Recombinant factor VIIa, originally developed and produced to bypass the defect of the intrinsic system in patients with factor VIII and factor IX inhibitors, is efficacious in patients with factor VII deficiency. However, it remain to be seen whether its viral safety justifies the use of this expensive product when less expensive virus-inactivated plasma-derived concentrates are available.

\subsection{Combined deficiency of factor V and factor VIII}

Since bleeding symptoms occur in patient with levels of factor V and VIII below 15 per 
Tab. 2 - Factor concentrates for rare coagulation disorders

\begin{tabular}{lll} 
Brand & Company & Viral inactivation \\
\hline Fibrinogen THE & Green Cross, Japan & $\begin{array}{l}\text { TNBP/ polysorbate } 80^{*} \text { plus dry heat } \\
60^{\circ} \mathrm{C} \text {, for } 72 \mathrm{hr}\end{array}$ \\
Clottagen (Fibrinogen) & LFB, France & TNBP/polysorbate 80 plus vapor heat, \\
& & $60^{\circ} \mathrm{C}$ for $10 \mathrm{hrs}, 80^{\circ} \mathrm{C}$ for $1 \mathrm{hr}$ \\
Factor VII (Provertin) & Immuno, Austria & Vapour heating \\
Factor VII & Bio Products Laboratory, UK & Dry heat, $80^{\circ} \mathrm{C}$ for $72 \mathrm{hr}$ \\
Facteur VII-LFB & LFB, France & TNBP/polysorbate 80 \\
Acset (Factor VIIa) & LFB, France & TNBP/polysorbate 80 \\
Novoseven (Factor VIla) & Novo Nordisk, Denmark & None \\
Factor XIII & Bio Products Laboratory, UK & Dry-heat, $80^{\circ} \mathrm{C}$ for $72 \mathrm{hr}$ \\
Fibronogammin HS (Factor XIII) & Centeon, Germany & Pasteurization at $60^{\circ} \mathrm{C}$ for $10 \mathrm{hr}$ \\
\hline
\end{tabular}

* Solvent/detergen

cent, it is surmised that hemostasis can be achieved by raising both factors above this level with $10-15 \mathrm{ml} / \mathrm{kg}$ of fresh-frozen plasma, preferably virally-inactivated.

\subsection{Factor $X$ deficiency}

Factor $\mathrm{X}$ has a relatively long plasma halflife of 40 hours (Table 1). Hence, fresh-frozen plasma can be conveniently used to treat relatively mild bleeding episodes which

\section{References}

1. Klein HG, Dodd RY, Dzik WH, Luban NL, Ness PM, Pisciotto P, Schiff PD, Snyder EL: Current status of solvent/detergent treated frozen plasma. Transfusion 1998; 38:102-7.

2. Mannucci PM: The choice of plasma derived clotting factor concentrates. In: Balliere's usually necessitate one or two infusions of $15-20 \mathrm{ml} / \mathrm{kg}$ to reach and maintain plasma factor levels of 10-15 per cent. Another possibility is to use factor IX concentrates, which contain factor $\mathrm{X}$ and are virally inactivated. The units of factor $X$ contained in concentrates correspond roughly to those of factor IX. Usually 20-30 U/kg every other day are sufficient to handle major surgical operations.

Clinical Haematology. Haemophilia. (C.A. Lee, editor) 1996, 9:272-290.

3. Lambrecht B, Mohr H, Knouwerhoft J, Schmitt $\mathrm{H}$ : Photoinactivation of viruses in human fresh plasma by phenothiazine dyes in combination with visible light. Vox Sang 1991, 60: 207-13. 


\section{chapter 5}

\section{General Conclusion}




\subsection{Pattern of bleeding symptoms}

Evaluation of the bleeding symptoms found in this large series of patients suggests that in general rare coagulation disorders tend to be less severe than the hemophilias caused by factor VIII or IX deficiency. This views is substantiated by the comparative analysis of symptoms occurring in 150 patients with hemophilia A strictly matched with those with factor V, VII and X deficiencies for age and severity (threefourth had severe disease). As expected, among hemophiliacs the most prevalent symptoms were joint, muscle and post-operative hemorrhages, whereas bleeding in the mucosal tracts was relatively rare (Figure 1). Among patients with rare coagulation disorders, only a minority had spontaneous hemarthroses and muscle hematomas, in spite of the fact that threefourth of them has severe deficiencies of clotting factors. Accordingly, permanent damage to the musculoskeletal system and the resulting handicaps was rarer. There were other differences in the type and frequency of bleeding symptoms (Figure 2-7). Hematuria, not rare in hemophilia, was relatively frequent only in factor $\mathrm{X}$ deficiency but occurred very rarely or not at all in the remaining defects. Bleeding from the umbilical stump, not seen in hemophiliacs and thought to be typical of the inherited defects of fibrin formation (afibrinogenemia and factor XIII deficiency), was not unusual also in prothrombin, factor $\mathrm{V}$ and factor $\mathrm{X}$ deficiency. A mild bleeding symptom such as epistaxis, rare in hemophiliacs, was very frequent in all rare defects. In afibrinogenemia and factor $\mathrm{V}$ deficiency this mucosal-type symptom might be explained by a concomitant platelet defect of these factors, reflected by a prolonged bleeding time. There is however no obvious explanation for the frequency of nose bleeds in defects of coagulation factors such as prothrombin, factor VII and X, not contained in platelets and not directly involved in primary hemostasis. The same considerations apply to another mucosal-type symptom such as menorrhagia, a frequent event that often caused iron deficiency in women. There was no clear evidence that the coagulation defects reduced fertility in affected women, nor did they cause recurrent abortions. The only exception is afibrinogenemia that adversely affects implantation of the embryo 
(1) and is sometime associated with recurrent abortions $(2,3)$. As it could be expected, surgical procedures were often followed by excessive bleeding when carried out without adopting preventive measures. Hemophilia was originally described in the Talmud because it caused fatal bleeding at birth after circumcision. Among Muslims circumcision is usually practiced at a later age (2-3 years) than in Jews, so that bleeding after this procedure was not always the revealing symptom in rare coagulation disorders. Lifeendangering hemorrhages in the gastrointestinal tract and central nervous system were rare. There are several examples in the literature of the frequent occurrence of these manifestations in patients with rare coagulation disorders, but report bias is likely to have emphasized their prevalence. The total number of patients with rare coagulation disorders studied by us is still relatively limited, although they are a large proportion of those listed in Iranian registry. More importantly, patients were not selected on the basis of the severity of bleeding symptoms as it has probably occurred in many cases previously reported in the literature.

At the moment, the observed quali-
Fig. 2 - Fibrinogen deficiency

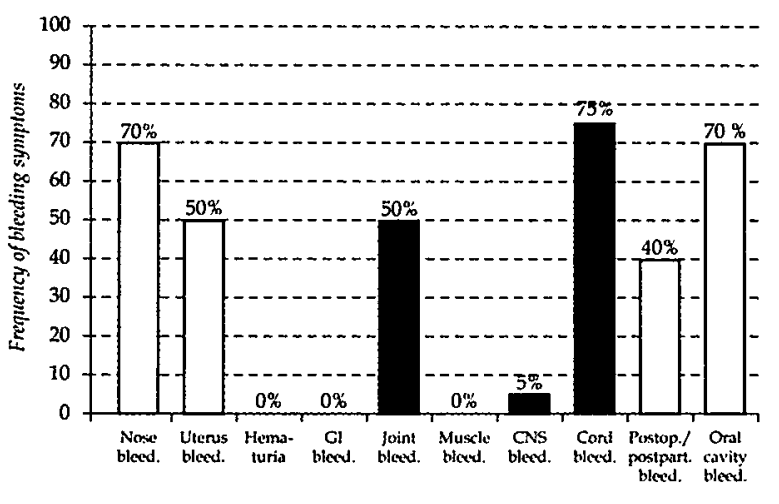

Fig. 3 - Prothrombin deficiency

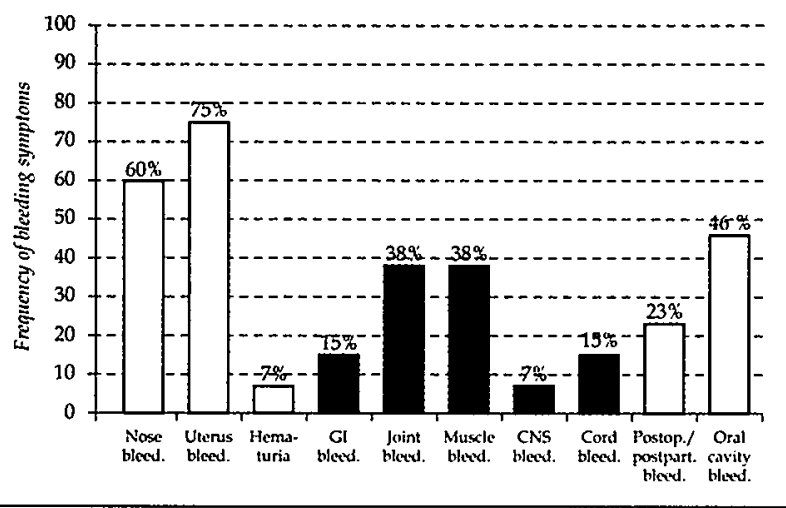

Fig. 4 - Factor V deficiency

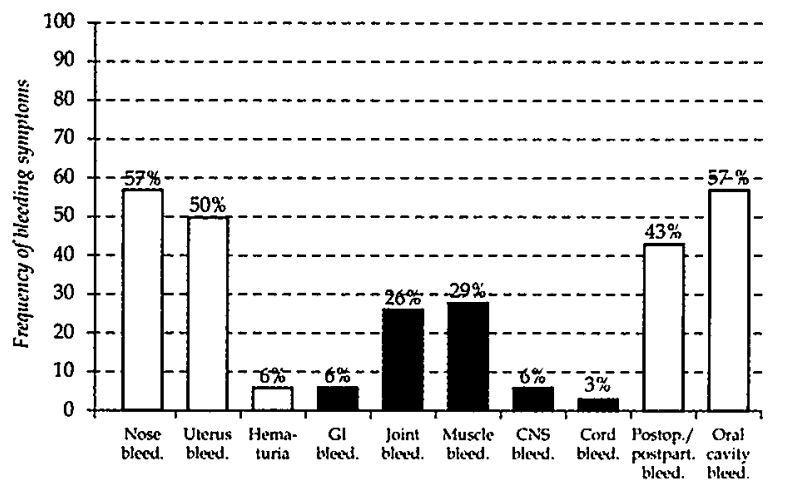


Fig. 5 - Factor VII deficiency

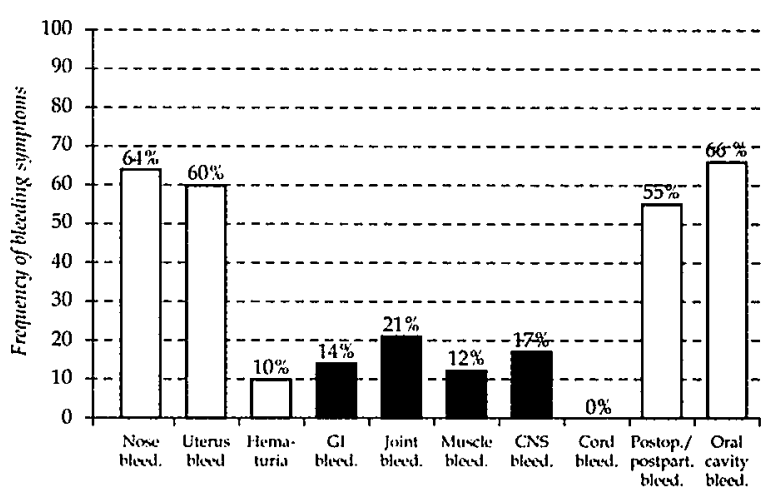

Fig. 6 - Factor V+VIII deficiency

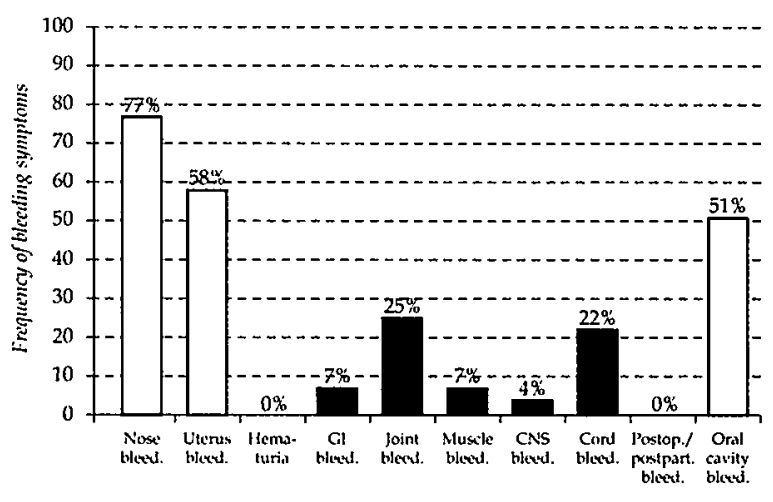

Fig. 7 - Factor $\mathrm{X}$ deficiency

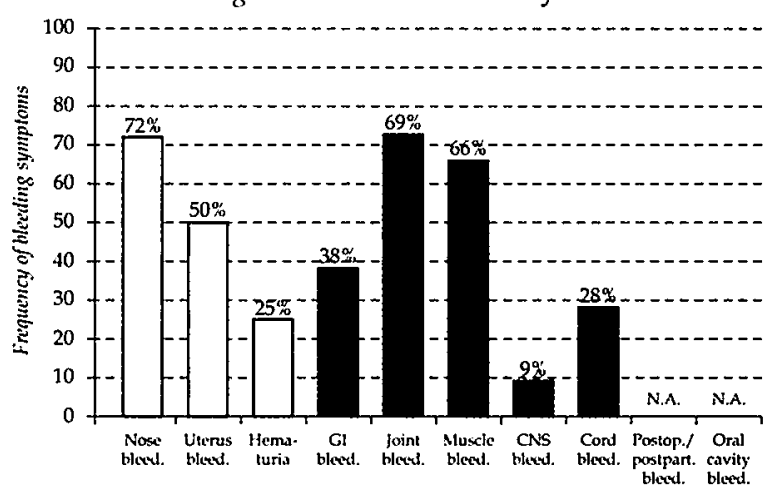

tative and quantitative differences between the different defects cannot be easily explained. Animal models of gene knock-out indicate that bleeding is more severe and often lethal in mice rendered deficient in prothrombin, factor $\mathrm{V}$ and factor $\mathrm{X}$ than in those with factor VII and fibrinogen deficiency $(1,4,5,6,7)$. Even though this pattern of varied severity of factor deficiency in mice is roughly similar to that observed in our patients, one has to consider that in knockout models the gene encoding a given clotting factor is completely abrogated. Accordingly, no trace of RNA or protein is produced, whereas the gene lesions found so far in humans are usually less devastating and less likely to completely impede protein production. Due to the limits of sensitivity of the bioassays of clotting factors currently used, it is difficult to establish whether or not a patient with unmeasurable plasma levels has a totally absent production of a given clotting factor. Hence, it is unclear to which extent mouse results apply to humans. Perhaps more understanding of the variability of bleeding symptoms in different defects will be possible when our knowledge on the spectrum of gene mutations will be larger than now. 


\subsection{Molecular defects}

Paper 3.1 analyzed 27 patients with factor VII deficiency, particularly from the Middle East. In these patients we used SSCP analysis to verify gene abnormalities in the coding region and in the 5' and 3 ' untranslated regions. Cases with abnormal bands on SSCP have been subsequently analyzed by direct sequencing. Nineteen mutations were found in this group of patients, 12 novel and 7 already reported. Conformational analysis of the crystal structure of the factor VIIa-tissue factor complex was used in the attempt to explain the effect of these mutations. The results of this study significantly enlarge our knowledge on gene mutations associated with factor VII deficiency and expand by $50 \%$ the number of the homozygous mutations already reported the current available database (1997)

Paper 3.2 reports for the first time a homozygous (-2bp) deletion mutation in the preproleader sequence of factor VII. This mutation is important because leads to a complete absence of measurable factor VII in plasma, conserving only 9 aminoacids of the $\mathrm{N}$-terminal preproleader sequence followed by a short series of irrelevant aminoacids.

Our results indicate for the first time that a complete factor VII deficiency does not necessarily result in fatal hemorrhage immediately after birth, at variance with what observed in the factor VII knockout mice (6) and in another family with complete absence of factor VII (3). It remains to be demonstrated how in our patient the coagulation defect is partially compensated for in vitro.

Paper 3.3 evaluates through expression studies the mechanism responsible for severe FVII deficiency in homozygous Italian patients with the Gly97Cys or the Gln100Arg mutations in the second EGF domain of FVII. The severe clinical phenotype of the patient with Gln100Arg is consistent with our data demonstrating a major secretion defect as well as markedly impaired function of the small amount of factor VII that is released from cells. In the patient with Gly97Cys it was not possible to obtain sufficient FVIICys97 protein to carry out detailed biochemical studies and probably the resulting alteration in protein folding causes factor VII Cys97 to undergo degradation in a preGolgi compartment.

Paper 3.4 reports the first case of an insertion type mutation in the factor VII (FVII) gene that results in severe FVII deficiency with FVII coagulant activity (FVII:C) of $<1 \%$ and factor VII antigen levels (FVII:Ag) of $10 \%$. DNA analysis revealed a homozygous $15 \mathrm{bp}$ in-frame insertion type mutation at nucleotide 10554 within the catalytic domain of FVII. This insertion consists of a duplication of the residues Leu213 to Asp217 (Leu,Ser,Glu,His,Asp), probably arising by slipped mispairing between 2 copies of a direct repeat (GCGAGCACGAC) separated by $4 \mathrm{bp}$. The importance of the Asp -212 and Leu-213 codons in factor VII structure and their 


\section{Rare $\overline{\text { Coagulation Disorders }}$}

integrity was studied by Dickinson et al using alanine scanning mutagenesis(8). They report that the mutations affecting proteolytic function are mapped on the face of the factor VIIa protease domain. Functional defects were observed for the replacements of residues within the catalytic cleft and most probably structural effects were seen for Asp-212 (c72) and Leu-213 (c73). Considering the importance of these residues in the proteolytic function any disruption created by the insertion mutation may effect the stabilization of the activity of protease domain in this mutant protein.

Molecular graphics analyses of FVIIa showed that the insertion is located at the surface of the catalytic domain in an exposed loop stabilized by extensive salt-bridge and hydrogen bond formation at which the calcium binding site is located. The insertion may interfere with protein folding during FVII biosynthesis and/or diminish procoagulant activity through the loss of calcium binding.

To explore these two hypotheses, wildtype FVII (FVIIWT) and mutant FVII (FVIIMT) cDNAs were expressed transiently in COS1 cells and stably in DHFR deficient Chinese hamster ovary cells (CHO). In lysates of cells transfected with either the FVIIWT or FVIIMT constructs, the FVII:Ag levels were equivalent. However the amount of FVII:Ag secreted by cells transfected with FVIIMT was $5-10 \%$ of that secreted by cells transfected with FVIIWT. Using stably transfected CHO cells, pulse chase studies demonstrated that FVIIMT did not accumulate intracellularly. A part of this recombinant protein was degraded in PreGolgi compartment as demonstrated by using different inhibitors of protein degradation. Accordingly, only small amounts of FVII were secreted into conditioned media, with undetectable procoagulant activity.

These results verify both the hypotheses derived from inspection of the FVIIa crystal structure, and demonstrate that both a secretion and a functional defect is the mechanism whereby this insertion causes FVII deficiency.

Paper 3.5: In the only study published so far on the molecular basis of combined factor $\mathrm{V}$ and factor VIII deficiency, mutation in the ERGIC 53 gene were found in nine Jewish families(9).

In the collaborative study reported in paper 3.5 we screened the gene using SSCP analysis in 35 new families of different ethnic groups and identified 13 different mutations accounting for 52 of 72 mutant alleles. These were 3 splice site mutations, 6 insertions and deletions resulting in translational frameshift, 3 nonsense codons. The mutations are predicted to result in the synthesis of either a truncated protein product or no protein at all. In our study, mutations have not been identified in approximately one fourth of the families studied, suggesting that other still unidentified lesions beside those in the ERGIC 23 gene are the molecular basis for the combined deficiency of factor $\mathrm{V}$ and factor VIII. 


\subsection{Recommendations on treatment}

Our recommendations are summarized in (Table 1: Chapter 4.) The avoidance of transmission of bloodborne infectious agents is the primary requisite in the choice of replacement material. Cost is the next most important determinant. Fresh-frozen plasma is inexpensive and has the advantage of containing all coagulation factors. Every effort should be made to use plasma that has undergone a procedure of viral inactivation. Virally-inactivated factor concentrates are available for the treatment of several disorders (Table 2: Chapter 4) and should be preferred when virally-inactivated plasma is not available or repeated infusions causing fluid overload are needed, as it may occur at surgery or in cases of bleeding in the central nervous system. For a few disorders, such as factor $V$ and combined factor $V$ and VIII deficiency, no concentrate is currently available, so that fluid overload may occur when large amounts of plasma are infused. Hence, manufacturers of plasma products should consider to pro-

\section{References}

1. Suh TT, Holmback K, Jensen NJ, Daugherty CC, Small K, Simon DI, Potter S, Degen JL:

Resolution of spontaneous bleeding events but failure of pregnancy in fibrinogen deficient mice. Genes Dev 1995; 15: 2020-33.

2. Goodwin TM: Congenital hypofibrinogenemia in pregnancy. Obstet Gynecol Surv 1989, 44: duce factor $V$-containing concentrates. In factor VII deficiency concentrates are essential, because the half-life of this factor is so short (ca. 6 hours) that closely spaced infusions of more than two-three doses of plasma one likely to create fluid overload. In prothrombin and factor $\mathrm{X}$ deficiency factor IX complex concentrates can be used for treatment. There is no obvious need for specific factor concentrates, even though the unnecessarily high post-infusion levels of vitamin- $\mathrm{K}$ dependent coagulation factors might be one of the causes for thrombogenicity of these concentrates(10).

Prevention of rare coagulation disorders through prenatal diagnosis is feasible in couples who have already had affected children, provided the mutation under-lying the deficiency is known. Primary prevention might be achieved by discouraging consanguineous marriages. Even though the cultural, religious and economic roots of this practice are deep in some communities in Iran, consanguineous marriages are becoming much less frequent in large cites and among younger generations.

157-161.

3. McVey JH, Boswell EJ, Takamiya O, Tamagnini G,Valente V, Fidalgo T, et al: Exclusion of the First EGF Domain of Factor VII by a Splice Site Mutation Causes Lethal Factor VII Deficiency. Blood 1998; 92: 920-6.

4. Sun WY, Witte DP, Degen JL, Colbert MC, 


\section{Rare Coagulation Disorders}

Holmback K, Xiao Q, Bugge TH, Degen SJ:

Prothrombin deficiency results in embryonic and neonatal lethality in mice. Proc.Natl Acad Sci USA 1998, 95: 7597-8002.

5. Cui J, O'Shea KS, Purkayastha A, Saunders TL, Ginsburg D: Fatal hemorrhage and incomplete block of embryogenesis in mice lacking coagulation factor V. Nature 1996, 384: 66.68.

6. Rosen ED, Chan JC, Idusogie E, Clotman F, Vlasuk G, Luther T, Jalbert LR, Albrecht S, Zhong L, Lissens A, Schoonjans L, Moons L, Collen D, Castellino FJ, Carmeliet P: Mice lacking factor VII develop normally but suffer fatal perinatal bleeding. Nature 1997, 390: 290-294.

7. Dewerchin M, Liang Z, Moons L,Carmeliet P, Castellino FJ, Collen D, Rosen ED: Blood coagulation factor $\mathrm{X}$ deficiency causes partial embryonic lethality and fatal neonatal bleeding in mice. Thrombo Hemostas $2000 \mathrm{Feb}, 83: 2: 185-190$

8. Dickinson CD, Kelly CR, Ruf W: Identification of surface residues mediating tissue factor binding and catalytic function of the serine protease factor VIIa. Proc Natl Acad Sci USA 1996; 93: 14379-14384.

9. Nichols WC, Seligsohn U, Zivelin A, Terry VH, Hertel CE, Wheatley MA, Moussali MJ, Hauri HP, Ciavarella N, Kaufman RJ, Ginsburg D: Mutations in the gene for ERGIC-53, a protein of the endoplasmic reticulum/Golgi intermediate compartment cause combined deficiency of coagulation factors V and VIII. Cell 1998; 93: 61. 64.

10. Mannucci PM: The choice of plasma derived clotting factor concentrates. In: Balliere's Clinical Haematology. Haemophilia. (C.A. Lee, editor) 1996, 9: 272-290. 


\section{chapter 6}

Summary 


\section{Rare Coagulation Disorders}

Clinical symptoms. The type of clinical manifestations and optimal treatment are not well established for recessively bleeding disorders, that have prevalences in the general population varying between $1: 500,000$ (factor VII deficiency) to 1:2,000,000 (prothrombin deficiency). These prevalences increase 8 to 10 times in countries where consanguineous marriages are customary. To establish the type and severity of symptoms in each coagulation defect, 237 patients with the inherited deficiencies of fibrinogen, factor II, factor $\mathrm{V}$, combined factor V and factor VIII and factor $X$ have been investigated. The most severe symptoms were found in patients with factor $\mathrm{X}$ and prothrombin deficiencies, with a relatively high frequency of joint and muscle bleeding. Severe bleeding manifestations like those in the gastrointestinal tract and central nervous system were relatively rare for all defects. Umbilical cord bleeding, typical of afibrinogenemia and factor XIII deficiencies, were relatively frequent also in prothrombin, factor V and factor X deficiencies. Mucosal type bleeding symptoms such as epistaxis was relatively frequent in fibrinogen and factor $V$ deficiencies.

Gene mutations. We report the genetic alteration of 21 families with factor VII deficiency from predominantly MiddleEast countries, where this deficiency has been poorly studied. Using screening techniques as SSCP and heteroduplex analysis of PCR products and sequence analysis of the abnormal fragments we identified 19 mutations of which 12 were novel and 7 have been previously reported. Of the previously reported mutations, those at Arg 152, Arg304 and Thr359 involved a $\mathrm{CpG}$ dinucleotide that provides an explanation for identical mutations in diverse populations. However, for the Cys310Phe mutation present in both the Iranian and Italian population haplotype studies established the possibility of identity by descent. Of the 12 novel mutations, 9 were missense mutations, localized mostly in the catalytic domain but also in the Gla domain and EGF2 domain of factor VII. Also 3 novel and one previously reported splice sites mutations were identified in these patients. We found a novel homozygous $(-2 b p)$ deletion type mutation on preproleader sequence of factor VII gene in 5 year old Chinese boy with severe factor VII deficiency. This mutation leads to a complete lack of detectable plasma FVII reporting that this situation is not incompatible with human life. We report also the first case of an insertion type mutation in the factor VII gene that caused a severe plasma deficiency in a 5 year old girl from Oman with factor VII: $\mathrm{C}$ coagulant activity of less than $1 \%$ and factor VII antigen levels of $10 \%$. This insertion consists of a duplication of codons 212 to 217 , probably by slipped mispairing between 2 copies of a direct repeat (GCGAGCACGAC) separated by $4 \mathrm{bp}$. In vitro study of the mutant recombinant protein by stable cell line using DHFR deficient CHO cells revealed a combined defect, i.e., intracellular degradation 
in the preGolgi compartment associated with a secretion defect demonstrated by pulse-chase labelling experiments using ${ }^{35} \mathrm{~S}$ methionine. Only small amounts of FVII with not detectable procoagulant activity were secreted into conditioned media.

These results verify both the hypothesis derived from molecular graphics analysis of FVIIa, and demonstrate that both a secretion and a functional defect is the mechanism whereby this insertion causes FVII deficiency. This mutation probably does not interfere with FVII synthesis, but is associated with various defects including abnormal folding, intracellular degradation, secretion failure and loss of coagulant activity. To our knowledge, this is the first instance of a FVII deficiency caused by a perturbation at its calcium-binding site in the catalytic domain.

On the whole, the novel factor VII gene mutations identified in this study extended by $30 \%$ the data base mutation analy. sis of the factor VII gene.

The spectrum of mutations in the ERIGC53 gene associated with the combined defi- ciency of factor V and factor VIII was substantially enlarged by this study conducted in 35 families. All the 13 mutations identified are likely to results in the production of a truncated protein or no protein at all. Our study has also shown that some patients with the combined deficiency produce normal amount of ERGIC-53, indicating that other as yet unidentified molecular defects are the basis of combined factor $\mathrm{V}$ and factor VIII deficiency.

Management. The treatment of rare coagulation defects is usually simpler than that of the hemophilias, because of the bleeding tendency is less severe, lower hemostatic levels of deficient factor are needed and factor half-lives are usually long except for factor VII. The first requirement of replacement therapy is safety from transmission of bloodborne infectious agents and the second requirement is low cost, particularly in developing countries. Fresh frozen plasma is inexpensive has the advantage of containing all coagulation factors and can be virally inactivated with solvent/detergent. 
$\mathrm{T}$ he research work described in this thesis is a result of four years of collaboration between four International Centres: the Haemophilia Centre of Tehran, the Hemophilia and Thrombosis Centre Angelo Bianchi Bonomi of the University of Milan, Italy, the Hemostasis Unit and Hemophilia Centre, Royal Free Hospital, University College, London and the Veteran Administration Hospital, Harvard University, Boston. First I would like to appreciate and thank the help and guidance of Prof. Mannucci who was the pillar of this research. He was the person also guiding me through the pilgrimages that led to this thesis. I would like also to thank Professor Hemker as my promoter and Prof. S. Béguin as my copromoter, for their help and advice throughout this thesis. I thank Dr. Perry and Professor Christine Lee, Professor Ken Bauer, Dr. Carew, Dr. Jenkins and Dr. Hunault for their invaluable help during my fellowships that allowed me to do this research. I thank Professor Ted Tuddenham for teaching me the first steps of genetics and to be available to help me through all my doubts and problems in each step. I also thank Professor Stephen Perkins for his important help on the crystal structure analysis of my studies. I appreciate the financial help of the Angelo Bianchi Bonomi Foundation, Katharine Dormandy Trust and Veteran Administration.

I thank my two "paranimfen" Duco Kaptain and Oriol Rosellò for accepting to assist me in the public discussion of the thesis. This thesis concludes and opens different research lines which required my work in the different parts of the world and without the understanding and help of my dear friends it could not be possible. I therefore would like to thank everyone with 
whom I shared my happiness and sadness in Tehran, Milan, London and Boston between 1996 to 2000.

I would like to thank Drs.Lak, Zeinali and Sharifian of the Hemophilia Centre and Pasteur Institute of Tehran to help me to find and collect the Iranian samples. I really appreciate the help of the Hemophilia Society of Tehran for their important collaboration in the organization of our samples collection. Many thanks to Mrs. Bidar for her help in diagnostic laboratory of the Hemophilia Centre, Tehran and Drs. Ahmadi, Jazebi and Shashaani of the Tranfusion Center of Tehran.Without them these studies could never be done. I also appreciate the help and comprehension of the patients who partecipated in this study.

The collaboration of Mrs. Elena Zumbo, Giuliana Peri and Luigi Ghilardini in Milan in the organization of my paper work and slides of this thesis is very much appreciated. I thank Dr. Olga Mosca for her important help upon my return in Italy in the organization of the cell biology laboratory at the Fondazione Luigi Villa, Italy.

Oriol Rosellò many thanks for your help to design the cover of my thesis. Last but not least, I want to thank my parents, who have always supported me without them this thesis could never be done. 
Clora Peyvandi was born on 29 November 1964 in Iran. In I 1984, she moved to Italy where in March 1985 she attended the Faculty of Medicine at the University of Milan. She obtained the MD degree on October 1991. She attended the residency in Haematology at the Department of Medicine of the Ospedale Maggiore, University of Milan, under the supervision of Prof. Mannucci. In 1996 she obtained the speciality in Hematology at this University. In November 1996 she went back to Iran to organize the collection of samples of patients with rare bleeding disorders as a material for a PhD study. She left Italy in 1996 for the United Kingdom to start a research project on the molecular characterization of FVII and FX deficiency under the supervision of Dr. David Perry at the Royal Free Hospital, University College, London, as a first step of her PhD thesis. She worked two years in this Centre to investigate the molecular alterations in 21 Iranian families with FVII deficiency. To further characterize the molecular alterations found in London she moved to Boston, VA Hospital, Harvard University where she studied the mechanisms causing FVII deficiency using the molecular and cell culture techniques under the supervision of Drs. Ken Bauer and J. Carew. In one year time of research she characterized six of the novel mutations on FVII gene using in vitro expression analysis and recombinant protein production followed by biochemical characterization. In May 1999 she came back to the Angelo Bianchi Bonomi Centre, University of Milan, Ospedale Maggiore to finish her $\mathrm{PhD}$ studies on the rare bleeding disorders and to continue a new line of research on molecular and cell biology studies on the serine proteases of coagulation. 